Portland State University

PDXScholar

$1-1-1982$

\title{
Investigation of the contribution of aquatic humus to the transport of DDT in the environment
}

Dan Philip Blunk

Portland State University

Follow this and additional works at: https://pdxscholar.library.pdx.edu/open_access_etds Let us know how access to this document benefits you.

\section{Recommended Citation}

Blunk, Dan Philip, "Investigation of the contribution of aquatic humus to the transport of DDT in the environment" (1982). Dissertations and Theses. Paper 796.

https://doi.org/10.15760/etd.796

This Dissertation is brought to you for free and open access. It has been accepted for inclusion in Dissertations and Theses by an authorized administrator of PDXScholar. Please contact us if we can make this document more accessible: pdxscholar@pdx.edu. 
INVESTIGATION OF THE CONTRIBUTION OF AQUATIC HUMUS

TO THE TRANSPORT OF DDT IN THE ENVIRONMENT

by

DAN PHILIP BLUNK

A dissertation submitted in partial fulfillment of the requirements for the degree of

\author{
DOCTOR OF PHILOSOPHY \\ in \\ ENVIRONMENTAL SCIENCES AND RESOURCES - CHEMISTRY
}

Portland State University

1982 


\section{ABSTRACT}

The fate and transport of insoluble, hydrophobic organic pollutarits in the aquatic environment constitutes a prominent area of concern. It is thought that pollutants of this nature may exist in association with organic carbon, which is predominantly aquatic humus. This type of association could significantly affect the kinetics of such transformation processes as volatilization or chemical and biological degradation of the pollutant. While dissolved organic matter (DOM) comprises the bulk of organic carbon (or aquatic humus) in natural waters, the interaction between naturally occurring DOM and insoluble organic pollutants has not been quantified.

The work presented in this dissertation is an effort to quantify the effect of dissolved organic matter on the solubility in water and, hence, the transport of hydrophobic organic compounds (specifically, DDT) in the environment.

Saturated aqueous solutions of DDT were generated by a method that is different from those used by other workers. Within a closed system, an excess of solid DDT was allowed to vaporize and enter an aqueous solution through the gas phase. The concentraction of DDT in solution increased with time, leveling off when equilibrium and a saturated solution was established.

The solubility of $p, p^{\prime}-D D T$ in distilled water was determined to be $1.87 \pm .01 \mathrm{ppb}$. The solubility of the $0, \mathrm{p}^{\prime}-\mathrm{DDT}$ isomer in distilled water was determined to be $4.88 \pm .03 \mathrm{ppb}$. The concentrations of $p, p^{\prime}-$ 
DDT and $0, p^{\prime}-D D T$ in distilled water solutions containing dissolved organic matter were definitely higher than the aqueous solubilities of these compounds. A minimum value for the DDT/DOM partition coefficient $\left(K_{p}\right)$ in water was determined. This partition coefficient, when normalized to organic carbon, is referred to as $K_{o c}\left(K_{o c}=K_{p} /\right.$ fraction organic carbon). A minimum $\log K_{o c}$ for both $p, p^{\prime}-D D T$ and $0, p^{\prime}-D D T$ was determined to be $4.7 \pm .2 \log$ units. Under environmental conditions, this partition coefficient indicates that the majority of DDT present in aqueous systems will be associated with dissolved organic matter. 
TO THE OFFICE OF GRADUATE STUDIES AND RESEARCH:

The members of the Committee approve the dissertation of Dan Philip Blunk presented May 19, 1982.

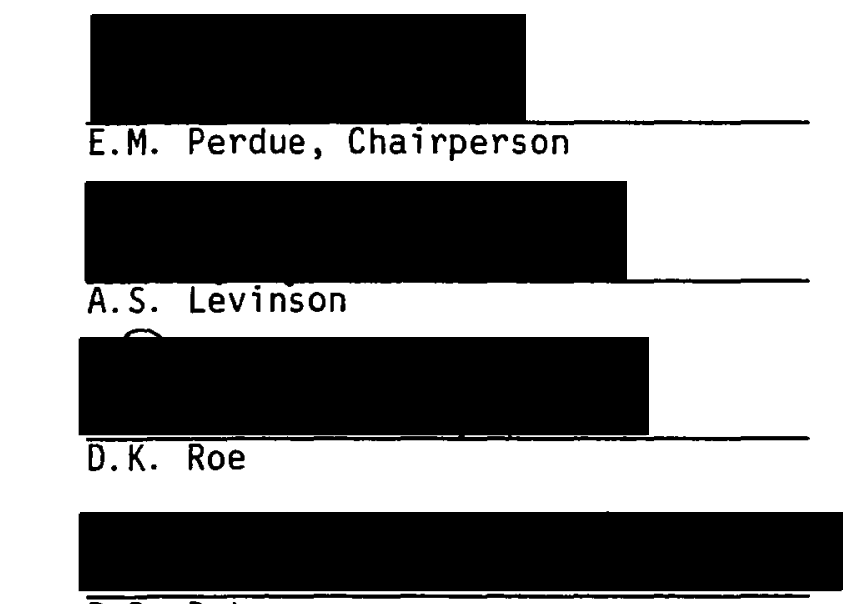

R.R. Petersen

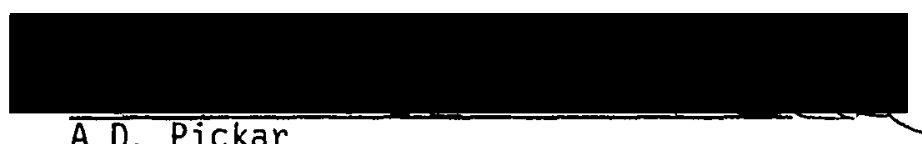

APPROVED:

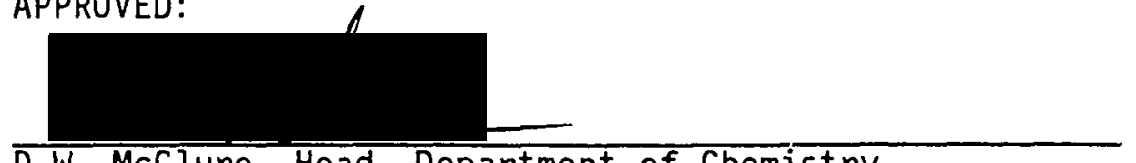

D.W. Meflure, Head, Department of Chemistry

Robert 0. Tinnin, Coordinator, Environmenta

Sciences and Resources Ph.D. Program

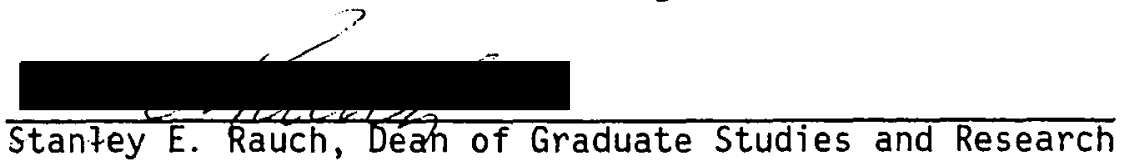




\section{DEDICATION}

This work is dedicated to my father, Philip Charles, and my mother, Luana Fae, whose unwavering support and encouragenient over the course of a much-too-lengthy endeavor is immensely appreciated. 


\section{ACKNOWLEDGEMENTS}

I am grateful to Dr. D.K. Roe for his advice, ideas, assistance with conceptual blockbusting and his solid support throughout this project. In addition, thanks are extenued to Dr. R.P. Lutz for his encouragement, Dr. A.S. Levinson for his sense of humor and to Dr. E.M. Perdue for his patience.

This work could not have been completed without the support of a number of people. The helpfulness of Tom Aldrich and Dennis Clark in obtaining chemicals, supplies and equipment is appreciated. The technical expertise of Rudolph Zupan, Brian McLaughlin and Garo Arakelian enabled concepts to be expressed in experimental design and equipment. Tnanks are extended to Allan Ryall for the great deal of custom glassblowing that was performed.

Appreciation is expressed to Dr. R.R. Petersen for the use of a computer/graphics system, to Andy Schaedel and the Oregon Department of Environmental Quality for the use of a truck to collect river water, and to $\mathrm{Bil}$ : Miller and the Oregon Department of Health for the temporary use of : shaker table.

i 'nks are extended to Cornelius Chan for his assistance in computer programming, to Ken Wong, Drs. J.M. Kennish and R.K. Lynn and the University of Oregon Health Sciences Center for performing the GLC/mass spectral work, and to Karen Davidson for her patience and typing ability which is expressed in this dissertation.

Special appreciation is expressed for the support, assistance and patience of Nancy Alstrum, who was instrumental in making these last two years enjoyable. 
TABLE OF CONTENTS

PAGE

DEDICATION $\ldots \ldots \ldots \ldots \ldots \ldots \ldots \ldots \ldots \ldots \ldots \ldots \ldots \ldots \ldots \ldots \ldots \ldots \ldots \ldots \ldots \ldots \ldots$

ACKNOWLEDGEMENTS $\ldots \ldots \ldots \ldots \ldots \ldots \ldots \ldots \ldots \ldots \ldots \ldots \ldots \ldots \ldots \ldots \ldots$ iv

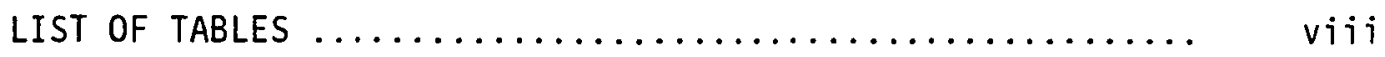

LIST OF FIGURES $\ldots \ldots \ldots \ldots \ldots \ldots \ldots \ldots \ldots \ldots \ldots \ldots \ldots \ldots \ldots \ldots \ldots \ldots$

CHAPTER

I INTRODUCTION $\ldots \ldots \ldots \ldots \ldots \ldots \ldots \ldots \ldots \ldots \ldots \ldots \ldots$

Statement of Problem ............... 4

Dissoived Organic Matter ............ 4

Representative of Chlorinated Hydrocarbons: DDT ............... 8

Physical Properties ........... 10

Solubility Determination ........... 12

Analytical Determination .......... 14

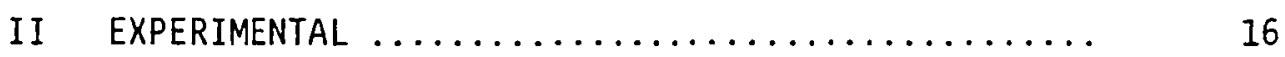

Course of Action ............... 16

Reagents $\ldots \ldots \ldots \ldots \ldots \ldots \ldots \ldots \ldots \ldots \ldots \ldots \ldots$

Instrumentation $\ldots \ldots \ldots \ldots \ldots \ldots \ldots \ldots \ldots$

EC-GLC $\ldots \ldots \ldots \ldots \ldots \ldots \ldots \ldots \ldots \ldots \ldots \ldots$

Absorbance $\ldots \ldots \ldots \ldots \ldots \ldots \ldots \ldots \ldots$

GC-Mass Spectrometry ............ 20

Glassware $\ldots \ldots \ldots \ldots \ldots \ldots \ldots \ldots \ldots \ldots \ldots \ldots \ldots \ldots \ldots$

Isolation of Dissolved Organic Matter ...... 21

DOM Stock Solution Preparation ........... 24

DOM Absorbance Calibration ............. 24 
DOM Concentration Determination ......... 26

Vapor Equilibrium Solution Preparation ...... 26

DOM Concentration Adjustment ........ 26

$\mathrm{pH}$ Adjustment $\ldots \ldots \ldots \ldots \ldots \ldots \ldots \ldots \ldots .26$

Ionic Strength Adjustment .......... 26

Saturated DDT Solution Preparation ........ 27

Extraction and Work-Up .............. 29

Controls $\ldots \ldots \ldots \ldots \ldots \ldots \ldots \ldots \ldots \ldots \ldots \ldots, 30$

Glassware Contamination .......... 30

Temperature $\ldots \ldots \ldots \ldots \ldots \ldots \ldots \ldots$

Blanks ..................... 30

Experimental Extraction Efficiency ........ 31

Immediate Extraction Efficiency ....... 32

Long-Term Extraction Efficiency ....... 33

Experimental Recovery Summary ........ 37

Immediate Extraction .......... 37

Long-Term Extraction .......... 37

Considerations ............ 37

III $\quad$ RESULTS $\ldots \ldots \ldots \ldots \ldots \ldots \ldots \ldots \ldots \ldots \ldots \ldots \ldots \ldots \ldots \ldots \ldots \ldots$

Electron Capture - Gas Chromatograph

Calibration ................... 39

Solubility Data: Two Compounds .......... 42

GLC - Mass Spectrometry .............. 42

DDT/Water Solubility ................ 50

DDT/Water Solubility Summary ......... 60

DDT/DOM Solubility ................. 61

VE System DOM Concentration ............ 77 
VE System $\mathrm{pH} \ldots \ldots \ldots \ldots \ldots \ldots \ldots \ldots \ldots \ldots \ldots \ldots$

Microorganisms $\ldots \ldots \ldots \ldots \ldots \ldots \ldots \ldots \ldots . . \ldots$

DDT Sorption to Glass $\ldots \ldots \ldots \ldots \ldots \ldots \ldots . . .60$

Biological Degradation of Aqueous DDT ...... 81

Chemical Degradation of Aqueous DDT ....... 81

IV DISCUSSION $\ldots \ldots \ldots \ldots \ldots \ldots \ldots \ldots \ldots \ldots \ldots \ldots \ldots \ldots \ldots$

Controlled Parameters .............. 82

Ionic Strength $\ldots \ldots \ldots \ldots \ldots \ldots \ldots \ldots \ldots \ldots$

Microorganisms $\ldots \ldots \ldots \ldots \ldots \ldots \ldots \ldots \ldots \ldots$

DDT Loss ........................ 84

VE System - Rate-Limiting Process ........ 88

$\quad$ CONCLUSIONS $\ldots \ldots \ldots \ldots \ldots \ldots \ldots \ldots \ldots \ldots \ldots \ldots \ldots \ldots \ldots$

Kinetic Model .................... 93

Modeling Analys is Summary .......... 114

Summary ...................... 114

REFERENCES $\ldots \ldots \ldots \ldots \ldots \ldots \ldots \ldots \ldots \ldots \ldots \ldots \ldots \ldots \ldots \ldots \ldots \ldots \ldots \ldots$

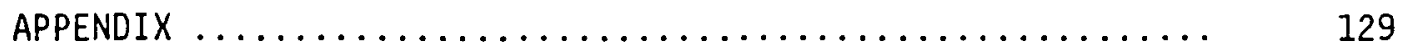




\section{LIST OF TABLES}

TABLE

PAGE

I Physical Properties of DDT-Type Compounds ....... 10

II Physical Properties of DDT-Type Compounds ...... 11

III $\quad \mathrm{DDT} / \mathrm{H}_{2} \mathrm{O}$ Solubility $\ldots \ldots \ldots \ldots \ldots \ldots \ldots \ldots \ldots \ldots \ldots$

IV DOM Solutions Initial Adjustment Parameters ...... 65

V VE System $[\mathrm{DOM}] \ldots \ldots \ldots \ldots \ldots \ldots \ldots \ldots \ldots \ldots \ldots \ldots \ldots$

VI DOM VE Systems Lower Limit for Equilibrium

Concentration ..................... 91 


\section{FIGURES}

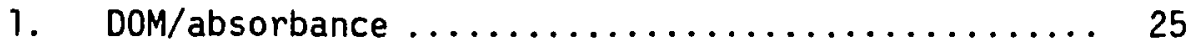

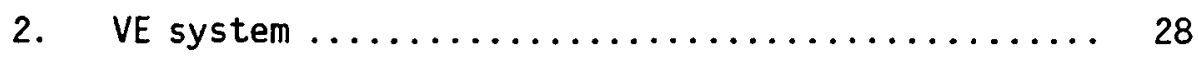

3. Long-term recovery .................. 34

4. Long-term recovery $\ldots \ldots \ldots \ldots \ldots \ldots \ldots \ldots \ldots \ldots \ldots$

5. Long-term recovery $\ldots \ldots \ldots \ldots \ldots \ldots \ldots \ldots \ldots \ldots \ldots \ldots \ldots \ldots \ldots$

6. GLC calibration ..................... 41

7. GLC./mass spec. data .................. 44

8. $\mathrm{GLC} /$ mass spec. data $\ldots \ldots \ldots \ldots \ldots \ldots \ldots \ldots \ldots \ldots$

9. GLC/mass spec. data $\ldots \ldots \ldots \ldots \ldots \ldots \ldots \ldots \ldots$

10. GLC/mass spec. data $\ldots \ldots \ldots \ldots \ldots \ldots \ldots \ldots, 47$

11. GLC/mass spec. $\operatorname{data} \ldots \ldots \ldots \ldots \ldots \ldots \ldots \ldots \ldots, 48$

12. $\mathrm{GLC} / \mathrm{mass} \mathrm{spec}$. data $\ldots \ldots \ldots \ldots \ldots \ldots \ldots \ldots \ldots \ldots$

13. $\mathrm{H}_{2} \mathrm{O}$ VE operation record $\ldots \ldots \ldots \ldots \ldots \ldots \ldots \ldots \ldots \ldots \ldots \ldots \ldots$

14. $\mathrm{H}_{2} \mathrm{O}$ VE operation record $\ldots \ldots \ldots \ldots \ldots \ldots \ldots \ldots \ldots \ldots \ldots \ldots \ldots \ldots \ldots$

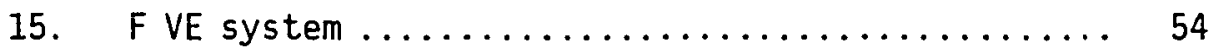

16. W VE system $\ldots \ldots \ldots \ldots \ldots \ldots \ldots \ldots \ldots \ldots \ldots \ldots \ldots$

17. F VE system $\ldots \ldots \ldots \ldots \ldots \ldots \ldots \ldots \ldots \ldots \ldots \ldots \ldots \ldots \ldots \ldots \ldots \ldots$

18. W VE system $\ldots \ldots \ldots \ldots \ldots \ldots \ldots \ldots \ldots \ldots \ldots \ldots \ldots$

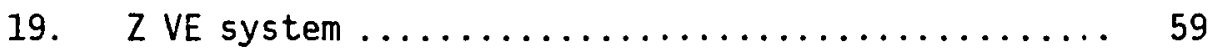

20. DOM VE operation record ................ 62

21. DOM VE operation record $\ldots \ldots \ldots \ldots \ldots \ldots \ldots \ldots$

22. DOM VE operation record $\ldots \ldots \ldots \ldots \ldots \ldots \ldots \ldots 6$

23. G VE system $\ldots \ldots \ldots \ldots \ldots \ldots \ldots \ldots \ldots \ldots \ldots \ldots \ldots \ldots \ldots \ldots \ldots \ldots$ 


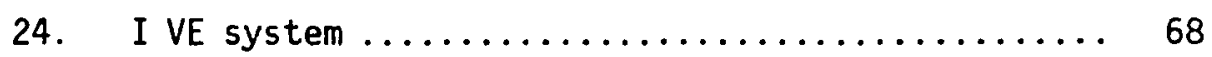

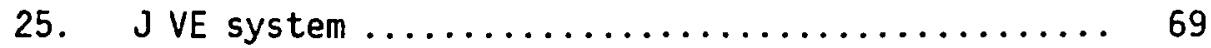

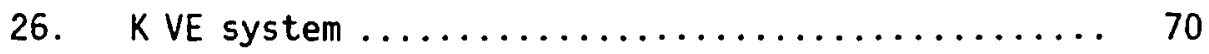

27. L VE system $\ldots \ldots \ldots \ldots \ldots \ldots \ldots \ldots \ldots \ldots \ldots \ldots \ldots \ldots \ldots \ldots \ldots$

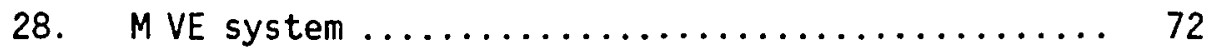

29. $N$ VE system $\ldots \ldots \ldots \ldots \ldots \ldots \ldots \ldots \ldots \ldots \ldots \ldots$

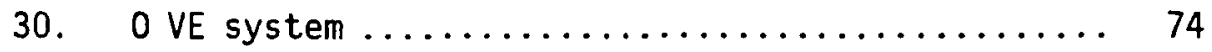

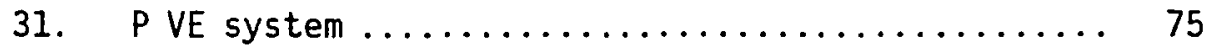

32. Q VE system $\ldots \ldots \ldots \ldots \ldots \ldots \ldots \ldots \ldots \ldots \ldots \ldots \ldots \ldots \ldots \ldots$

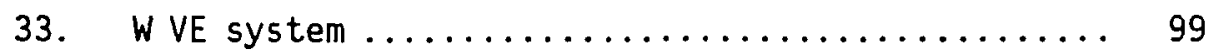

34. G VE system $\ldots \ldots \ldots \ldots \ldots \ldots \ldots \ldots \ldots \ldots \ldots \ldots$

35. I VE system $\ldots \ldots \ldots \ldots \ldots \ldots \ldots \ldots \ldots \ldots \ldots \ldots \ldots \ldots \ldots$

36. G VE system .......................... 104

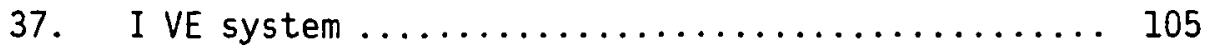

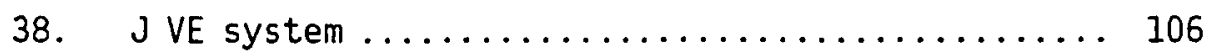

39. L VE system ........................ 107

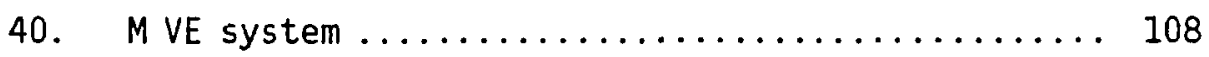

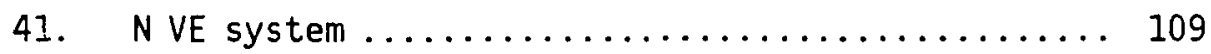

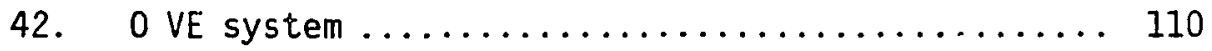

43. P VE system $\ldots \ldots \ldots \ldots \ldots \ldots \ldots \ldots \ldots \ldots \ldots \ldots \ldots$

44. Q VE system $\ldots \ldots \ldots \ldots \ldots \ldots \ldots \ldots \ldots \ldots \ldots \ldots \ldots$ 


\section{CHAPTER I}

\section{INTRODUCTION}

The fate and transport of chemical pollutants in the environment is a prominent area of concern and a focus of much research activity. The environmental processes affecting a pollutant must be understood before the ecological significance of that chemical can be predicted or assessed $(1,2)$. Although much information concerning the fate and transport of various pollutants in the environment has been gained, our understanding of these processes is far from complete.

One group of chemical pollutants receiving much attention is the chlorinated hydrocarbons. The presence of chlorinated hydrocarbons in the environment has been well documented and is generally considered a hazard to man and his surroundings (3-31). Representative of this class are DDT, Kepone, Dioxin and the PCB's (polychlorinated biphenyls). A11 of these compounds are hydrophobic, and their water solubilities are extremely small. Most have very low vapor pressures as well. The physical properties of a pollutant play a major role in determining its environmental fate, and the various chlorinated hydrocarbons demonstrate similar behavior in the environment. This similarity allows for information concerning the environmental fate and transport of a specific chlorinated hydrocarbon to be extrapolated to the class as a whole.

One active area of study deals with the major modes of transport of chlorinated hydrocarbons within the environment (25, 31-44). Movement of these compounds from their point of entry is well documented $(17,31$, 
$35,37,42,45-49)$. Presently, it appears that all regions of this planet contain detectable levels of these chemicals $(11,17,25,26,29$, 42, 50-54). This degree of movement may at first seem surprising when one considers the low solubilities and vapor pressures of these compounds. These physical properties suggest that this class of pollutant should be resistant to environmental transport, and one would expect such chemicals to remain in the region of environmental entry.

A chemical pollutant travels by way of the air and the water. In movement, the chemical can be either associated with particulates or dissolved in the phase through which it's traveling (as a vapor in the gas phase and as a solute in the liquid phase). Due to their low vapor pressures, it was believed that chlorinated hydrocarbons migrated in air only in association with particulates, and that atmospheric transport was not a significant process. Lately these compounds have been shown to volatilize to an important degree (55-57), and that distribution through the atmosphere plays an integral part in the movements of these pollutants $(42,51-60)$.

During aqueous transport, chlorinated hydrocarbons are found in association with naturaliy occurring organic matter in fresh and marine water. The nature of this association has been the subject of much work. Naturally occurring organic matter is present in both particulate and dissolved states. While the interaction between hydrophobic compounds and dissolved organic matter is poorly understood, chlorinated hydrocarbons in aqueous systems have been shown to associate strongly with the organic matter of soils $(37,61-71)$, sediments $(37,71-73)$, particulates and suspended solids $(40,73-78)$. 
At the dilute concentrations of pollutants observed in the environment, the equilibrium isotherms for adsorption of these compounds to particulate organic matter are linear, so the association reaction has been modeled as a partitioning of the pollutant between the aqueous phase and the organic fraction of the solid phase $(38,40,69,71$, 79-82). This partitioning is analogous to the partitioning of a compound between the aqueous and organic phases in a separatory funnel. A partition coefficient, $k_{p}$, can be calculated, where

$$
\mathrm{K}_{\mathrm{p}}=\frac{\text { concentration of compound in sorbed phase }}{\text { concentration of compound in aqueous phase }}
$$

As the partition coefficient exhibits a linear dependence on the amount of organic carbon present, the coefficient is normalized for the amount of orgaric matter by dividing by $\alpha_{\text {oc }}(38,69,71,79,80,82-84)$, where $\alpha_{\text {oc }}=$ fraction of organic carbon present, and

$$
K_{o c}=K_{p} / \alpha_{o c}
$$

Letting $\rho_{O C}=\frac{\text { weight of organic carbon }}{\text { weight of water }}$,

this normalized partition coefficient $\left(K_{o c}\right)$, can be expressed as

$$
K_{o c}=\frac{\text { fraction of pollutant sorbed }}{\text { fraction of pollutant in aqueous phase }} \frac{1}{\rho_{\text {oc }}} \text {, }
$$

and is independent of the amount of organic matter present.

The $K_{o c}$ 's have been calculated for the partitioning of many compounds into the naturally occurring organic matter of various solids. For a specific compound, the respective $K_{o c}$ has been shown to be remarkably constant over a variety of soils, sediments, particulates and suspended solids $(38,69,79,82,84)$. 
A linear relationship has been shown to exist between the logarithm of the $K_{o c}$ and the aqueous solubility of that compound $(80,82,84)$. Improved fits have been made by adding terms to correct for crystal energies (82). A linear relationship has also been demonstrated between the $\log K_{o c}$ and the logarithm of the octanol/water partition coefficient $K_{\text {ow }}(79,82,84)$.

While the partitioning of hydrophobic compounds to solid or particulate organic matter has thus been extensively characterized, the interaction between dissolved organic matter (DOM) and chlorinated hydrocarbons is not well understood. DOM comprises the bulk of organic carbon in natural waters: the ratio of dissolved to particulate organic carbon averages 10:1 for small temperate forest watersheds $(85,86)$. With an estimated $10^{14}$ to $10^{15}$ grams of organic carbon transported by the rivers of the world each year $(86,87)$, the interaction between chlorinated hydrocarbons and naturally occurring DOM is an area of prime environmental concern.

\section{STATEMENT OF PROBLEM}

This work is an effort to quantify the effect of dissolved organic matter (DOM) on the solubility in water and, hence, the transport of hydrophobic organic compounds (specifically, DDT) in the environment.

\section{Dissolved Organic Matter}

Concentrations of DOM in rivers range from one to $80 \mathrm{mg} / \mathrm{L}$. For example, the Columbia River averages $6 \mathrm{mg} / \mathrm{L}$ DOM, the lower Mississippi 8 $\mathrm{mg} / \mathrm{L}$, and the Williamson River in southern Oregon averages $40-50 \mathrm{mg} / \mathrm{L}$ at one location (88). 
The physical and chemical nature of dissolved organic matter in natural waters has been extensively studied ( $85,88-94)$. While the input of labile organic matter of biological origin is large, this material is rapidly degraded and comprises a relatively small part of the DOM in natural waters $(85,94)$. On an average, $70-80 \%$ of the organic matter occurring in natural waters is humic matter $(94,95)$. Humic matter is an amorphous, polymeric material that is resistant to chemical or biological degradation. It is this degradative resistance that is responsible for the high proportion of river organic matter that is humic material.

Humic matter is divided into three operationally defined parts. Humin is that fraction which is not soluble in base. Humic acid is the fraction that is soluble in base, but not acid. Fulvic acid is the fraction that is soluble in both acid and base. While all three fractions are found in soils, sediments, and particulates, fulvic acid comprises $90 \%$ or more of the dissolved humic matter of natural waters, the remainder being humic acid $(89,91,94)$.

Humic matter has been extensively studied (93, 96-118). Although its structural features are not well known, it is thought to be comprised of large molecules ranging between 500-1000 daltons for fulvic acid (1000-1500 for humic acid). Extensive efforts at physical and chemical characterization have resulted in some generally recognized models for these substances. Humic and fulvic acids are thought to be polymeric compounds containing a sizable portion of aromatic, phenolic and carboxylic functionalities. Futvic acid contains a higher proportion of oxygen-containing polar functional groups. The macromolecular properties of these compounds have been an area of much interest (118- 
130). It is thought that these molecules contain regions that exhibit hydrophobic properties. It is known that hydrophobic molecules or hydrophobic areas of large molecules demonstrate an attraction for each other in aqueous systems $(131,132)$. It has been suggested that humic materials, due to their hydrophobic nature, could preferentially partition or sorb insoluble organic compounds from an aqueous medium (68, 117, 118, 133-135). As fulvic acid contains more polar groups and a higher aqueous solubility, it would not be unreasonable to expect that a hydrophobic compound might partition to the humic acid of sediments and particulates to a greater extent than to the fulvic acid which predominates in DOM.

Recently, work has indicated that there may be considerable aliphatic nature to humic molecules (136). It has also been found that, at an aquatic $\mathrm{pH}$ of greater than 6.5 and a concentration 1 ess than $3500 \mathrm{mg} / \mathrm{L}$, the molecules may "unwind" to form a more open, flexible structure (137). The effects of macromolecular shifts in configuration of humus on the association with hydrophobic compounds is not known.

Although the chlorinated hydrocarbons - DOM association has been investigated, the interaction has not been well quantified. Hassett and Anderson (138) showed that DOM in river water reduced solvent extraction recoveries of radiolabeled cholesterol. Boucher and Lee (139) found that naturally occurring dissolved organics in lake water reduced absorption of Dieldrin on aquifer sand by $40-47 \%$. Coburn, et al (140) fortified distilled water and natural waters with a mixture of organochlorinated pesticides and PCB's. The natural waters gave lower recoveries of pollutants when extracted with XAD-2 resin. 
In general, the available quantitative data concerning the association between aquatic humic matter and insoluble organic compounds are difficult to extrapolate to an environmental situation involving naturally occurring DOM and pollutants. Wershaw, et al (141) reported that a $5000 \mathrm{mg} / \mathrm{L}$ sodium humate solution increased the solubility of DDT by a factor of twenty. Boehm and Quinn (142) found that naturally occurring DOM and sediment fulvic acid enhance the solubility of normal alkanes, hexadecane and eicosane in sea water. Phenanthrene showed no solubility enhancement. Poirrier, et al (77) spiked a natural water sample containing iron-organic colloids with radiolabeled DDT. The colloids were removed by centrifugation. The centrifuge pellet concentrated the DDT by a factor of 15,800 relative to the supernatent solution. Carter and Suffet (143) examined the assocation of radiolabeled DDT and dissolved humic materials. Solutions of organic matter extracted from soils and sediments were retained within dialysis tubing and allowed to equilibrate with DDT solutions. DDT concentrations of the solutions were well below the aqueous DDT solubility, and the concentrations of organic matter were in the range of environmental conditions. DDT was found to partition to the soil/sediment organic matter with a $\log K_{o c}$ of 5.1 to 5.7. A few experiments conducted with pond and reservoir water containing a small amount of naturally occurring DOM indicated a DDT $\log K_{\text {oC }}$ of $4.8(143)$.

Thus, while extraction efficiencies demonstrate a qualitative interaction of DOM and hydrophobic organic compounds, most quantitative work has involved (1) conditions difficult to extrapolate to the environment (Wershaw), (2) iron-organic colloids which were not actually dissolved (Poirrier, et al), or (3) solutions of soil or sediment organ- 
ic material which is only similar to naturally occurring dissolved organic matter (Carter and Suffet). The only environmentally related quantitative work utilizing actual DOM involved a few measurements of two water samples containing a small amount of dissolved organic carbon (Carter and Suffet). This lack of quantitative data limits the understanding of the interactions between pollutants and dissolved organic matter in aqueous systems.

\section{Representative of Chlorinated Hydrocarbons: DDT}

DDT was selected for use in this work as representative of the class of chlorinated hydrocarbons. The selection of DDT offered several advantages: (1) it is readily obtainable in a highly purified form, (2) its physical and chemical characteristics have been well studied and (3) relative to other compounds in the same class, it is less toxic.

The term DDT often refers to $p, p^{\prime}-D D T$, Chemical Abstracts: 1, 1'(2,2,2-tricholoroethylidene)bis[4-chlorobenzene] [50-29-3]. The $p, p^{\prime}-$ DDT used in this work was contaminated with about one percent of the isomer o,p'-DDT, Chemical Abstracts: 1-chloro-2-[2,2,2-trichloro-1-(4chloropheny1)ethylbenzene] [789-02-6], and a lesser amount of a degradation product, $P, P^{\prime}-D D E$, Chemical Abstracts: 1,1'-(dichloroethenylidene) bis[4-chlorobenzene] [72-55-9]. As this work includes solubility data for both the $p, p^{\prime}-D D T$ and $0, p^{\prime}-D D T$ isomers, "DDT" will be used to represent both isomers collectively. Reference to an individual isomer will be made as "p,p'-DDT" or "o,p'-DDT."

While much work has been done to characterize the physical properties of DDT, there is not yet precise agreement on aqueous solubility or vapor pressure. This disparity reflects the difficulties involved in 
accurately measuring the minute quantities of DDT that are involved. While there is some scatter in the reported values of solubility and vapor pressure, presented in Tables I and II, a range of agreement is clearly established. 
TABLE I

PHYSICAL PROPERTIES OF

DDT-TYPE COMPOUNDS

Physical Properties

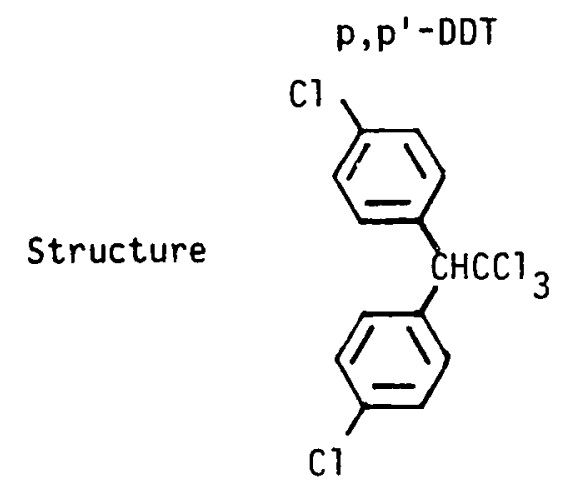

Molecular

Weight

Melting

Point

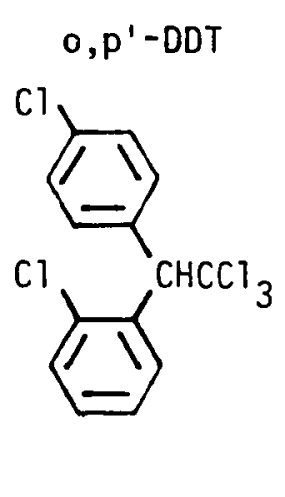

354.5

$74-74.5^{\circ} \mathrm{C}$

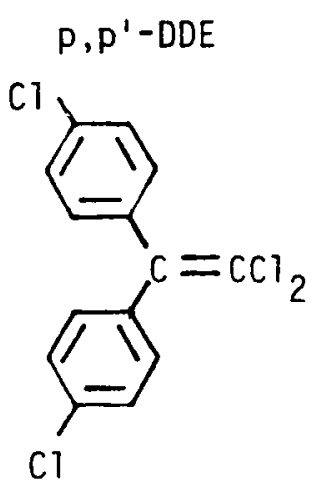

318.0

$82^{\circ} \mathrm{C}$

Vapor Pressure

Compound

$p, p^{\prime}-D D T$

$0, P^{\prime}-D D T$

$p, p^{\prime}-D D E$
Value

$7.3 \times 10^{-7} \operatorname{torr}\left(30^{\circ} \mathrm{C}\right)$

$1.5 \times 10^{-7} \operatorname{torr}\left(20^{\circ} \mathrm{C}\right)$

$1.5 \times 10^{-7} \operatorname{torr}\left(20^{\circ} \mathrm{C}\right)$

$4.3 \times 10^{-7} \operatorname{torr}\left(25^{\circ} \mathrm{C}\right)$

$5.5 \times 10^{-6} \operatorname{torr}\left(30^{\circ} \mathrm{C}\right)$

$8.8 \times 10^{-6} \operatorname{torr}\left(30^{\circ} \mathrm{C}\right)$

$6.5 \times 10^{-6} \operatorname{torr}\left(20^{\circ} \mathrm{C}\right)$

$1.3 \times 10^{-5} \operatorname{torr}\left(30^{\circ} \mathrm{C}\right)$
Reference

Spencer \& Cliath (144)

Spencer \& Cliath (144)

Metcalf (145)

Rothman (146)

Spencer \& Cliath (144)

Westcott, et al (147)

Spencer \& Cliath (144)

Westcott, et al (147) 


\section{TABLE II \\ PHYSICAL PROPERTIES OF \\ DDT-TYPE COMPOUNDS}

Aqueous Solubility

\begin{tabular}{|c|c|c|c|c|}
\hline Compound & Value & $\begin{array}{l}\text { Generation of } \\
\text { Saturated Solution }\end{array}$ & $\begin{array}{l}\text { Analytical } \\
\text { Method }\end{array}$ & Reference \\
\hline \multirow[t]{6}{*}{$p, p^{\prime}-D D T$} & $37.5 \mathrm{ppb}\left(25^{\circ} \mathrm{C}\right)$ & Centrifugation & Radiometric & Babers (148) \\
\hline & $<1.2 \mathrm{ppb}\left(25^{\circ} \mathrm{C}\right)$ & Centrifugation & Radiometric & $\begin{array}{l}\text { Bowman, et al } \\
(149)\end{array}$ \\
\hline & $1.7 \mathrm{ppb}\left(25^{\circ} \mathrm{C}\right)$ & Centrifugation & $E C-G L C$ & $\begin{array}{l}\text { Biggar, et al } \\
(150)\end{array}$ \\
\hline & $5.5 \mathrm{ppb}\left(25^{\circ} \mathrm{C}\right)$ & Flow System & & $\begin{array}{l}\text { Weil, et al } \\
(157)\end{array}$ \\
\hline & $4 \quad \operatorname{ppb}\left(25^{\circ} \mathrm{C}\right)$ & $\begin{array}{l}\text { Extrapolated from } \\
\text { nephelometric method }\end{array}$ & $\begin{array}{l}\text { Spectrophoto } \\
\text { fluorometer }\end{array}$ & $\begin{array}{l}\text { Hollifield } \\
(152)\end{array}$ \\
\hline & $5.0 \mathrm{ppb}\left(20^{\circ} \mathrm{C}\right)$ & Centrifugation & $E C-G L C$ & $\begin{array}{l}\text { Chiou, et al } \\
(153)\end{array}$ \\
\hline $0, p^{\prime}-D D T$ & $\mathrm{ppb}\left(25^{\circ} \mathrm{C}\right)$ & Flow System & & $\begin{array}{l}\text { Wei1, et al } \\
(151)\end{array}$ \\
\hline \multirow[t]{3}{*}{$P, P^{\prime}-D D E$} & $\mathrm{ppb}\left(25^{\circ} \mathrm{C}\right)$ & Flow System & & $\begin{array}{l}\text { Wei1, et al } \\
(151)\end{array}$ \\
\hline & $\mathrm{ppb}\left(20^{\circ} \mathrm{C}\right)$ & Static equilibrium & $E C-G L C$ & $\begin{array}{l}\text { Chiou, et al } \\
(154)\end{array}$ \\
\hline & $65 \mathrm{ppb}\left(25^{\circ} \mathrm{C}\right)$ & $\begin{array}{l}\text { Extrapolated from } \\
\text { nephelometric method }\end{array}$ & $\begin{array}{l}\text { Spectrophoto } \\
\text { fluorometer }\end{array}$ & $\begin{array}{l}\text { Holififield } \\
(152)\end{array}$ \\
\hline
\end{tabular}

The chemical reactivity of DDT has been well documented $(4,5,21$, 155-159).

The biological reactivity of $p, p^{\prime}-$ DDT has been well studied (29, 42, 155-170). There is general agreement that the major degradation products are $p, p^{\prime}-D D E$ and $p, p^{\prime}-D D D$, Chemical Abstracts: 1, 1'-(2,2-di- 
chloroethylidene) bis[4-chlorobenzene] [72-54-8]. Further degradation of these products may or may not occur, depending on the existing environmental conditions and on the biological system(s) involved. It has been observed in general that $p, p^{\prime}-D D E$ is quite resistant to further degradation.

The partitioning of DDT between water and the organic matter in soils and sediments has been measured and $K_{O C}$ 's have been calculated for the partitioning of $p, p^{\prime}-D D T$ to particulate humic material.

$$
\begin{aligned}
\text { DDT } K_{\text {oc }}= & 1.31 \times 10^{5} \\
& 2.38 \times 10^{5} \\
& 3.55 \times 10^{5} \\
& 1.23-5.50 \times 10^{5}
\end{aligned}
$$

\section{Solubility Determination}

The accurate determination of aqueous solubilities for compounds essentially insoluble in water is very difficult. The critical step involves the generation of a solution that is saturated with the compound of interest. There are three basic methods that have been employed to generate saturated DDT solutions:

(1) Supersaturate and remove excess. This is the method most commonly used. An excess amount of DDT is added to water and the mixture is shaken for several days or sonicated. The undissolved DDT is then removed, usually by high-speed centrifugation for extended periods.

(2) Three-phase system. This method is used most often for solubility estimation. A near saturated solute-octanol solution is mixed with a volume of water. The solubility of the solute in the octanol phase decreases due to the equilibrium content of water in the 
alcohol. The quantity of solute that is no longer soluble in the octanol is more than enough to saturate the aqueous phase. Thus, crystalline solute appears at the interface of the two liquid phases (after centrifugation), and a saturated aqueous phase is generated. Because the determination is rapid, this method finds its greatest applicability in estimating the solubility of compounds that are unstable in water (not a problem with DDT) and therefore cannot be equilibrated with water for long periods of time (173).

(3) Approach to saturation. This method involves coating the interior walls of a vessel or the surface of glass beads with solid DDT. Water is then allowed to equilibrate with the solid by swirling in the flask or slowly flowing through a column packed with the beads. The concentration of DDT in the water is monitored over time to determine when equilibrium (saturation) has been reached.

Each of these three methods has its own inherent problems. In removing undissolved DDT from a supersaturated solution, an operationally defined "saturated solution" is generated. It has been shown that the concentration of DDT in the supernatent liquid is a function of the speed and duration of centrifugation (150, 174). In addition, centrifugation has been determined not suited for solubility enhancement work (see Appendix). The three-phase system cannot generate accurate saturated solutions. The water phase is saturated with the organic phase, and this small amount of organic solvent in the water has been shown to affect the aqueous concentration of DDT (15i: 175, 176). The method involving the approach to saturation has the best potential for generating a saturated concentration that is independent of operating para- 
meters. The problem involved with this method arises from the physical contact of solid DDT and the solution. This contact permits the entry of particles of DDT into the solution in an undissolved state. At the low concentrations of DDT being measured, a uniform suspension of undissolved DDT particles could result in a large error in the determined solubility.

The work described in this dissertation utilizes a different method for generation of a saturated solution. A saturated solution is approached from a low concentration side, but the solution does not physically contact solid DDT.

\section{Analytical Determination}

The sensitivity required to accurately determine DDT concentrations in the ppb range narrows the choice of analytical methods to two: radioisotope techniques or electron capture gas liquid chromatography (ECGLC). While both methods have disadvantages, EC-GLC was selected for use in this work.

The major drawback with the radioisotopic labeling method is fourd in the "blind counting" during the analysis. The counter counts all radio labels, regardless of the chemical species. The accuracy of this method is therefore dependent on the purity of the radiolabeled DDT. Impurities in radiolabeled DDT have been observed to significantly affect the results of volatization and solubility determinations (146149). As some of these impurities have markedly different physical properties, even a small amount of a contaminant can significantly affect results. 
With the proper operating parameters, the EC-GLC method allows for a separate quantification of the electron capturing isomers and degradation products of DDT (177-185). Thus, contaminants are monitored. Difficulties of this method involve the inability to analyze aqueous solutions directly $(186,187)$. This, along with the concentration step required by the low levels to be measured, necessitates an involved sample work-up (188-191). In addition, the EC detector is extremely sensitive to a whole host of laboratory generated contaminants $(55,188$, 190, 192, 193). As a result, the procedures required for accurate results at the $\mathrm{ppb}$ level demand extreme cleanliness and tedious quantitative exactness. 


\section{CHAPTER II}

\section{EXPERIMENTAL}

\section{COURSE OF ACTION}

DDT solubility in distilled water was determined by an approach to saturation method. Aliquots of the solution approaching saturation were removed over a period of time. After each aliquot was extracted, EC-GLC was used to determine the amount of DDT in the extract. GLC-mass spectrometry was used to confirm the identities of the DDT isomers that were measured. When the concentration of DDT in solution, over a period of time, reached and maintained a maximum leve?, equilibrium (and saturation) had been achieved.

The concentration of DDT (over time) was also measured in approach to saturation systems containing solutions of naturally occurring dissolved organic matter (DOM). DOM used in these systems was isolated from river water. The concentration of DOM in solution was determined by absorbance measurements in the UV-visible range.

The $\mathrm{pH}$, ionic strength and DOM concentration of each solution were adjusted to reflect a range of environmental fresh water conditions.

\section{REAGENTS}

\section{Amberlite $X A D-7$ macroretricular resin}

Rohm and Haas, Inc.

The resin was extracted with methanol in a Soxhlet apparatus overnight and stored in methanol until ready for use. 
Amberlite 120 IR resin

The resin was acidified with $\mathrm{HCl}$, then washed with distilled water until neutral.

Triethyl amine

Baker Chemical Company

Reagent Grade

The amine was distilled in glass before use.

\section{Organic matter}

Williamson River in Southern Oregon

Isolated material was freeze-dried, then vacuum-dried.

$\mathrm{C}, \mathrm{H}, \mathrm{N}$ analysis (duplicate samples): \% C $47.43 \pm 0.00$

$\% \mathrm{H} \quad 4.10 \pm 0.00$

$\% \mathrm{~N} \quad 1.65 \pm 0.07$

$\% 0 \quad 41.74 \pm 0.09$

$\%$ ash $\quad 5.08 \pm 0.02$

Water

House-distilled water

The water was distilled in glass from a $0.1 \mathrm{~N} \mathrm{KOH}, 0.01 \mathrm{~N} \mathrm{KMnO}_{4}$ solution before use.

Sodium chloride

Mallinckrodt Chemical Company

Analytical Reagent Grade

The sodium chloride was crystalized from quartz-distilled water and oven-dried. 
$\mathrm{P}, \mathrm{P}^{\prime}-\mathrm{DDT}$

Aldrich Chemical Company

1,1-bis-(p-chloropheny 1)-2,2,2-trichloroethane, Gold Label, 99+\%

$p, p^{\prime}-D D T$ was used without further purification.

\section{$\underline{\text { DDT-coated glass beads }}$}

$4 \mathrm{~mm}$ borosilicate glass beads were cleaned in the same manner as all glassware (see Glassware). Approximately 350 beads were combined with $40 \mathrm{~mL}$ of hexanes containing $0.1 \mathrm{~g} \mathrm{p}, \mathrm{p}^{\prime}-\mathrm{DDT}$ and the hexanes were removed by rotory evaporation. The coated beads were stored in glass.

\section{Aldrin}

Polyscience Corporation

$1,2,3,4,10,10$,-hexachloro- $1,4,5,8,8$-hexahydro- 1,4 -endo-exo-5,8-dimethanonaphthalene, Qual Grade, 99\%.

Aldrin was used without further purification.

\section{Dichloromethane}

American Scientific and Chemical

Laboratory Grade (glass bottles with aluminum foil cap liners)

The dichloromethane was fractionally distilled in an all-glass apparatus and stored in glass.

\section{Hexanes}

American Scientific and Chemical

Laboratory Grade (55 gal stee] barrel fitted with a brass spigot)

The hexanes were fractionally distilled in an all-glass apparatus and stored in glass. 
Sodium sulfate, anhydrous

Mallinckrodt Chemical Company

Analytical Reagent Grade

The sodium sulfate was heated at $250^{\circ} \mathrm{C}$ overnight and stored in all glass.

Hengar granules

Hengar Company

Selenized

The Hengar granules were washed with hexanes, then heated at $250^{\circ} \mathrm{C}$ overnight and stored in all glass.

Heptane (normal)

Mallinckrodt Chemical Company

Spectrometric Grade ( $g$ lass bottle with aluminum foil cap liner)

Heptane was used without further purification.

$\underline{0, p^{\prime}-D D T}$

Aldrich Chemical Company

1-(o-chloropheny 1$)-1-(p-c h$ loropheny 1$)-2,2,2-$ trichloroethane, Gold Label, $99+\%$

$0, p^{\prime}$-DDT was used without flirther purification.

$p, p^{\prime}-D D E$

PolyScience Corporation

1,1-dich1oro-2,2-bis(p-chloropheny1)ethylene, Qual Grade, 99\%

$p, p^{\prime}-D D E$ was used without further purification. 


\section{INSTRUMENTATION}

\section{$\underline{E C-G L C}$}

Gas chromatography data was collected from a Hewlett Packard 5750 B gas chromatograph with ${ }^{63} \mathrm{Ni}$ electron capture detector. Separation of the internal standard and the DDT isomers was accomplished on a $6 \mathrm{ft}$., 1/4" OD, $4 \mathrm{~mm}$ ID glass column packed with $1.5 \% \mathrm{SP}-2250 / 1.95 \% \mathrm{P}-2401$ on 100/120 Supelcoport (similar to OV-17/QF-1 or OV-17/0V-210). The carrier gas used was 95\% Argon/5\% Methane. Operating parameters included: injection port $245^{\circ} \mathrm{C}$, column $200^{\circ} \mathrm{C}$ (isothermal), detector $222^{\circ} \mathrm{C}$ pulsed at $15 \mu \mathrm{sec}$, flow rate at $90 \mathrm{~mL} / \mathrm{min}$. Five $\mu \mathrm{L}$ of sample were injected.

The chromatogram was recorded and the peaks integrated by a Hewlett Packard 3380 A integrator.

\section{Absorbance}

UV-visible absorbances were measured with a Cary 14 UV-Visible spectrophotometer. Absorption of $\mathrm{pH} 10$ organic matter solutions in a $5.0 \mathrm{~cm}$ cell were measured at $420 \mathrm{~nm}$.

\section{GC-Mass Spectrometry}

GC/MS work was performed on a Finnigan 4023 GC/MS at the University of Oregon Health Sciences Center. Gas chromatographic separation of the isomers was accomplished with a $6 \mathrm{ft}$, $1 / 4 \mathrm{in.}$ OD glass column packed with $1.5 \%$ SP-2250/1.95\% SP-2401 on 100/120 Supelcoport. The carrier gas was nitrogen, run with a flow rate of $25 \mathrm{~mL} / \mathrm{min}$. The injection port was set at $225^{\circ} \mathrm{C}$. The column oven temperature was varied by the following program: 2-minute hold at $175^{\circ} \mathrm{C}, 5$-minute increase at $10^{\circ} \mathrm{C} / \mathrm{min}$, and 
3-minute hold at $225^{\circ} \mathrm{C}$. The mass spectrometer was operated in the positive and negative chemical ionization modes (with a 5-minute delay). Methane was the reagent gas, and the electron energy was $70 \mathrm{eV}$.

\section{GLASSWARE}

Wherever feasible, borosilicate glassware was the only material allowed to contact samples, solutions and purified reagents. Exceptions were limited to the use of stainless steel and fluorocarbon polymers, which were present in stopcocks and in spiking and analysis syringes.

The polymeric stopcocks were shown to sorb small amounts of pesticide during sample work-up. The quantity sorbed was not significant to the recovery of any one sample, but would have been significant if allowed to accumulate over a number of samples. For this reason, the stopcocks were extracted twice for 15 minutes with dichloromethane and washed in soap after each sample. No accumulation of pesticide by the fluorocarbon polymer stopcocks was observed with this cleaning procedure.

Routinely after each sample work-up, the glassware was rinsed with tapwater, soaked in soap, rinsed with tap water, air dried and heated at $250^{\circ} \mathrm{C}$ overnight.

\section{ISOLATION OF DISSOLVED ORGANIC MATTER}

The Williamson River in southern Oregon was utilized as the source of dissolved organic matter (DOM) used in this study. The section of river between Klamath Marsh and Upper Klamath Lake contains as much as $50 \mathrm{mg} / \mathrm{L}$ DOM. The sampling site is located near Kirk at USGS Gage Sta- 
tion \#18010201, latitude $42^{\circ} 44^{\prime} 25^{\prime \prime}$, Tongitude $121^{\circ} 50^{\prime} 00^{\prime \prime}$. The sample was collected on 01-14-79; water temperature was $0^{\circ} \mathrm{C}$.

Water was withdrawn via a motor-driven pump which was first flushed with river water. Maximum output of the pump was $46 \mathrm{gal} / \mathrm{min}$. The water was pumped into 55-gallon drums that had previously contained 95\% ethyl alcohol. The drums were rinsed three to four times with river water before they were filled. The water collected was stored at $4^{\circ} \mathrm{C}$ until the DOM was isolated.

To remove particulates, the river water was centrifuged in a cont inuous flow system involving a Sorvall SS-3 centrifuge with a SS-34 rotor. Centrifugation was carried out at 10,000 rpm at a flow rate of 150-160 $\mathrm{mL} / \mathrm{min}$. These conditions allowed for the removal of particulates with a diameter of $\psi \mathrm{um}$ or greater. Centrifugation did not remove particles with a diameter of $0.45 \mu \mathrm{m}$, which is the generally accepted operational definition distinguishing particulate and dissolved species. The sampling site, however, has been shown to contain only three to five percent of its organic matter as particles of diameter greater than $0.45 \mathrm{jm}$ (assayed by absorbance at $420 \mathrm{~nm}$ and $\mathrm{pH} 10$ ) (88). Thus, the centrifuged water contained only an extremely small amount of material with a diameter between 0.45 and $1 \mu \mathrm{m}$.

After centrifugation, the river water was acidified to $\mathrm{pH} 1.8$ with HC1. Dissolved organic matter was adsorbed on Rohm and Haas Amberlite XAD-7 macrorecticular resin in a $9 \mathrm{~cm}$ diameter glass column following procedures recommended by the manufacturer (194). Retention of humic substances was $280 \%$ as determined by absorbance at $420 \mathrm{~nm}$ of a pH 10 solution. Any metals or traces of ethanol that might have originated from the 55-galion storage drums would not have been retained by the macrorecticular resin. 
Triethylamine was selected as the base for elution of the organic matter for the following reasons: (1) To minimize the possibility of base catalyzed degradation of the humic substances, elution should be done with a weak base. Since a solution of triethylamine has a lower $\mathrm{pH}$ than a solution of $\mathrm{NaOH}$ of the same concentration, any base catalyzed degradation of the organic matter would proceed at a slower rate in the presence of amine. (2) Following elution of the organic matter, excess base in the effluent may be removed by evaporation of the $E t_{3} N$, since this base has an appreciable vapor pressure. (3) Use of a tertiary amine minimizes inclusion of the base by the humic matter, as condensation reactions with carbonyl functionalities do not occur. Inclusion of less highly substituted amines has been observed (195).

After elution with $0.15 \mathrm{MEt}_{3} \mathrm{~N}$, excess base was removed via rotary evaporation. The concentrated effluent was diluted with distilled water prior to desalting on a $4 \mathrm{~cm}$ diameter glass column of Amberlite 120 IR resin to prevent precipitation of the less soluble "humic acid" fraction of aquatic humus in the acidic environment of the resin. The effluent $(\mathrm{pH} 2.4)$ was concentrated by rotary evaporation, freeze-dried, then vacuum-dried at room temperature. Approximately 10 grams of organic matter was isolated from 500 liters of river water in this way. Duplicate $C, H, N$ analyses gave the following results:

$\begin{array}{lr}\text { \% C } & 47.43 \pm 0.00 \\ \% \mathrm{H} & 4.10 \pm 0.00 \\ \% \mathrm{~N} & 1.65 \pm 0.07 \\ \% 0 & 41.74 \pm 0.09 \\ \text { \% ash } & 5.08 \pm 0.02\end{array}$


DOM STOCK SOLUTION PREPARATION

Freeze-dried organic matter $(0.6 \mathrm{~g})$ was mixed with $20.0 \mathrm{~mL}$ of $0.1 \mathrm{~N}$ $\mathrm{NaOH}$. One liter of distilled water was added, and the solution was mixed for several hours before filtering through a 4-8 $\mathrm{\mu m}$ glass frit. The filtrate was then diluted to three liters and aerated with nitrogen. An aliquot was removed for determination of DOM concentration ( $~ 90$ $\mathrm{mg} / \mathrm{L}$ ). Stock solutions were stored in the dark.

\section{DOM/ABSORBANCE CALIBRATION}

A DOM stock solution was adjusted to $\mathrm{pH}=10$ and serially diluted with $\mathrm{pH} 10 \mathrm{NaOH}$ solution. The resulting $\mathrm{pH} 10$ DOM solutions were placed in $5.00 \mathrm{~cm}$ cells ( $\mathrm{pH} 10 \mathrm{NaOH}$ solution reference) and their absorbance at $420 \mathrm{~nm}$ was measured with a Cary 14 spectrophotometer.

The DOM concentration of the stock solution was determined gravimetrically after drying an aliquot at $106^{\circ} \mathrm{C}$ overnight.

A linear regression analysis of concentration in $\mathrm{mg} / \mathrm{L}$ versus absorbance at $420 \mathrm{~nm}$ yields a straight line of slope 61.55 and intercept 0.655 and a correlation coefficient of 0.9999 (see Figure 1). 


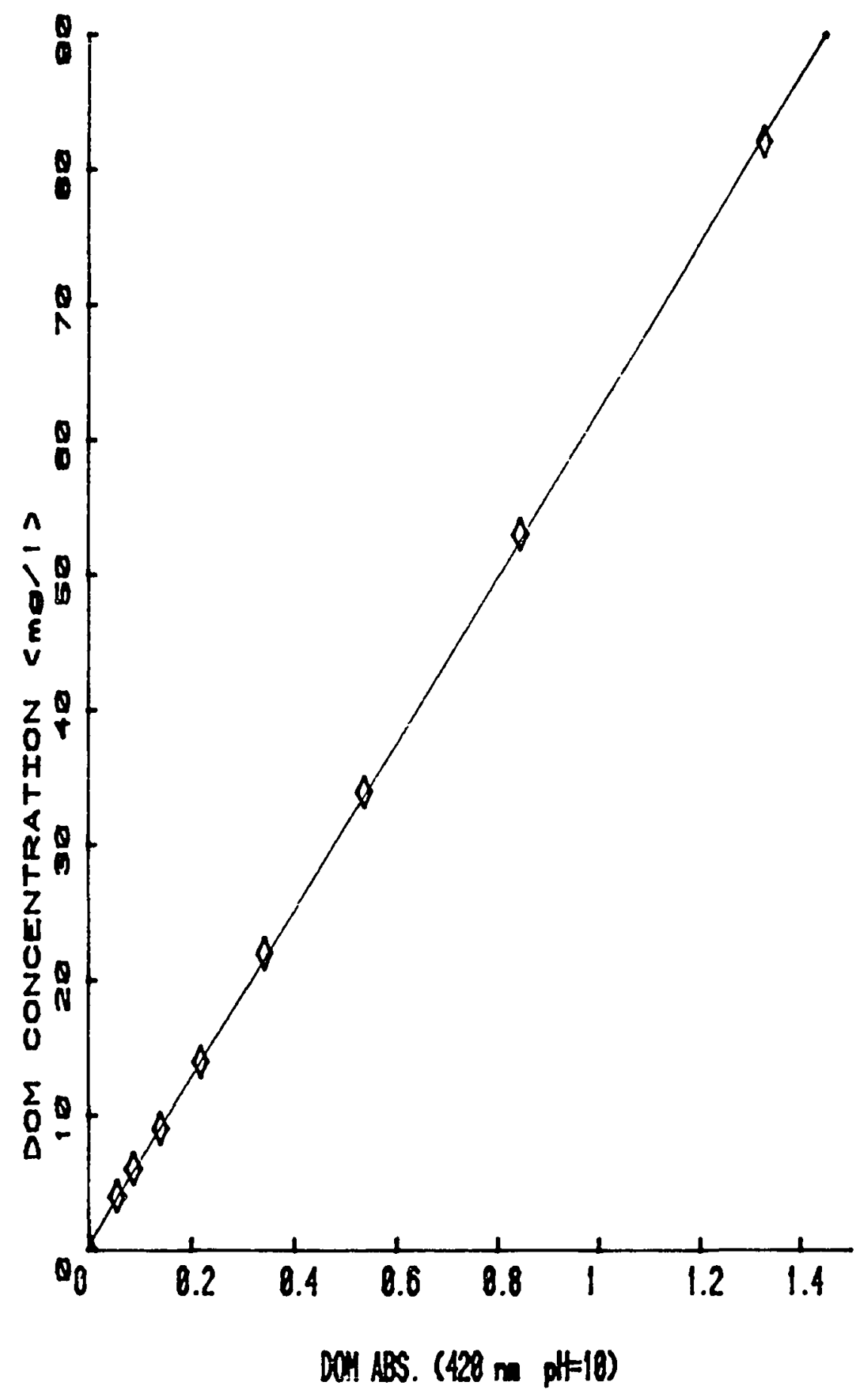

Figure 1. D0i1/Absorbance 
DOM CONCENTRATION DETERMINATION

A $20.0 \mathrm{~mL}$ aliquot of the organic solution to be analyzed was titrated with $0.01 \mathrm{~N} \mathrm{NaOH}$ to $\mathrm{pH} 10$ by use of a $250 \mu \mathrm{L}$ Finnpipet. To avoid possible alteration of the solution by the $\mathrm{pH}$ electrode, this aliquot was discarded and a second $20.0 \mathrm{~mL}$ aliquot was treated with the same volume of $0.01 \mathrm{~N} \mathrm{NaOH}$, then diluted to $25.0 \mathrm{~mL}$ with a $\mathrm{pH} 10 \mathrm{NaOH}$ solution.

The adsorption of this $\mathrm{pH} 10$ solution at $420 \mathrm{~nm}$ was determined by using $5.00 \mathrm{~cm}$ cells (pH $10 \mathrm{NaOH}$ solution reference) and a Cary 14 spectrophotometer. The absorbance measured was corrected for dilution and the concentration determined from the absorbance vs. concentration calibration plot (Figure 1).

\section{VAPOR EQUILIBRIUM SOLUTION PREPARATION}

\section{DOM Concentration Adjustment}

DOM stock solution was diluted with distilled water to give $1200 \mathrm{~mL}$ of solution with the desired DOM concentration.

$\mathrm{pH}$ Adjustment

The $\mathrm{pH}$ of the solution was adjusted to the desired level with $\mathrm{HCl}$ or $\mathrm{NaOH}$ solutions.

\section{Ionic Strength Adjustment}

Assuming an average molecular weight of 1000 for fulvic acid, the concentration of fulvic acid is $8 \times 10^{-5} \mathrm{M}$ in an $80 \mathrm{mg} / \mathrm{L} \mathrm{DOM}$ solution. For the dissolved organic matter, one may assume 


$$
\left[\mathrm{H}^{+}\right] \simeq\left[\mathrm{A}^{-}\right] \simeq \sqrt{\mathrm{KC}}
$$

where $K=1 \times 10^{-4}$ (based on carboxylic funtionality)

For an $80 \mathrm{mg} / \mathrm{L}$ solution $C=8 \times 10^{-5} \mathrm{M}$ and $\left[\mathrm{H}^{+}\right] \simeq\left[\mathrm{A}^{-}\right] \simeq 9 \times 10^{-5} \mathrm{M}$ or the ionic strength (I), equals 0.00009 , which may be considered insignificant. Based on these assumptions, the $\mathrm{NaOH}$ added during the stock solution preparation and the $\mathrm{pH}$ adjusment are the only significant factors in determining the ionic strength of the solution prior to ionic strength adjustment. The concentration of sodium was calculated from the amounts of $\mathrm{NaOH}$ that were added, and $\mathrm{NaCl}$ was added to adjust the sodium (hence the ionic strength) to the desired level.

Finally, the solution was placed in a two-liter, round-bottom flask and aerated with nitrogen.

\section{SATURATED DDT SOLUTION PREPARATION}

An indirect method of obtaining a saturated DDT solution was developed for this work. The method involves a vapor phase equilibrium system which allows for a gradual increase in the DDT concentration of an aqueous solution until saturation has been reached. The system consists of a stoppered flask containing solid DDT which is isolated (with respect to physical contact) from the aqueous solution. DDT vaporizes, then dissolves in the solution from the vapor phase. When the system reaches equilibrium, the solution is saturated with DDT. Since this procedure approaches a saturated solution from the low concentration side, the problems associated with removal of undissolved solute are of no concern.

Extensive efforts were made to prepare saturated solutions of DDT by the commoniy used method of centrifugation of a supersaturated solu- 
tion (148-150, 174). Centrifugation proved unsatisfactory for rendering a saturated solution from a supersaturated one. See Appendix.

Specifically, the actual vapor equilibrium (VE) apparatus (see Figure 2) consisted of a two-liter, round-bottom flask fitted with a glass stopper. Extending down from the bottom of the stopper was a glass cup on a glass stem. The aqueous solution was placed in the flask. Solid DDT coated on glass beads is suspended above the solution in the cup. The system was swirled on an orbital table shaker to accelerate the attainment of equilibrium.

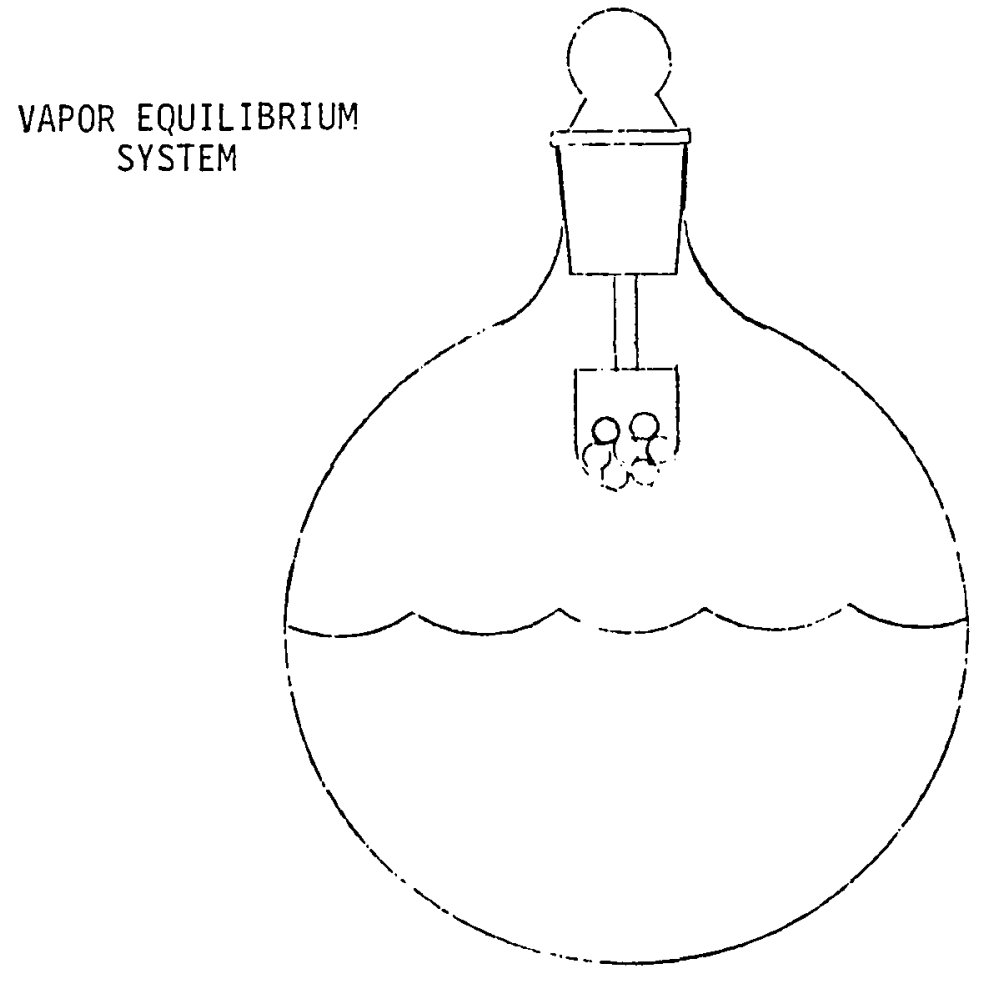

Figure 2. VE system.

After the aqueous solution was placed in the flask, the solution was aerated with nitrogen. Ten DDT beads were then placed in the glass cup, and the flask was sealed with the attached glass stopper. Flasks containing DOM solutions were covered with foil to minimize light- 
induced degradation of the humic material. At two-day intervals the stopper and DDT beads assembly was exchanged with a second stopper and bead assembiy. This rotation was instituted to provide a constant source of dry DDT. Without rotation, moisture would condense on the beads, slowing the rate of DDT vaporization. After removal from the VE system, the beads were allowed to air dry in a fume hood for one hour. The beads were then stored in a glass vial until they were rotated back into the flask. The stopper/cup assemblies were washed via the standard procedure (see Glassware) as part of the rotation process.

\section{EXTRACTION AND WORK-UP}

A $50 \mathrm{~mL}$ volumetric pipet was rinsed with the vapor equilibrium solution to be sampled. Duplicate $50 \mathrm{~mL}$ aliquots were removed and worked up side by side. A $50 \mathrm{~mL}$ aliquot was placed in a $250 \mathrm{~mL}$ separatory funnel fitted with a glass stopper and fluorocarbon polymer stopcock. The aliquot was extracted three times with $25 \mathrm{~mL}$ portions of dichloromethane. Following the removal of both phases after extraction, the funnel was rinsed three times with dichloromethane. The rinses were added to the extract, and the solution filtered through anhydrous sodium sulfate which had been washed twice with hexanes. Filtration was performed under aspirator vacuum with a 4-5 $\mu \mathrm{m}$ glass frit filter supporting the sodium sulfate. The sodium sulfate was then rinsed three times with hexanes, and the rinses were added to the dried solution.

The extract solution was concentrated to $2 \mathrm{~mL}$ on a Kuderna-Danish evaporative concentrator fitted with a three-ball Snyder column. One $\mathrm{mL}$ of heptane (used as a keeper) and five $\mathrm{mL}$ of hexanes were added. The calibrated $10 \mathrm{~mL}$ pot was removed from the apparatus and fitted with a 
micro Snyder column. The solution was reduced in volume to $0.8 \mathrm{~mL}$, diluted to $6 \mathrm{~mL}$ with hexanes, and concentrated again to $\sim 0.2 \mathrm{~mL}$. This final concentrate was spiked with $10 \mu \mathrm{L}$ of Aldrin internal standard solution and diluted to $1.0 \mathrm{~mL}$ with hexanes. Samples were stored in glass vials and analyzed within 24 hours.

\section{CONTROLS}

\section{Glassware Contamination}

A check was made on the efficiency of DDT removal from glassware by oven baking. A clean $1 \mathrm{~mL}$ vial used to contain samples for analysis was filled with $2 \times 10^{-9} \mathrm{~g} / \mu \mathrm{L} \mathrm{p}, \mathrm{p}^{\prime}-\mathrm{DDT} /$ hexanes ( 20 times normal sample concentration) and allowed to stand for 30 minutes. The solution was then poured out and, without further cleaning, the vial was baked at $250^{\circ} \mathrm{C}$ for four hours. After cooling, the vial was filled with hexanes. Analysis of the hexanes in the vial showed no trace of DDT.

\section{Temperature}

Temperature of the VE Systems was dependent on room temperature. Room temperature was recorded twice a day. Overnight temperature fluctuations were monitored for several weeks with a 36-hour temperature recorder. Temperature of the room fluctuated $1-2^{\circ} \mathrm{C}$ during a 24-hour period. During the course of the VE Systems runs, the daily average room temperature ranged from $19^{\circ} \mathrm{C}$ to $21^{\circ} \mathrm{C}$.

\section{Blanks}

Prior to exposure to DDT, a $50 \mathrm{~mL}$ aliquot of each VE System solution was worked up and analyzed. These sample blanks, along with peri- 
odic distilled water blanks, never showed a trace of DDT. These results would indicate:

(1) There is no detectable background level of DDT in the isolated river organic matter or the distilled water used to make the solutions.

(2) There is no DDT contaminant in the reagents used to adjust ionic strength and $\mathrm{pH}$ of the VE System solutions.

(3) There is no DDT contaminant in the reagents used for the extraction and work-up of a sample.

(4) There is no buildup of residual DDT over time on glassware used in extraction and work-up.

In addition, a check was made to determine if a significant amount of DDT remained on the glassware after a sample had been worked up but prior to glassware cleaning. In this case, $50 \mathrm{~mL}$ of hexanes were run through the same glassware after a sample had been worked up. Analysis of the resulting $1.0 \mathrm{~mL}$ hexanes blank concentrate showed no trace of DDT.

\section{EXPERIMENTAL EXTRACTION EFFICIENCY}

Due to the long period of time over which the VE solutions are sampled, it was important to determine if a long contact time between DDT and the VE solution would affect the extraction efficiency. This concern was based on the possibility that the DDT might be slowly sorbed to glass or complexed by DOM in such a fashion as to affect subsequent extraction. Therefore, extraction efficiencies were determined for a long-term situation in addition to the standard (immediate) recovery. 
Immediate Extraction Efficiency

An aqueous solution was spiked with a DDT/acetone solution to give a DDT/aqueous concentration of $\sim 1.6 \mathrm{ppb}$. This solution was extracted and worked up as usual, yielding a one $\mathrm{mL}$ analysis sample containing an internal standard.

A spike standard was made by adding the same amount of the previously-described DDT/acetone spike solution, and the internal standard to one $\mathrm{mL}$ of hexanes. This solution was then analyzed directly to give the standard against which the aqueous solution work-up was compared.

More specifically, $50 \mathrm{~mL}$ of distilled water or aqueous DOM solution were spiked with $10 \mu \mathrm{L}$ of $8 \times 10^{-9} \mathrm{~g} / \mu \mathrm{L}, \mathrm{p}, \mathrm{p}^{\prime}-\mathrm{DDT} / \mathrm{acet}$ ne solution. This spiked sample was extracted and worked up as usual (which included the addition of $10 \mathrm{HL}$ of $4 \times 10^{-9} \mathrm{~g} / \mathrm{LL}$ aldrin/hexanes internal standard). The spike standard consisted of $10 \mu \mathrm{L}$ of $8 \times 10^{-9} \mathrm{~g} / \mu \mathrm{L} \mathrm{p}, \mathrm{p}^{\prime}$-DDT/ acetone and $10 \mu \mathrm{L}$ of $4 \times 10^{-9} \mathrm{~g} / \mu \mathrm{L}$ aldrin/hexanes added to one $\mathrm{mL}$ of hexanes. The ratio of the GLC DDT peak area to the aldrin peak area for the worked-up sample was compared to the ratio of peak areas for the spike standard. The percent recovery was calculated from the peak ratios. Recovery studies were done throughout this work and consistently showed recoveries of $90 \%$ or higher. The following data were obtained under the same extraction and work-up methods described previously.

\section{IMMEDIATE EXTRACTION EFFICIENCY}

\section{GLC Peak Area Ratio}

Sample

*DOM Soln.

p, $p^{\prime}$-DDT/ATdrin

Average

Recovery

$\mathrm{H}, \mathrm{O} \# 1$

$\mathrm{H}_{2}^{2} \mathrm{O} \# 2$

$1.29,1.30,1.19,1.23$

$1.25 \pm 0.05$

$102 \pm 4 \%$

$1.16,1.18,1.28,1.08$

$1.19,1.11,1.20,1.18$

$1.17 \pm 0.06$

$95 \pm 5 \%$ 
Spike Std. \#1

Spike Std. \#2
$1.21,1.24,1.26$

$1.20,1.21,1.3 ., 1.16$
$1.23 \pm 0.05$

*DOM Soln.: $\quad 66 \mathrm{mg} / \mathrm{L}, \mathrm{pH} 7.4$

\section{LONG-TERM EXTRACTION EFFICIENCY}

Extraction recovery as a function of elapsed time between spiking of an aqueous solution and extraction was investigated. Identical spiked solutions of $0.8 \mathrm{ppb}$ DDT were prepared in a number of borosilicate bottles. At various intervals of time the contents of a bottle would be extracted and worked up, yielding a one $\mathrm{mL}$ analys is sample containing an internal standard. A spike standard was made by adding the same amount of spike and the internal standard to one $\mathrm{mL}$ of hexanes. This solution was then analyzed directly to give the standard against which the aqueous solution work-up was compared.

More specifically, $10 \mu \mathrm{L}$ of $8 \times 10^{-9} \mathrm{~g} / \mu \mathrm{L} \mathrm{p}, \mathrm{p}^{\prime}-\mathrm{DDT} /$ acetone were added to $100 \mathrm{~mL}$ of distilled water or aqueous solution ( $0.8 \mathrm{ppb}$ DDT) in eight $125 \mathrm{~mL}$ borosilicate bottles with glass stoppers. The bottles were kept sheltered from the light until they were analysed. During analysis, one $50 \mathrm{~mL}$ aliquot was removed via a volumetric pipet. This aliquot and $\mathrm{CH}_{2} \mathrm{Cl}_{2}$ rinses of the pipet were combined and worked up as one sample. The $50 \mathrm{~mL}$ of solution remaining in the bottle were removed and combined with $\mathrm{CH}_{2} \mathrm{Cl}_{2}$ bottle rinses and worked up as a second sample. A third sample consisted of $100 \mathrm{~mL}$ of hexanes that were allowed to stand in the rinsed bottle for 2-3 hours. During work-up, all samples received $10 \mathrm{\mu L}$ of $4 \times 10^{-9} \mathrm{~g} / \mathrm{\mu L}$ aldrin/hexanes as an internal standard. The spike standard consisted of $10 \mu \mathrm{L}$ of $8 \times 10^{-9} \mathrm{~g} / \mu \mathrm{L}, \mathrm{p}, \mathrm{p}^{\prime}$-DDT/acetone and $10 \mu \mathrm{L}$ of $4 \times 10^{-9} \mathrm{~g} / \mu \mathrm{L}$ aldrin/hexanes added to one $\mathrm{mL}$ of hexanes. The amount of DDT in the worked-up sample was compared to the amount of DDT in the spike standard. Results are presented in Figures 3-5. 


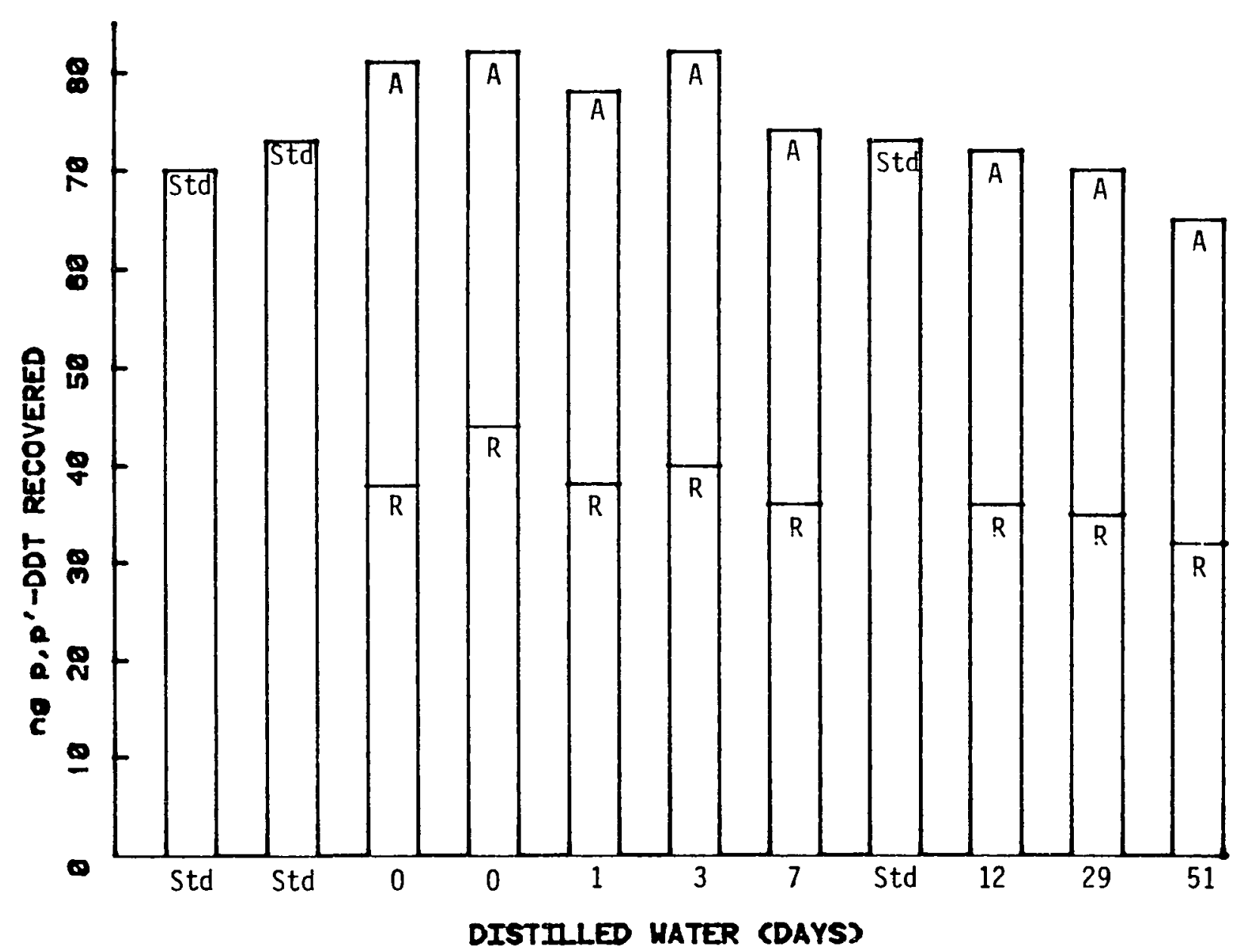

A Aliquot

(Hexanes soak solutions

$\mathrm{R}$ Remaining solution showed no trace of DDT)

Figure 3. Long-term recovery. 


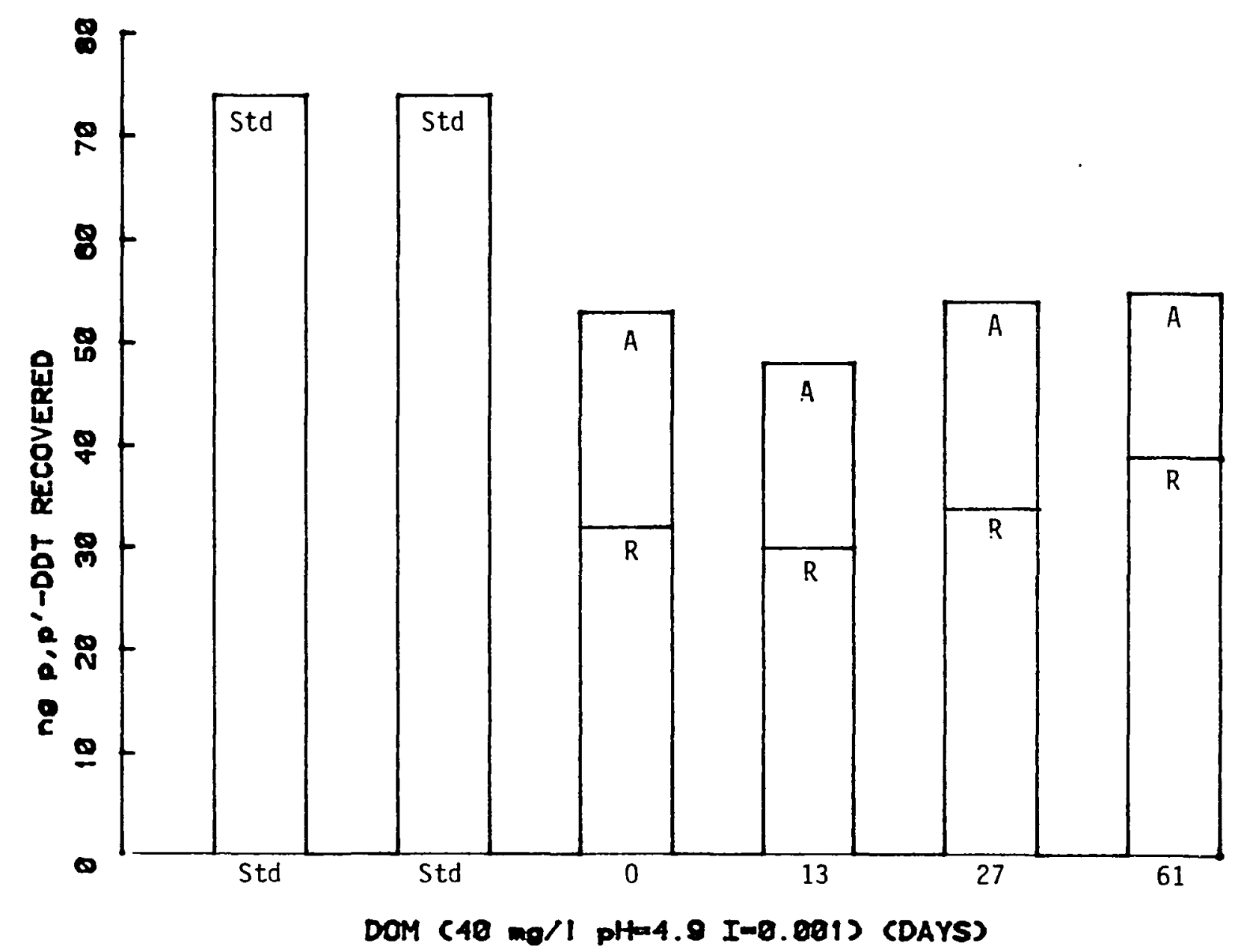

A Aliquot

$R$ Remaining solution

(Hexanes soak solutions showed no trace of DDT)

Figure 4. Long-term recovery. 


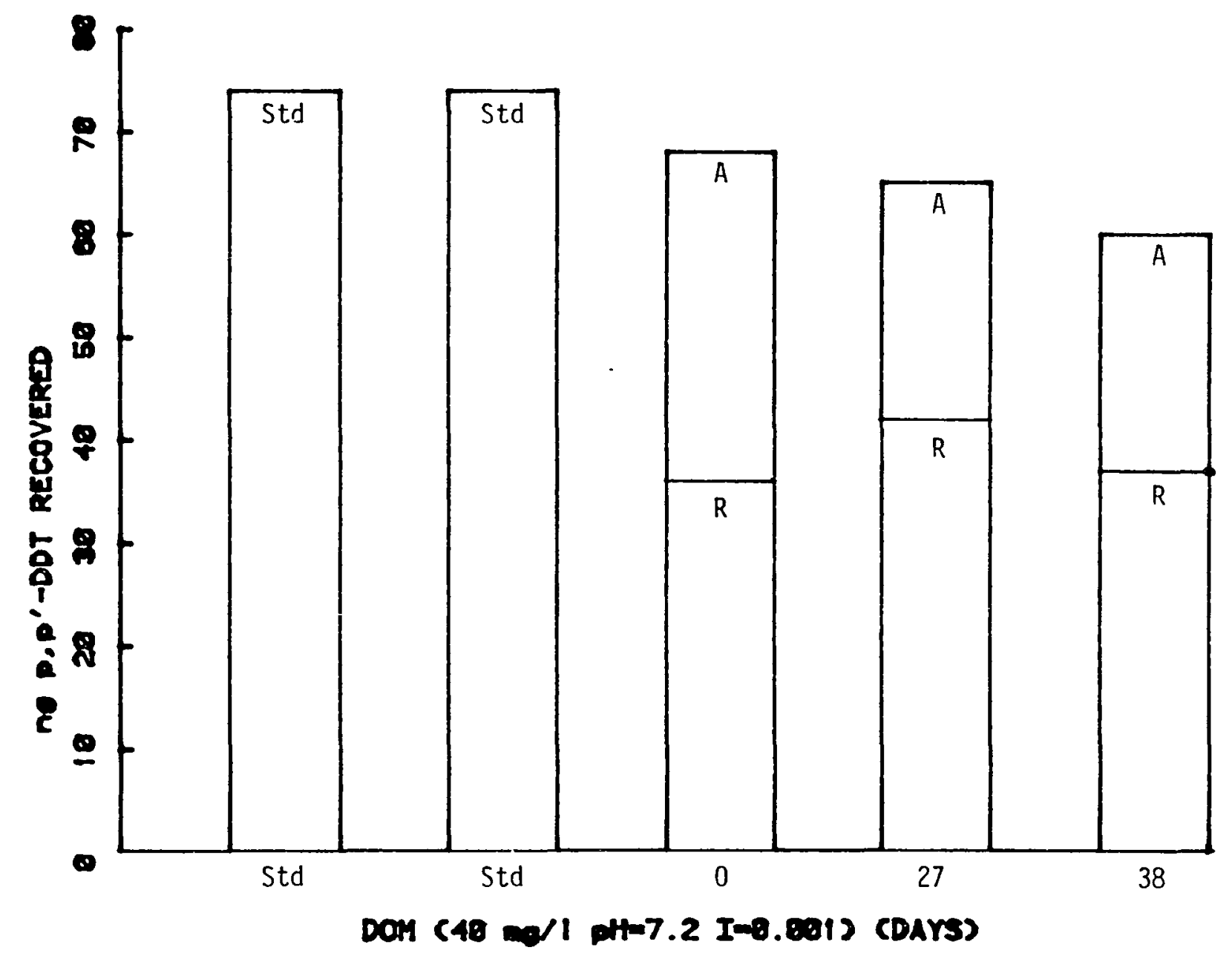

A Aliquot

$\mathrm{R}$ Remaining solution

(Hexanes soak solutions

showed no trace of DDT)

Figure 5. Long-term recovery. 


\section{Experimental Recovery Summary}

Immediate Extraction. Recoveries were consistently $90 \%$ or better.

Long-Term Extraction. Distilled water solutions showed a drop in recoverable DDT of about $20 \%$ over 50 days. There was no detectable sorption of DDT to the glass walls of the sample bottle during this period.

DOM solutions showed a drop in total recoverable DDT of $10 \%$ or less over 38 and 61 days. Between 10 and 20 percent of the added DDT was sorbed to the borosilicate walls of the DOM solution bottles. The sorbed DDT was compleiely removed by $\mathrm{CH}_{2} \mathrm{Cl}_{2}$ rinses.

Considerations. While the recovery studies indicated that there may be some loss in recovery over time for static systems, it must be kept in mind that the vapor equilibrium systems used to determine DDT solubility were not static, but dynamic systems. The VE systems employed a constant flux of DDT entering the solution from the vapor phase. Since the time-dependent loss in recovery was relatively small for the static systems, it is safe to assume that this loss would not have a significant effect on the DDT solubilities determined by the VE systems. 


\title{
CHAPTER III
}

\author{
RESULTS
}

Electron capture - gas chromatography was the analytical method used to measure concentrations of DDT, and calibration data for this instrument will be presented. The fact that the VE systems generated solubility data for two DDT isomers is discussed, and GLC-mass spectral data confirming the identities of the isomers are presented.

The VE systems require extended periods of time to generate solubility data. Because of this large time factor, it was not practicable to repeat all of the experiments after the VE system operation procedures were optimized. For this reason, the solubility data generated by the distilled water systems reflect several procedural modifications in operation of the VE systems. As these modifications changed the rate at which the solution concentration of DDT increased, each system exhibited a different rate of DDT increase, depending on when the modification was made. As correct interpretation of the distilled water solubility data requires an understanding of these operational differences between the VE systems, the procedural modifications will be discussed in some detail prior to the presentation of the data. In contrast, a number of DOM systems were started after these modifications were instituted. The DOM data presented was generated by $V E$ systems that were identical in their modes of operation. 
The concentration of DOM and the $\mathrm{pH}$ of the DOM VE solutions were monitored, and the results are presented following the solubility data. Due to the long periods of time the VE systems were in operation, the effect of microorganisms in the systems was of some concern. Results of plate counts and microscopic examination of the DOM and distilled water VE solutions are summarized.

With regard to the fate of DDT within the VE system, an investigation of biological and chemical degradation of the compound as well as its sorption to glass was undertaken and the results presented.

\section{ELECTRON CAPTURE - GAS CHROMATOGRAPH CALIBRATION}

Aldrin was used as an internal standard for GLC analysis. An addition of $10.0 \mu \mathrm{L}$ of a $4 \times 10^{-9} \mathrm{~g} / \mu \mathrm{L}$ solution of aldrin in hexanes was made to each sample (volume of $1.0 \mathrm{~mL}$ ) to give an analysis concentration of $4 \times 10^{-11} \mathrm{~g} / \mu \mathrm{L}$.

GLC calibration standards consisted of hexanes solutions of $p, p^{\prime}-$ DDE, $0, p^{\prime}-D D T$ and $p, p^{\prime}-D D T$ over a range of concentrations and aldrin at a constant concentration. The DDE and DDT isomers ranged from $1 \times 10^{-11}$ $\mathrm{g} / \mu \mathrm{L}$ to $1 \times 10^{-9} \mathrm{~g} / \mu \mathrm{L}$ and represented final sample concentrations that would result from the work-up of solution concentrations of $0.2 \mathrm{ppb}$ to $20 \mathrm{ppb}$. The aldrin concentration in these standards was $4 \times 10^{-11} \mathrm{~g} / \mathrm{L} \mathrm{L}$.

Multiple injections of $5.0 \mu \mathrm{L}$ of these standards were made. The peak area to aldrin peak area ratio for each of the three compounds was averaged for each standard. For each compound of interest ( $p, p^{\prime}-D D E$, $0, p^{\prime}-D D T$, and $\left.p, p^{\prime}-D D T\right)$, a linear regression analysis of the peak area/ aldrin area ratio versus concentration was done to find the line of best fit. The resulting lines are shown in Figure 6 . For $p, p^{\prime}-D D E, 0, p^{\prime}-D D T$ 
and $p, p^{\prime}-D D T$ the respective correlation coefficients of the line of best fit were $0.9955,0.9995$ and 0.9993 . The equations describing these lines are:

$p, p^{\prime}-\operatorname{DDE}\left(g / \mu L \times 10^{-11}\right)=\left[4.7086\left(\right.\right.$ area/aldrin)-0.40513] $\times 10^{-11}$

$0, p^{\prime}-$ DDT $\left(g / \mu L \times 10^{-11}\right)=[6.659]($ area/aldrin $\left.)+0.19135\right] \times 10^{-11}$

$\mathrm{p}, \mathrm{P}^{\prime}-$ DDT $\left(\mathrm{g} / \mu \mathrm{L} \times 10^{-11}\right)=[5.3668($ area/aldrin $)+0.25824] \times 10^{-11}$

Detection limits (at the $95 \%$ confidence level) calculated from this calibration are, in terms of original sample concentration:

$\begin{array}{lc}\text { Isomer } & \text { Detection Limits } \\ \text { o, } p^{\prime}-D D T & 0.05 \mathrm{ppb} \\ \mathrm{p}, \mathrm{p}^{\prime} D D T & 0.09 \mathrm{ppb}\end{array}$




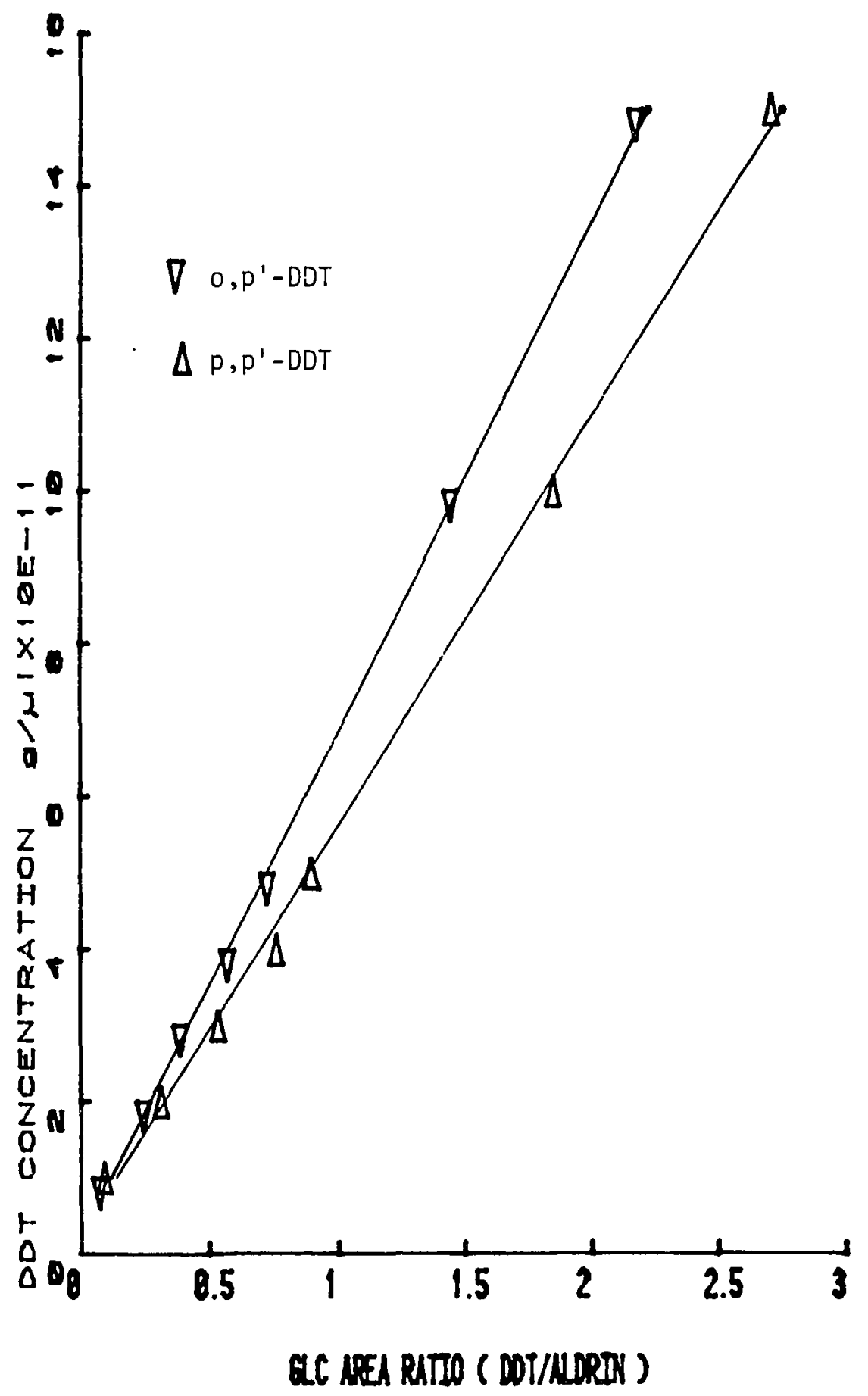

Figure 6. GLC calibration. 


\section{SOLUBILITY DATA: TWO COMPOUNDS}

Each VE system generated solubility data for both $0, p^{\prime}-D D T$ and p, $p^{\prime}-D D T$. Dacia for two isomers were generated due to the presence of an $0, p^{\prime}-D D T$ contaminant in the $p, p^{\prime}-D D T$ coated on the glass beads of each system. Contamination of the $p, p^{\prime}-D D T$ included about one percent of $0, p^{\prime}-D D T$ as well as a lesser amount of $p, p^{\prime}-D D E$. All three isomers volatilized from the beads and were detected in the VE system solutions. Identities of the three compounds in the solutions were assigned by correlation of GLC retention times with known standards and with the solid material coated on the beads. The assigned identities of $0, p^{\prime}-D D T$ and $p, p^{\prime}-D D T$ in the VE solutions were confirmed by GLC/Mass Spectrometry analysis (Figures 7-12). The assignment of $p, p^{\prime}-D D E$ to the third compound was not confirmed by GLC/Mass Spectrometry due to an insufficient quantity of this compound in the sample analyzed.

\section{GLC-MASS SPECTROMETRY}

Negative ion chemical ionization (NICI) GLC - mass spectrometry was performed on DDT isomers standard solutions ( $p, p^{\prime}-D D E, 0, p^{\prime}-D D T$ and $p, p^{\prime}-D D T$ ) (Figures $7,9,11$ ) and on the extract of a distilled water $V E$ system solution (49 days, $600 \mathrm{~mL}$ ) (Figures $8,10,12$ ). The mass spectra are presented for the compounds of the VE solution sample possessing the same GLC retention time as the $o, p^{\prime}-D D T$ and $p, p^{\prime}-D D T$ standards. The excellent agreement between the mass spectra of the two standards and the corresponding VE solution compounds (with the corresponding GLC retention times) establishes positive identification. 
A greater degree of fragmentation of the molecular ion occurred than has been reported for NICI (196) and NI (negative ion ionization) (197). This is most probably due to differences in operating parameters. The types of fragmentation observed have been reported (196-198). When methane is the reagent gas, fragmentation processes include the nucleophilic displacement of chlorine atoms by a negative oxygen atom $\left(0^{-}\right)$ (198). The oxygen atom arises from the presence of water, a contaminant of the methane. 


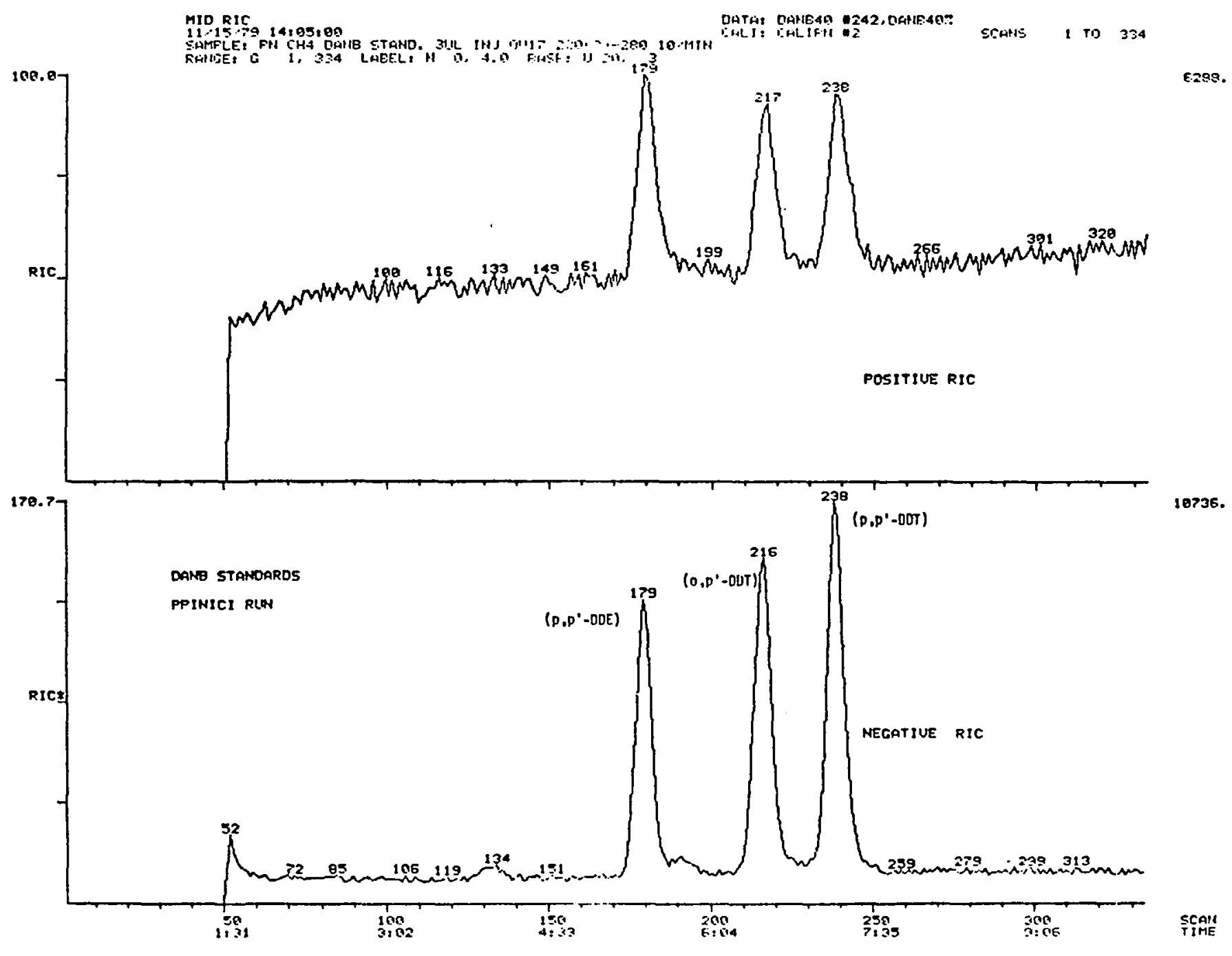

Figure 7. GLC/mass spec. data. 


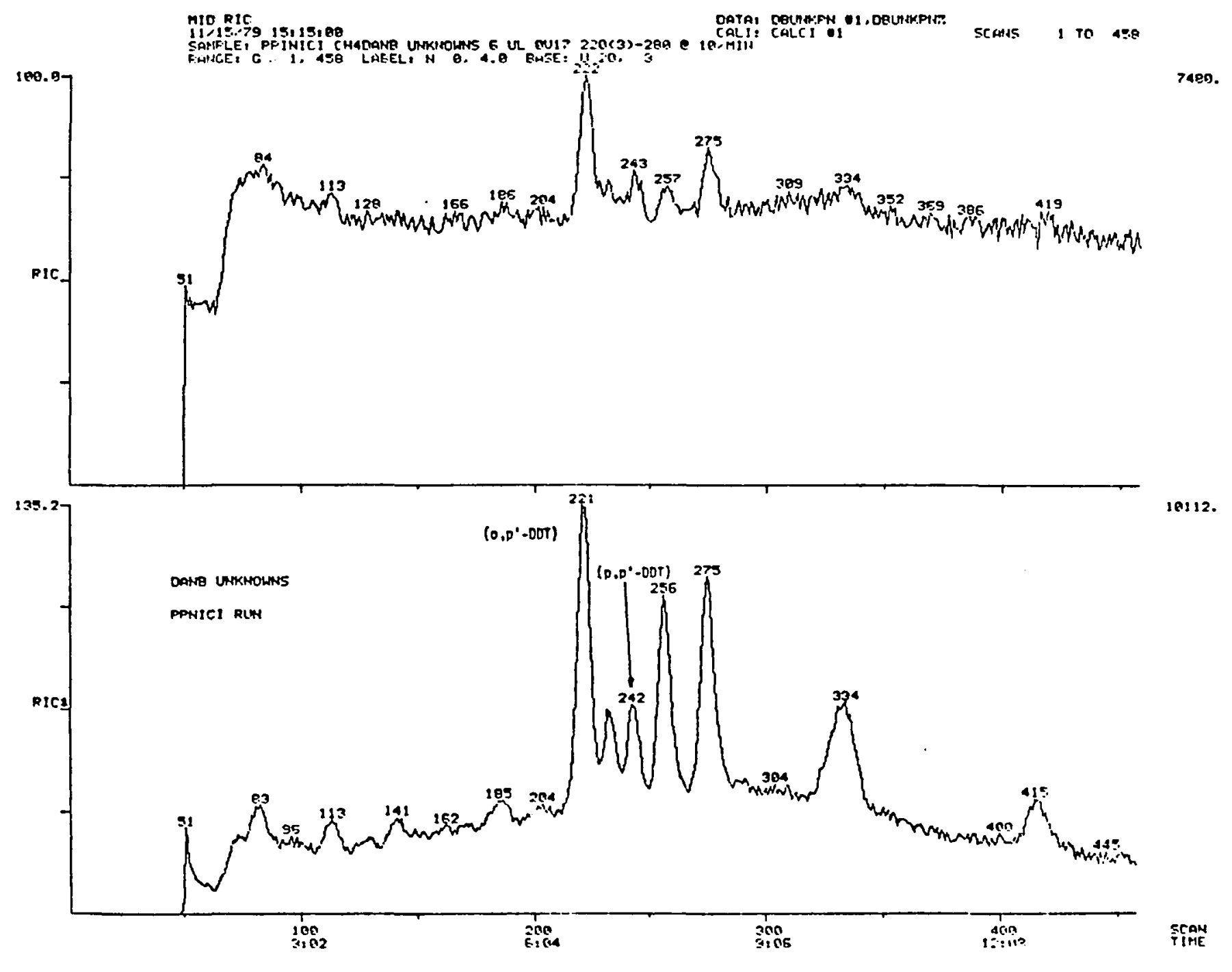

Figure 8. GLC/mass spec. data. 


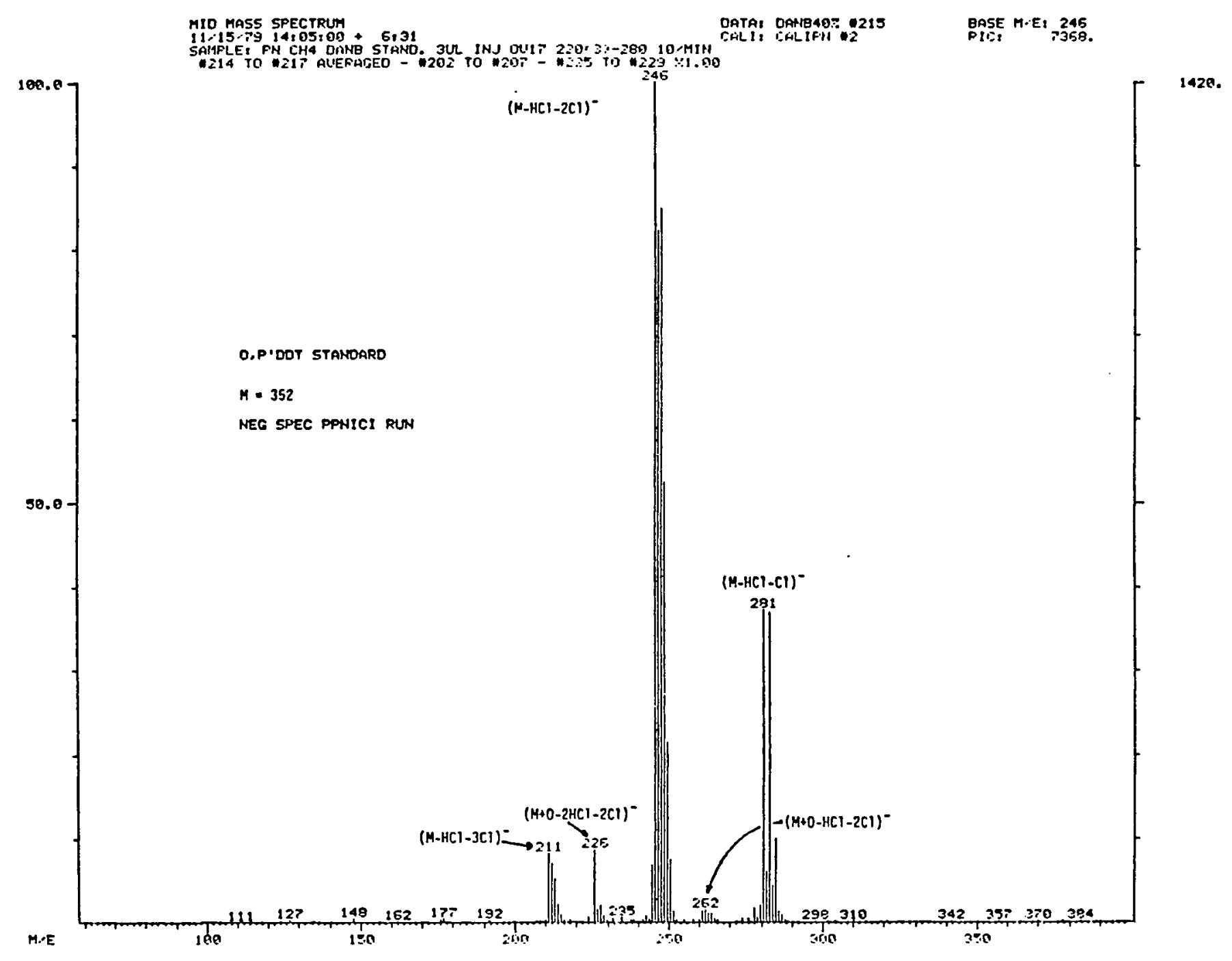

Figure 9. GLC/mass spec. data. 


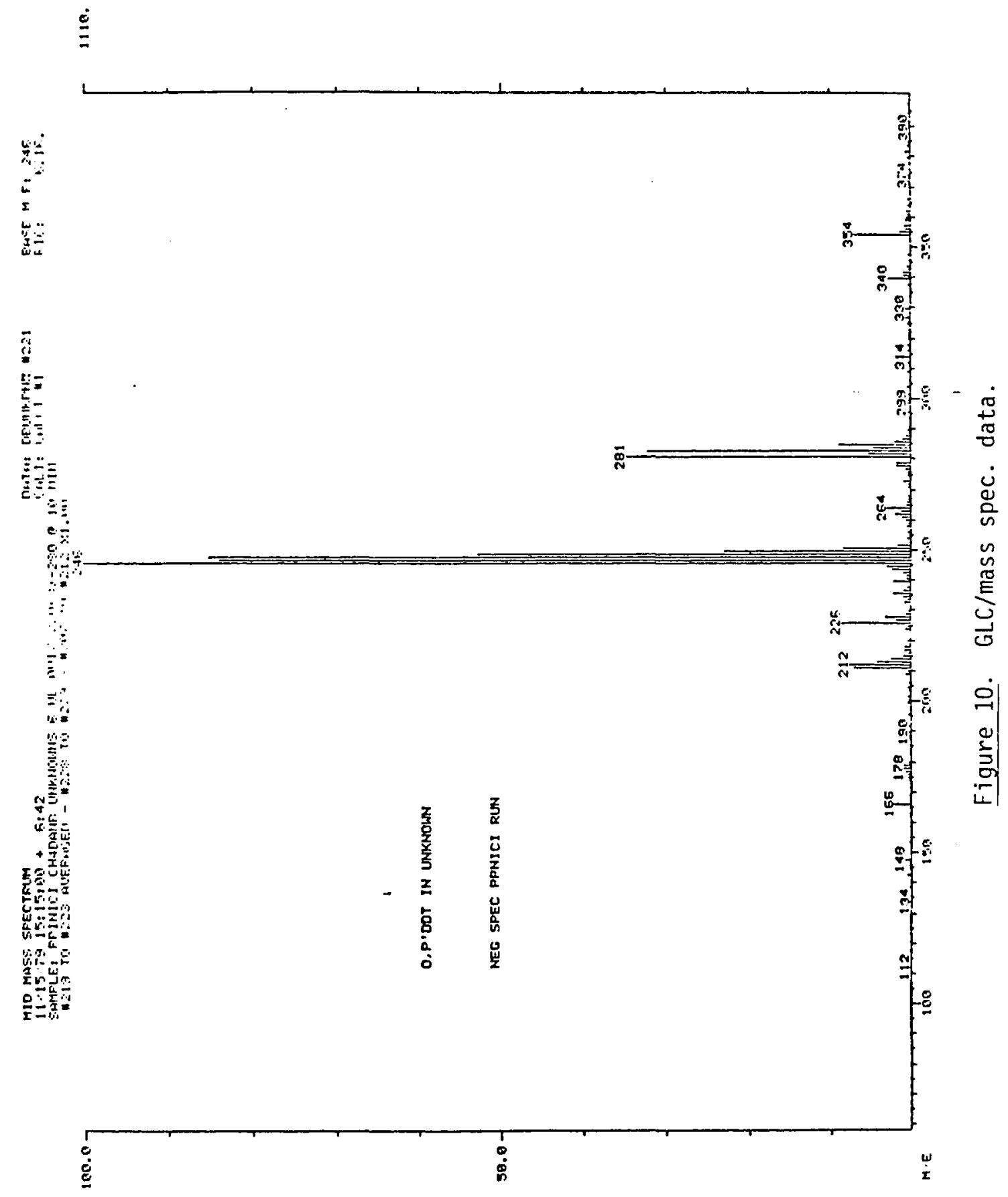




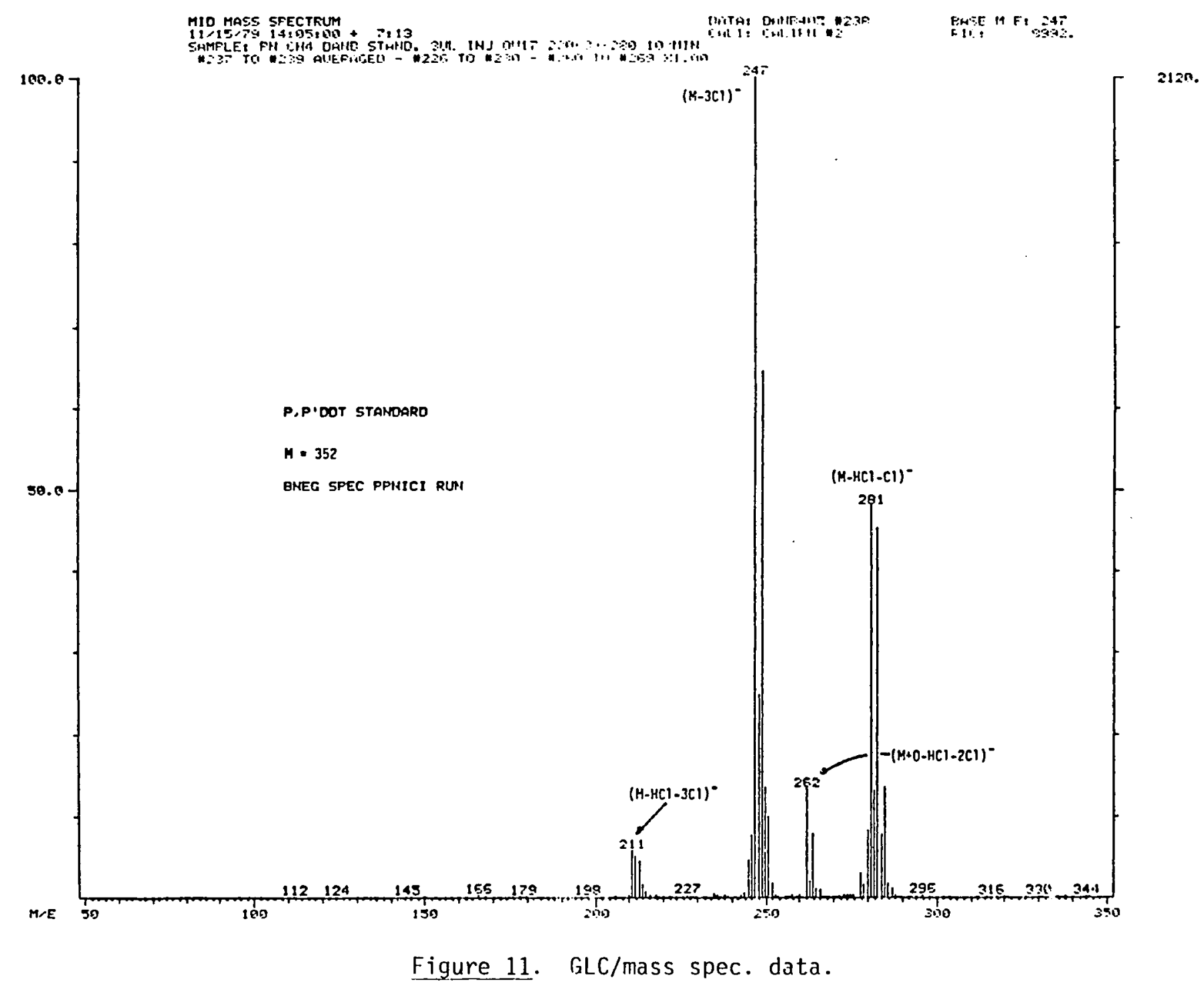




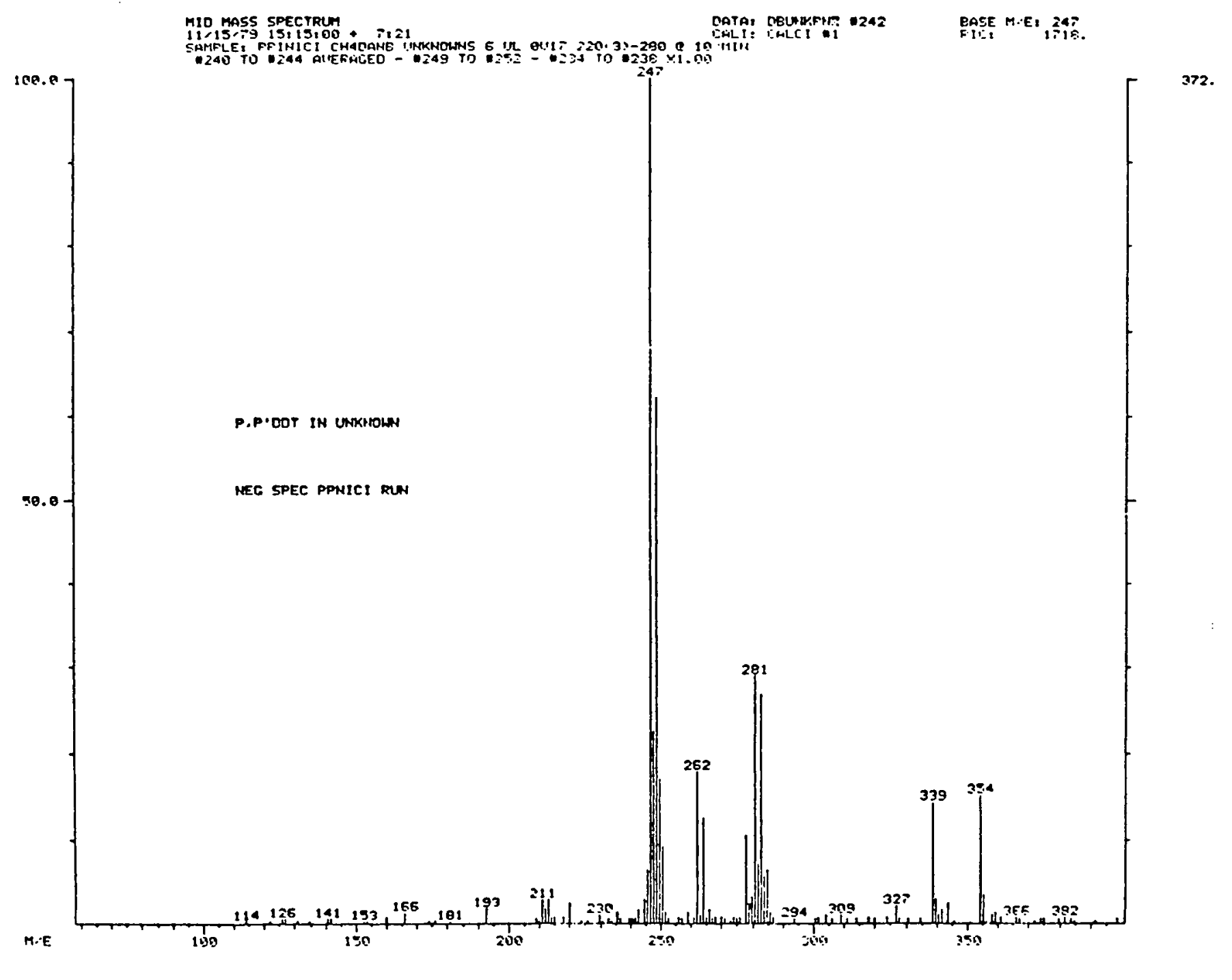

Figure 12. GLC/mass spec. data. 
DDT/WATER SOLUBILITY

DDT solubility data was obtained for a number of different distilled water VE systems. Some solutions were $\mathrm{pH}$ and ionic strengthadjusted, some were ionic strength-adjusted only, and others were unadjusted. Correct interpretation of the distilled water solubility data requires an understanding of the operational differences between the distilled water VE systems. Changes in operating procedures were made at different times during the lifetime of each VE system. No two systems have the same history of operational procedures. A record of operation (over time) for each system is presented in Figures 13 and 14 . As this information is important to any consideration of the data, these differences in operation between the VE systems will be reviewed in some detail. 


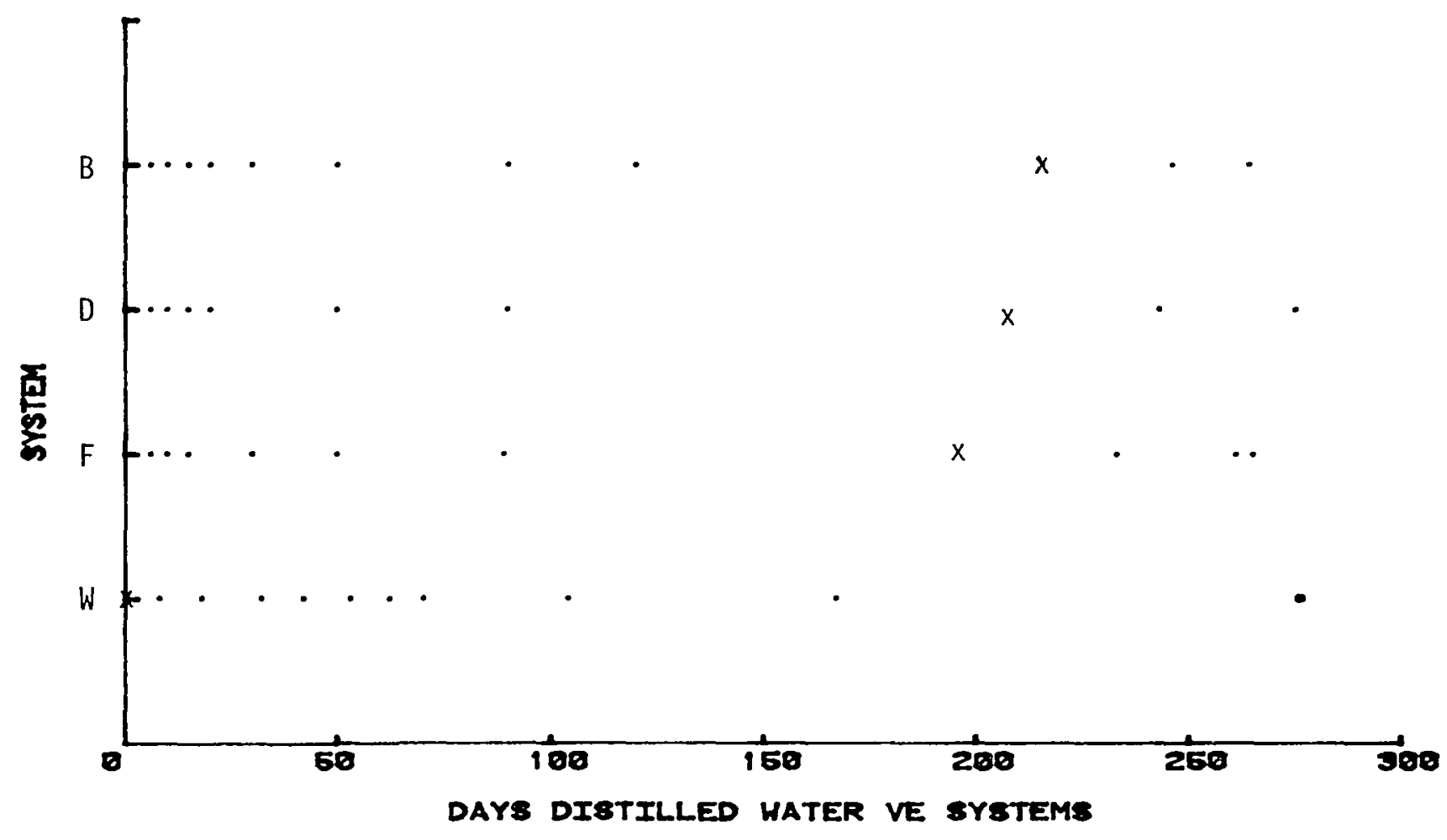

- Determined concentration of DDT isomers

$x$ DDT-bead exchange initiated

Figure 13. $\mathrm{H}_{2} \mathrm{O}$ VE operation record. 


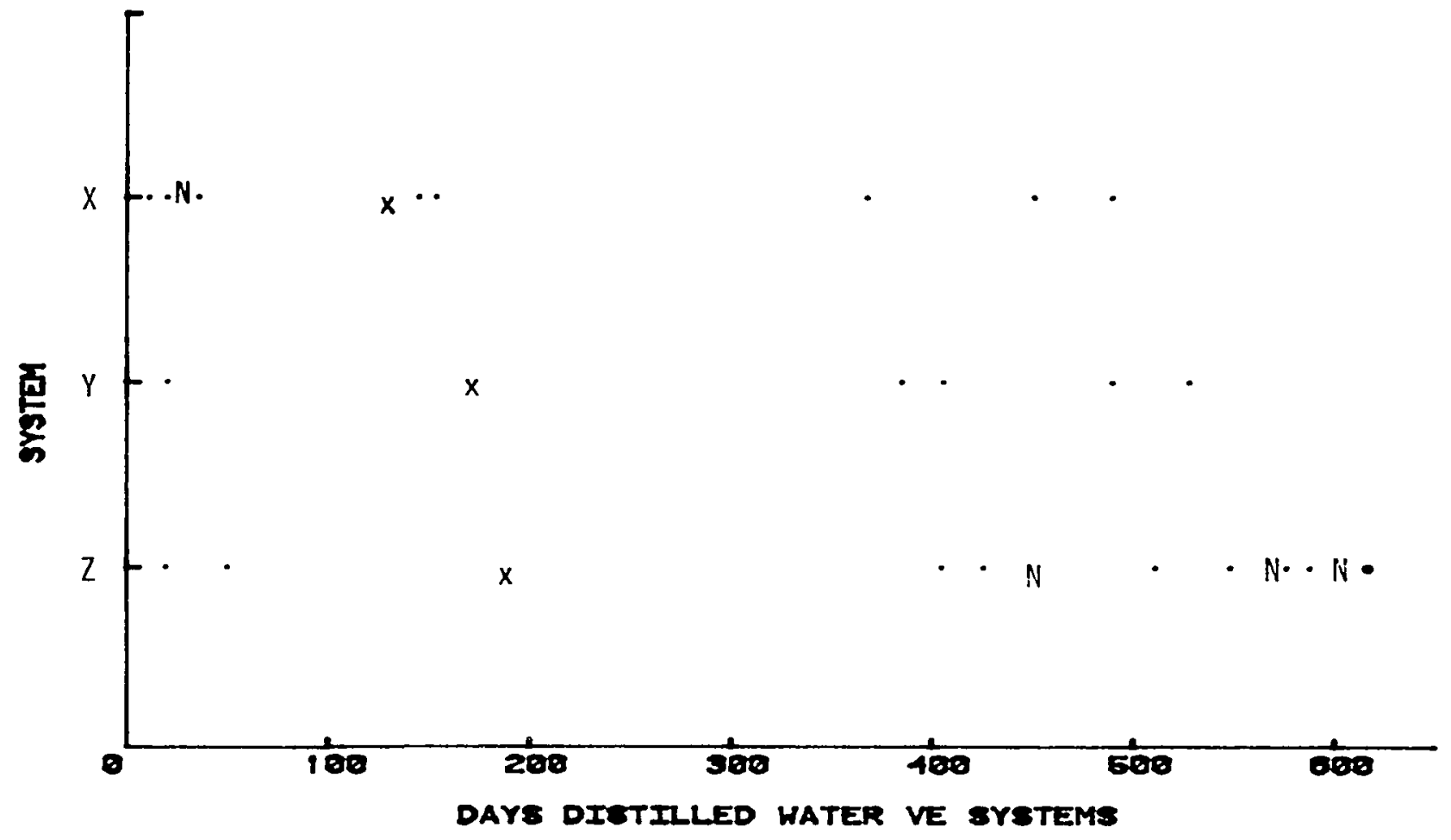

- Determined concentration of DDT isomers

$x$ DDT-based exchange initiated

$N$ New DDT-coated beads introduced

Figure 14. $\mathrm{H}_{2} \mathrm{O} V E$ operation record. 
With one exception (W VE system), changes were made in the distilled water systems after they had been running for 100 to 200 days. Initially, the original ten DDT-coated glass beads were never removed from their respective VE flasks. This procedure was modified because it was found that the beads became coated with water vapor, slowing the rate of DDT vaporization from the bead surface. To provide a dry surface of DDT, the beads in the VE systems were removed and replaced with freshly coated, dry beads. The removed beads were allowed to dry, then returned to the flask before the fresh set of beads became too wet. The two sets of beads were used in rotation; one set was in the VE flask while the other set was being dried. Once initiated, this exchange of beads was performed at two-day intervals. As this modification increased the rate of vaporization, hence equilibration, the concentration of DDT in solution increased at different rates in each system, depending on when DDT bead exchange was initiated. This may be seen by comparing a plot of [DDT] vs. time for two VE systems (Figures 15 and 16). Bead exchange was started after the $F$ system had been running 196 days (Figure 15). In contrast, the W VE system (Figure 16) operated with DDT bead exchange from day zero. While both systems reached the same final equilibrium concentration of $p, p^{\prime}-D D T$, the kinetics of equilibrium attainment were quite different. 
54

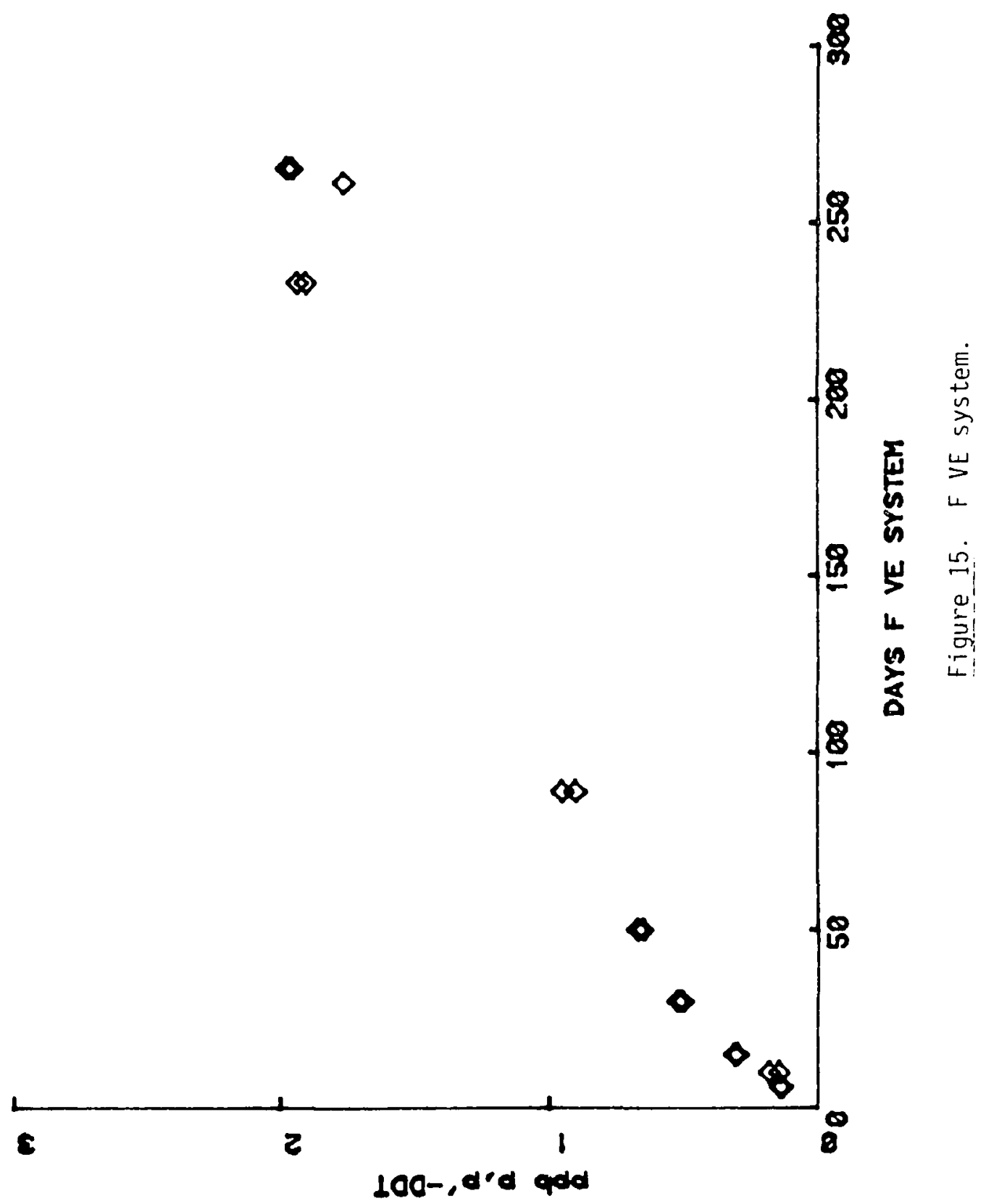




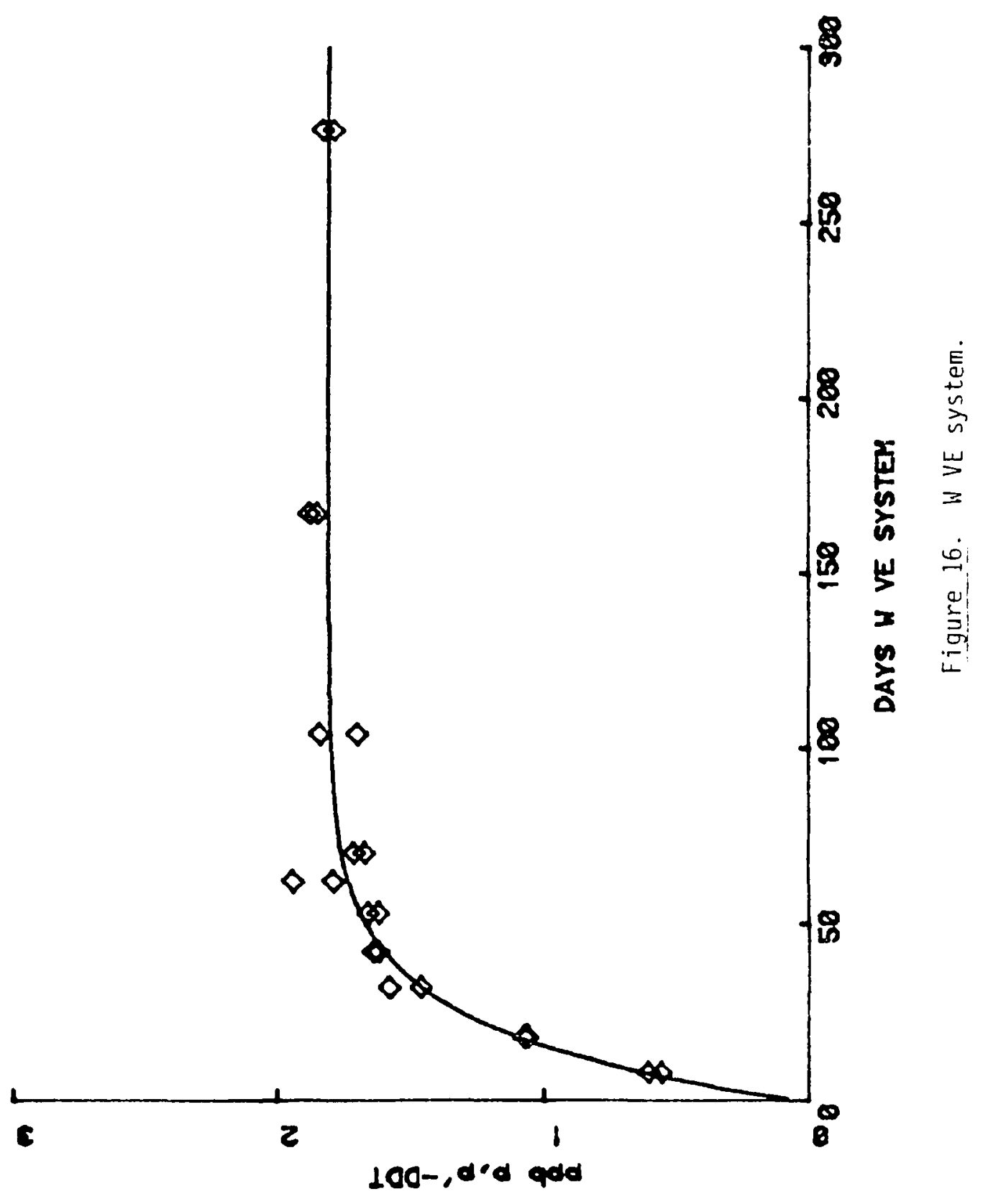


It was observed that when the DDT beads were removed from a VE system and the flask was stoppered, the concentrations of the two DDT isomers $\left(0, p^{\prime}-D D T\right.$ and $\left.p, p^{\prime}-D D T\right)$ in the solution decreased with time. Explanations for the DDT loss are examined in the Discussion Chapter. In addition, VE solutions showed a loss of DDT over time with continued exposure to the same set of 20 beads. As long as the coated beads supplied an adequate input of vaporized DDT, solution concentrations of the isomers would increase until equilibrium was established. With continued exposure, however, the beads lost enough of their original coating that an adequate input of vaporized DDT was not maintained. At this point, continued use of the same beads resulted in a decreasing solution DDT concentration.

The $0, p^{\prime}-D D T$ isomer was particularly subject to solution concentration decline due to depletion of DDT on the beads. This isomer constituted only $1 \%$ of the DDT in the bead coating, but has a vapor pressure more than seven times greater than $p, p^{\prime}-D D T(144,147)$ and a solubility of more than four times the other isomer (151).

Actually, 20 DDT beads used in continuous rotation did not supply enough $o, p^{\prime}-D D T$ to establish equilibrium of this isomer in the VE systems. For these systems, a plot of the $0, p^{\prime-j}$ somer concentration vs. time does not reach and maintain an equilibrium concentration (Figures 17 and 18). In order to establish an equilibrium concentraction of $0, P^{\prime}-D D T$ in distilled water, the $Z$ VE system was further modified. For the $Z$ system, a set of 20 freshly coated DDT beads was introduced periodically (at 449, 568 and 602 days). A plot of both DDT isomer concentrations vs. time for the $Z$ VE system indicates that equilibrium was established for both compounds (Figure 19). 


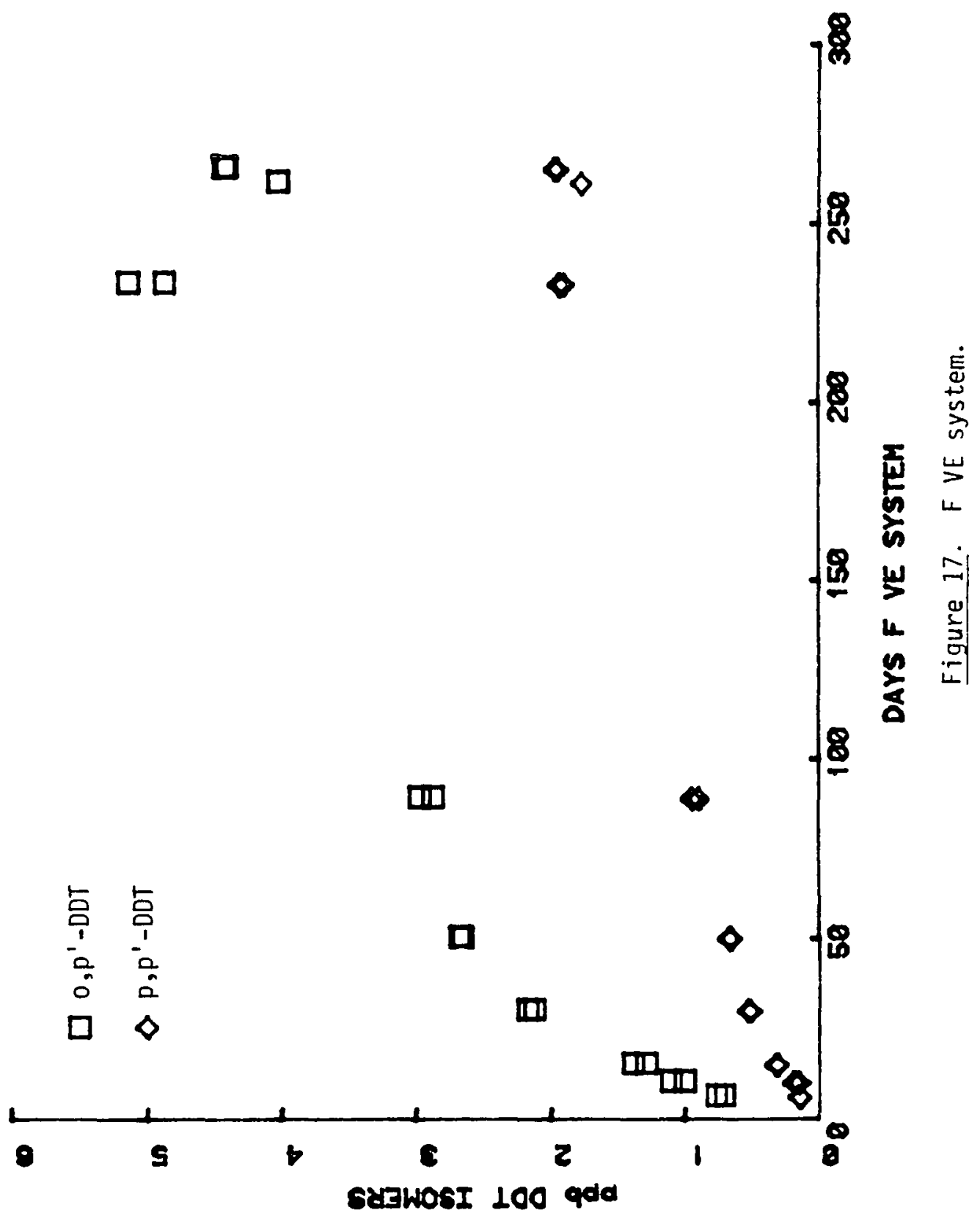




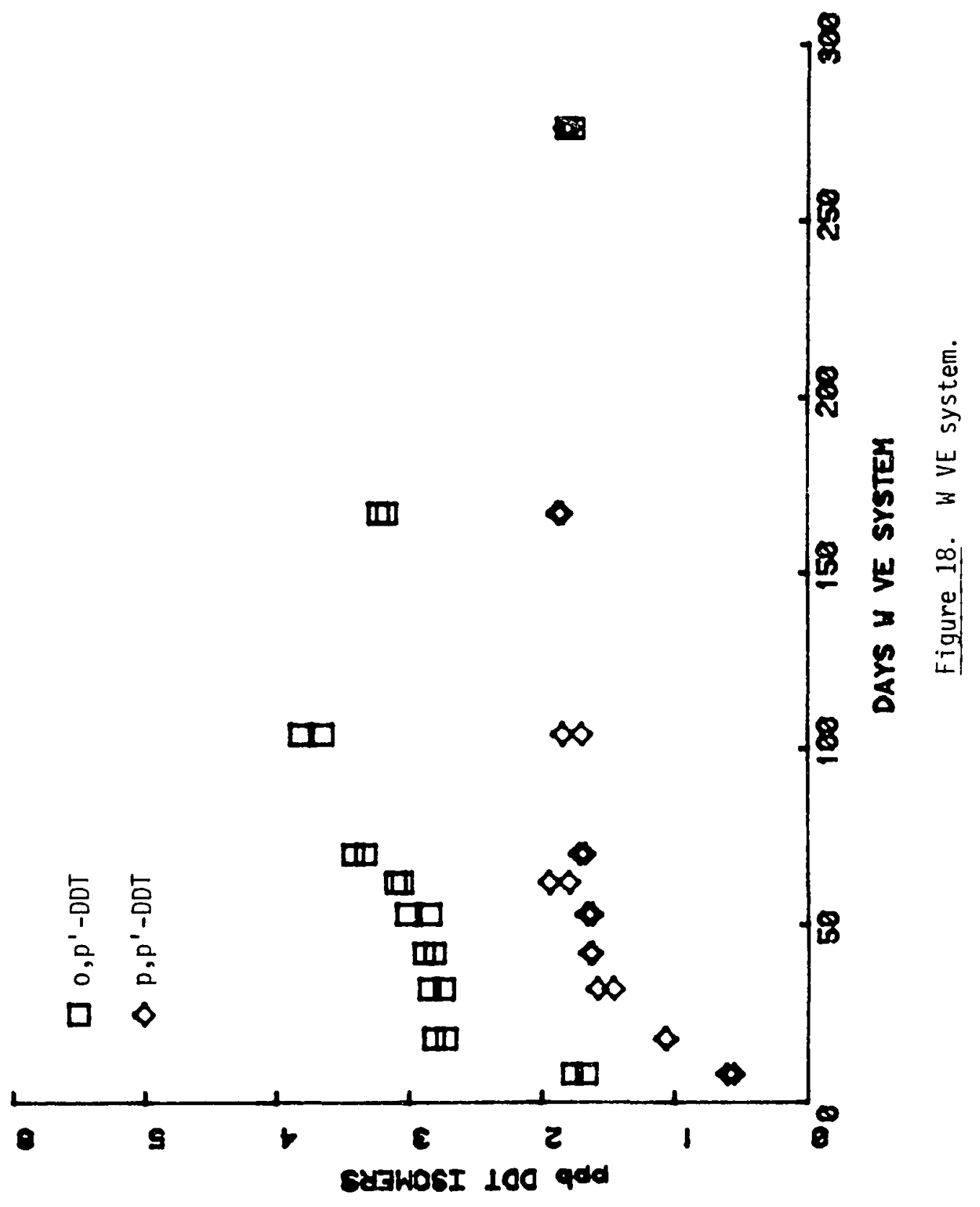




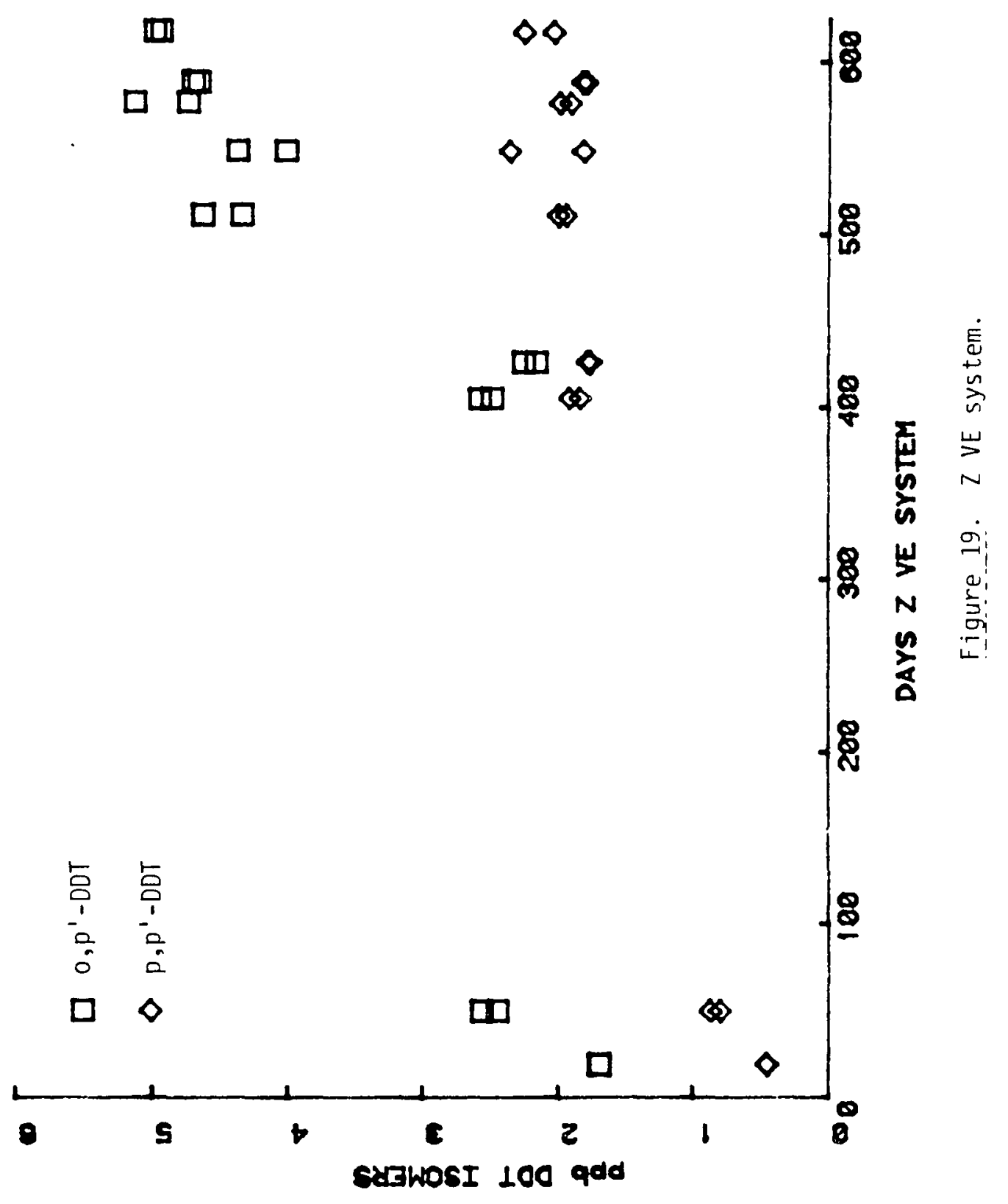


DDT/Water Solubility Summary

Plots of DDT isomer concentrations vs. time for distilled water VE systems will not be presented, as the solution DDT concentration increased at different rates for each system, depending on when bead exchange was initiated. Thus, equilibrium concentrations for these systems, rather than plots, are presented in Table III.

TABLE III

$\mathrm{DDT} / \mathrm{H}_{2} \mathrm{O}$ SOLUBILITY

$\mathrm{p}, \mathrm{p}^{\prime}-\mathrm{DDT}$

\begin{tabular}{|c|c|c|c|c|c|}
\hline system & $\mathrm{pH}$ & ionic strength & days & $\begin{array}{r}\text { number } \\
\text { samples }\end{array}$ & ${ }^{\text {of }}$ concentration \\
\hline B & $\sim 7$ & $0.001 \mathrm{M}$ & 246 to 264 & 4 & $1.74 \pm .01 \mathrm{ppb}$ \\
\hline$D$ & $\sim 9$ & $0.001 \mathrm{M}$ & 243 to 275 & 4 & $2.20 \pm .03 \mathrm{ppb}$ \\
\hline $\mathrm{F}$ & $\sim 5$ & $0.001 \mathrm{M}$ & 233 to 265 & 4 & $1.94 \pm .03 \mathrm{ppb}$ \\
\hline W & unadj & unadj & 62 to 276 & 10 & $1.82 \pm .01 \mathrm{ppb}$ \\
\hline$x$ & unadj & unadj & 145 to 451 & 8 & $1.78 \pm .01 \mathrm{ppb}$ \\
\hline Y & unadj & unadj & 385 to 490 & 6 & $1.89 \pm .01 \mathrm{ppb}$ \\
\hline Z & unadj & $0.001 \mathrm{M}$ & 405 to 617 & 14 & $\star * \frac{1.97 \pm .01 \mathrm{ppb}}{1.87 \pm .01 \mathrm{ppb}}$ \\
\hline & & & $p^{\prime}-D D T$ & & \\
\hline
\end{tabular}

\begin{tabular}{cccccc} 
system & $\mathrm{pH}$ & ionic strength & days & $\begin{array}{c}\text { number of } \\
\text { samples }\end{array}$ & $*_{\text {* concentration }}$ \\
\hline $\mathrm{Z}$ & unadj & $0.001 \mathrm{M}$ & 576 to 617 & 6 & $4.88 \pm .03 \mathrm{ppb}$
\end{tabular}

*concentration is expressed as the mean \pm the standard error of the mean

**mean and standard error derived by the standard method for pooling of the means; H.H. Ku. Nat. Bur. Stand. Spec. Pub1. 300, Vol. 1, P. 296. 
DDT/DOM SOLUBILITY

The DOM solutions were initially adjusted to a pH of 5, 7, or 9 and ionic strengths of $0.001 \mathrm{M}$ or $0.01 \mathrm{M}$. From day zero, the ten DDT-coated glass beads in each VE flask were cycled with a set of dry DDT-coated beads at two-day intervals. A set of twenty beads with a fresh DDT coating was introduced to each VE system at approximateiy 145, 180 and 215 days. The freshly coated beads were introduced to insure an adequate source for vaporization of the two DDT isomers (o, $p^{\prime}-D D T$ and $p, p^{\prime}-D D T$ ). A record of operation (over time) for each system is presented in Figures 20-22.

The initial adjustment parameters for the DOM solutions in the VE systems are given in Table IV. 

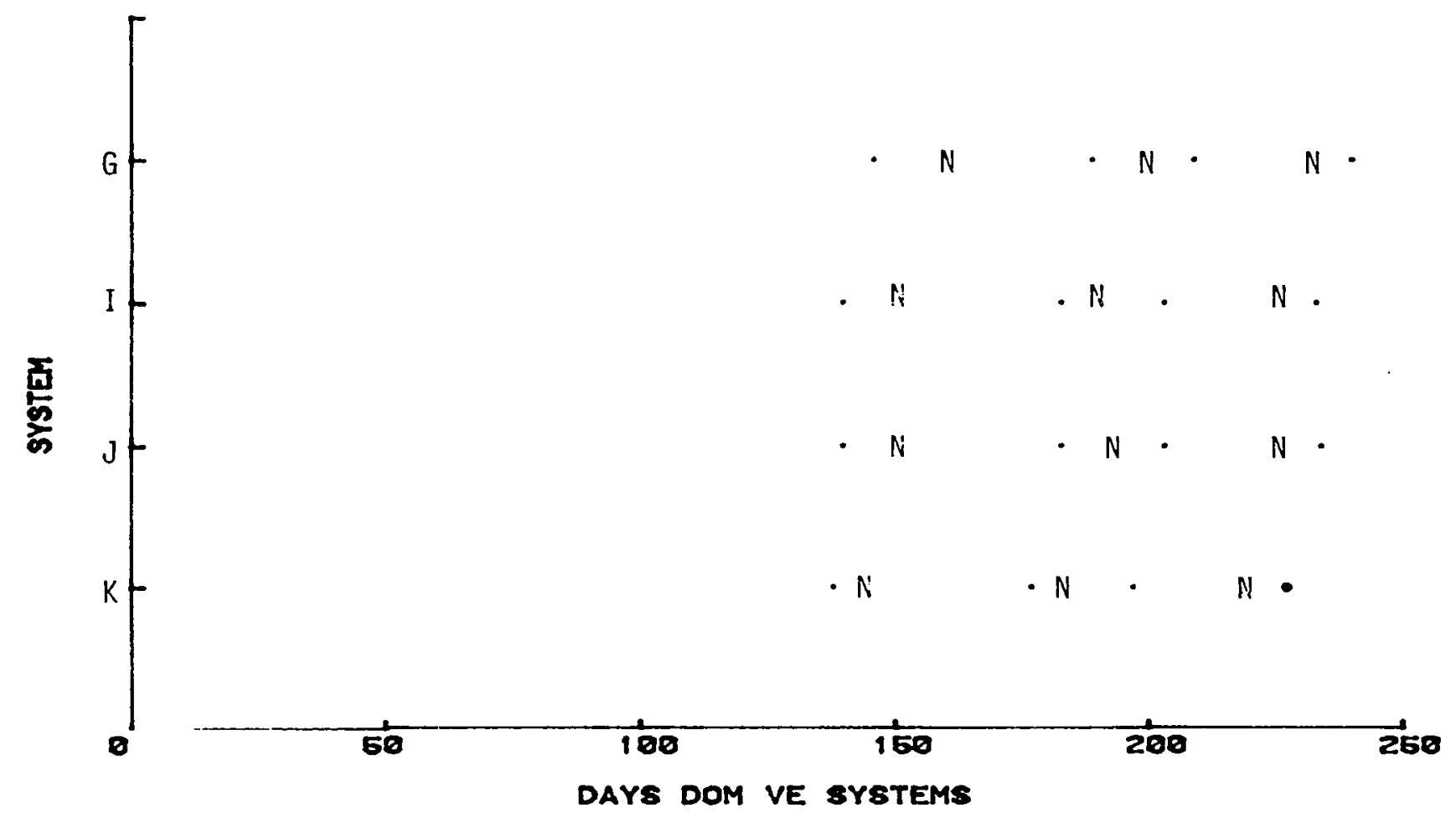

- Determined concentrations of DDT isomers

$N$ New DDT-coated beads introduced

Figure 20. DOM VE operation record. 


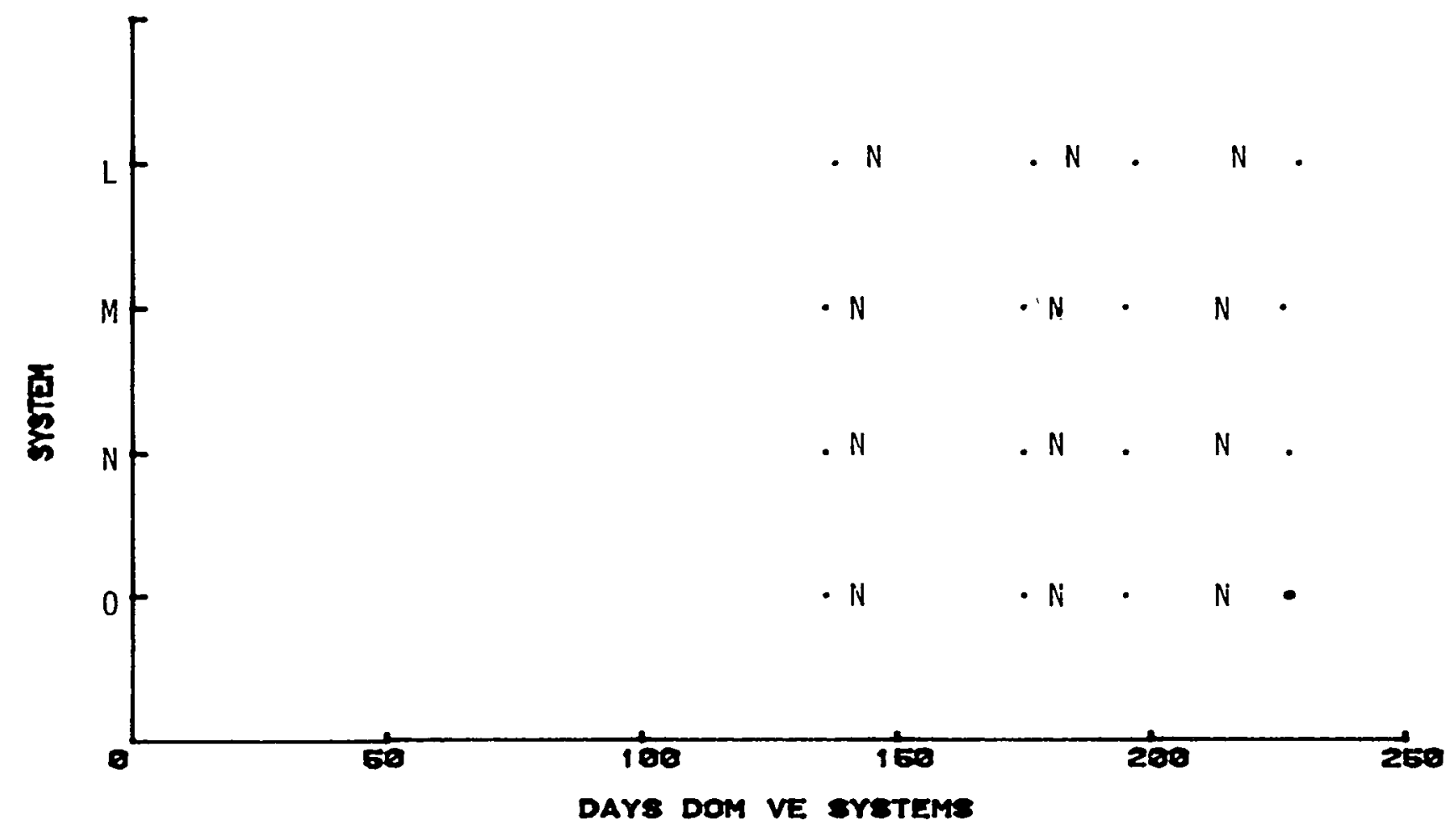

- Determined concentrations of DDT isomers

$N$ New DDT-coated beads introduced

Figure 21. DOM VE operation record. 


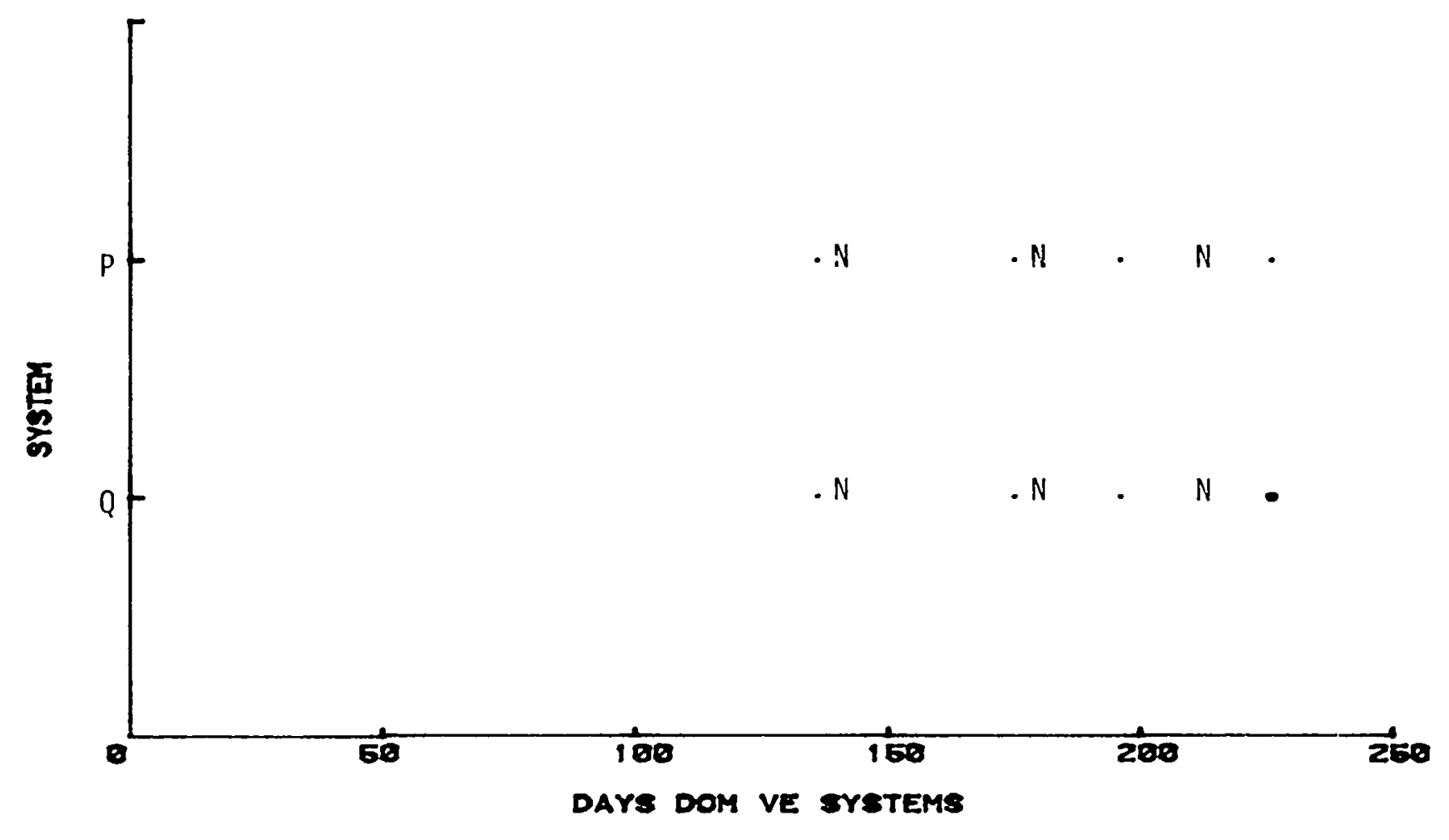

- Determined concentrations of DDT isomers

$\mathrm{N}$ New DDT-coated beads introduced

Figure 22. DOM VE operation record. 
TABLE IV

DOM SOLUTIONS INITIAL

ADJUSTMENT PARAMETERS

\begin{tabular}{llll} 
system & $\mathrm{PH}$ & ionic strength & DOM \\
\hline G & & & \\
$\mathrm{I}$ & 7.0 & $0.001 \mathrm{M}$ & $64 \mathrm{mg} / \mathrm{L}$ \\
$\mathrm{J}$ & 9.0 & $0.01 \mathrm{M}$ & $80 \mathrm{mg} / \mathrm{L}$ \\
$\mathrm{K}$ & 7.0 & $0.01 \mathrm{M}$ & $79 \mathrm{mg} / \mathrm{L}$ \\
$\mathrm{L}$ & 5.0 & $0.001 \mathrm{M}$ & $76 \mathrm{mg} / \mathrm{L}$ \\
$\mathrm{M}$ & 5.0 & $0.01 \mathrm{M}$ & $74 \mathrm{mg} / \mathrm{L}$ \\
$\mathrm{N}$ & 5.0 & $0.001 \mathrm{M}$ & $48 \mathrm{mg} / \mathrm{L}$ \\
0 & 9.0 & $0.001 \mathrm{M}$ & $50 \mathrm{mg} / \mathrm{L}$ \\
$\mathrm{P}$ & 5.0 & $0.001 \mathrm{M}$ & $24 \mathrm{mg} / \mathrm{L}$ \\
Q & 7.0 & $0.01 \mathrm{M}$ & $55 \mathrm{mg} / \mathrm{L}$ \\
& 7.0 & $0.01 \mathrm{M}$ & $27 \mathrm{mg} / \mathrm{L}$
\end{tabular}


The concentrations of $0, p^{\prime}-D D T$ and $p, p^{\prime}-D D T$ in the DOM VE solutions are plotted versus time in Figures 23-32. 


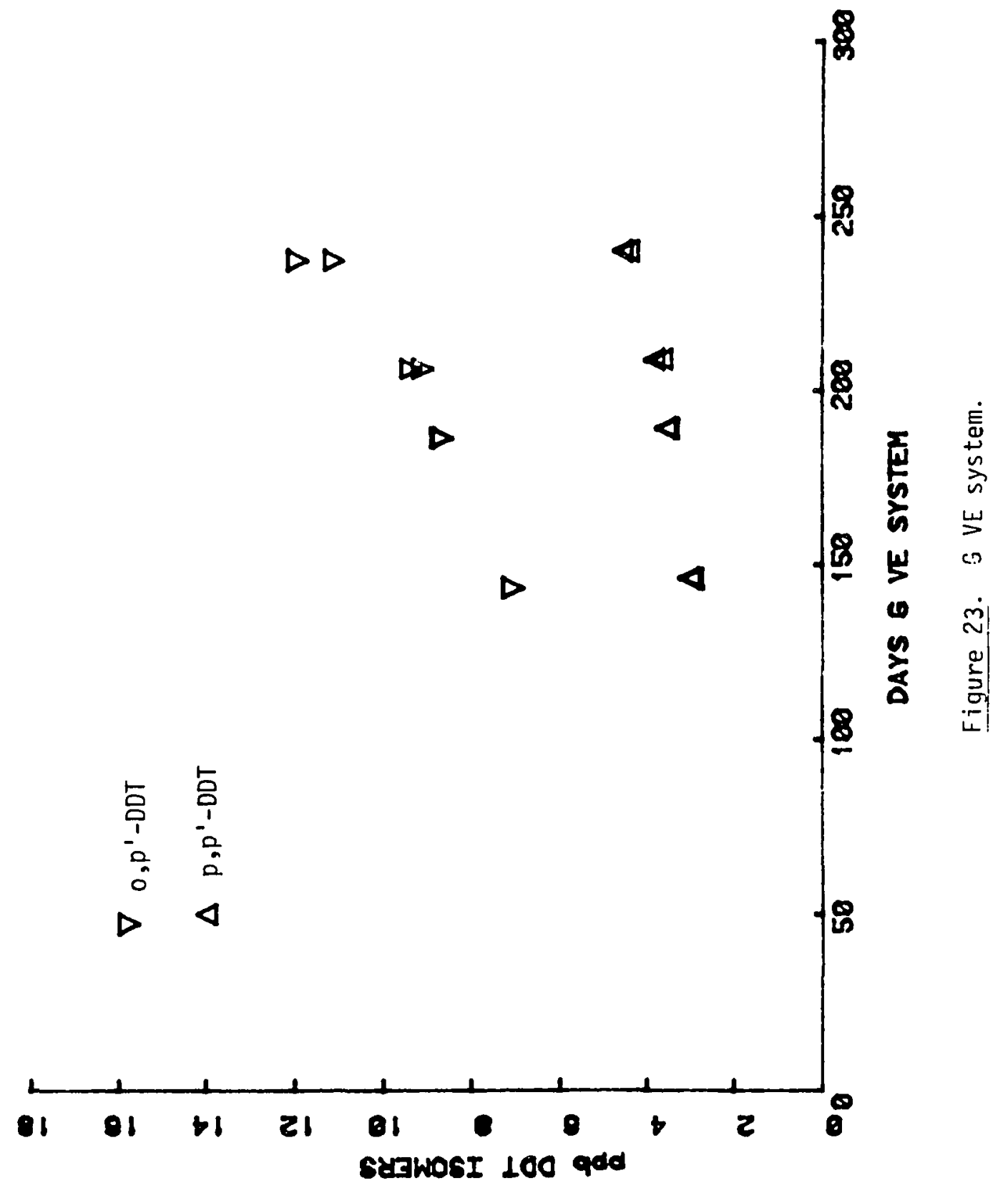




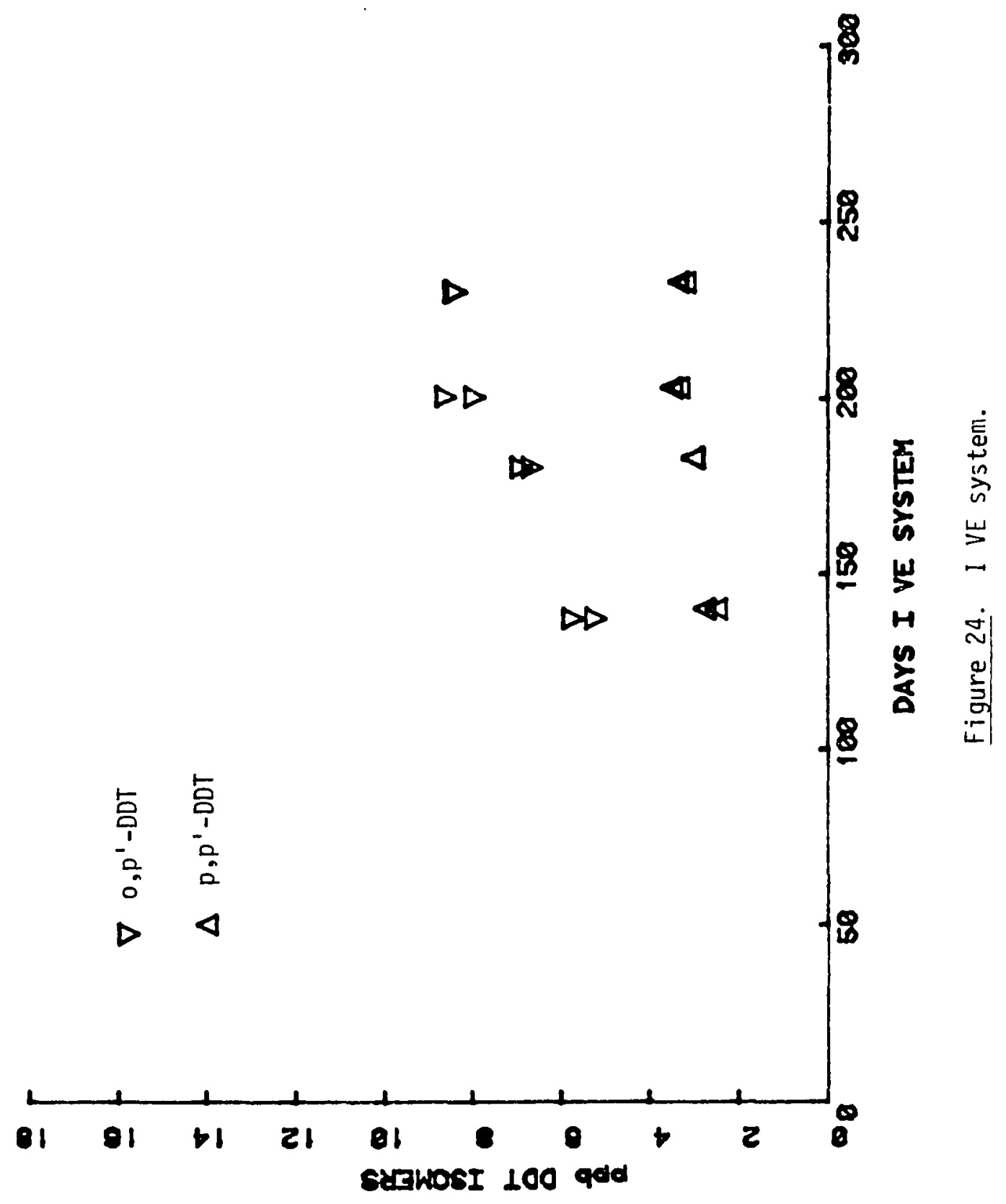




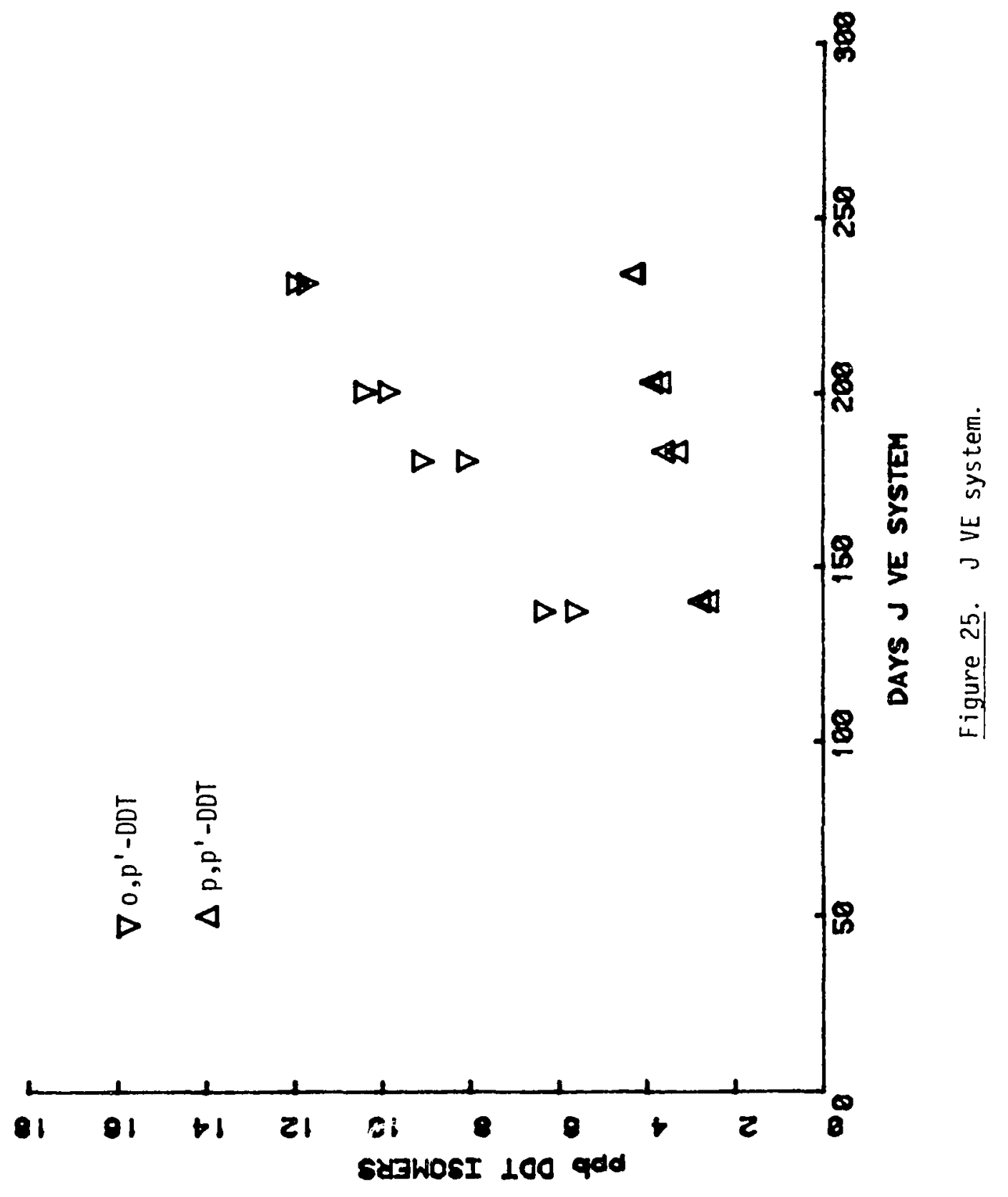




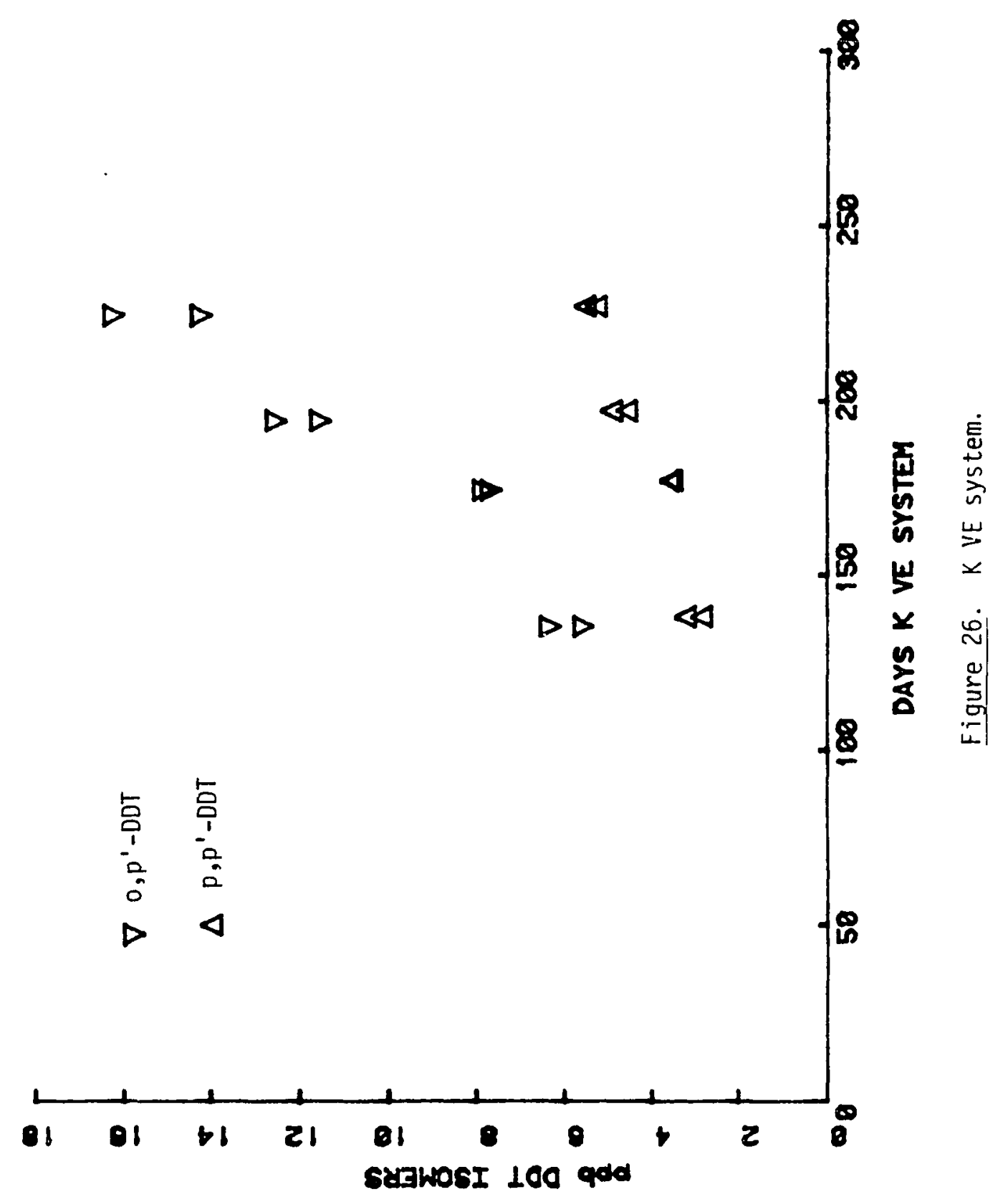




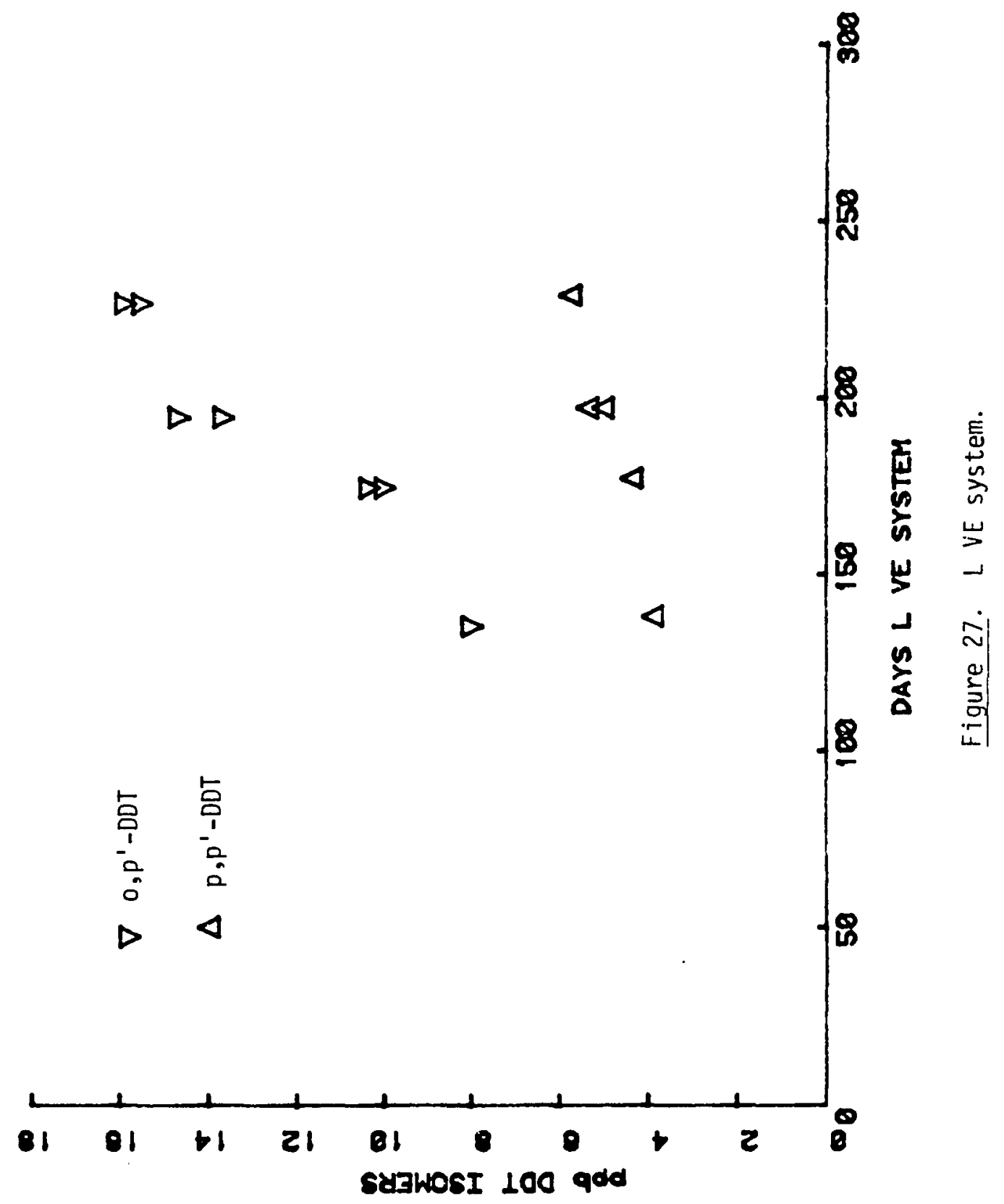




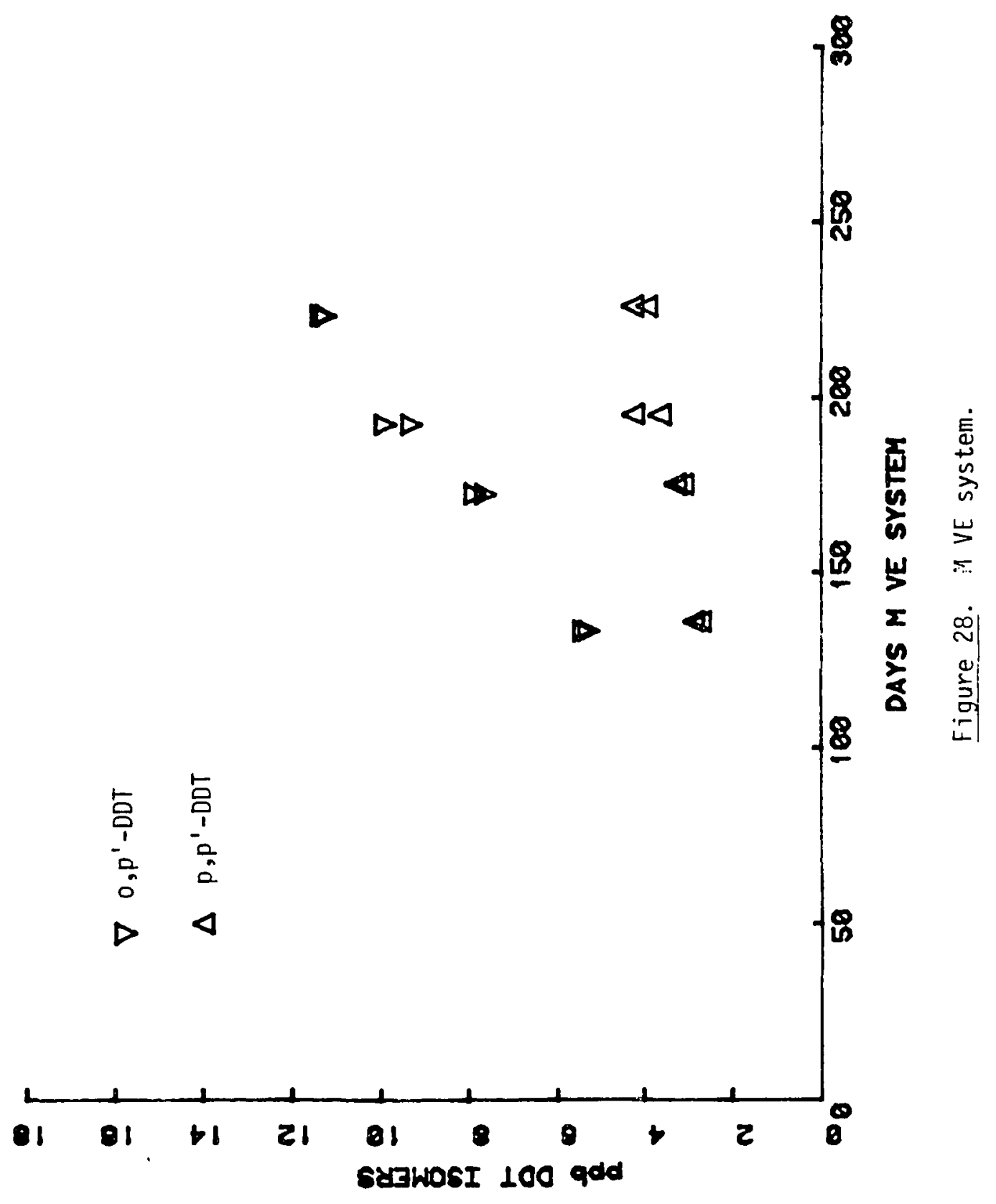




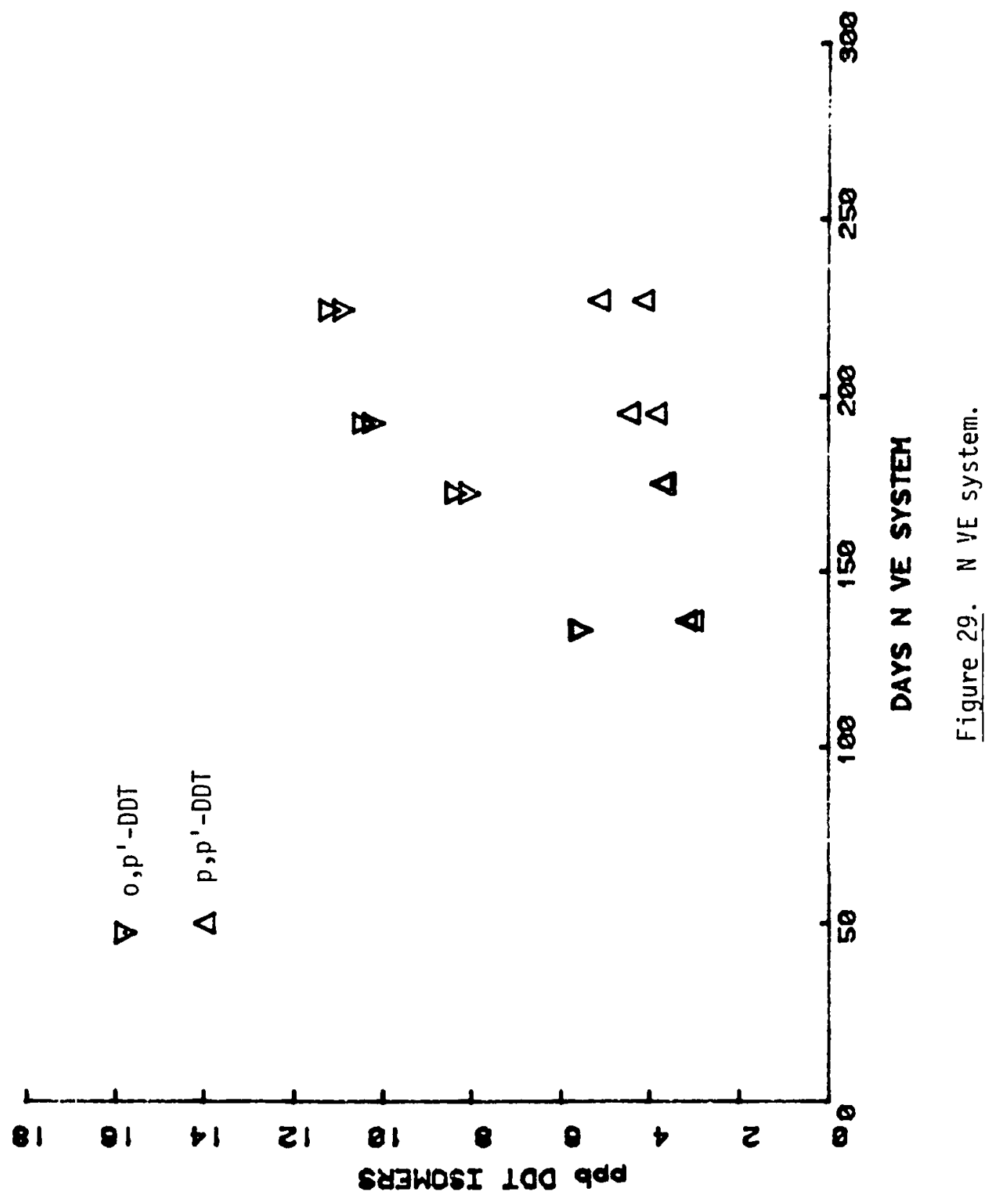




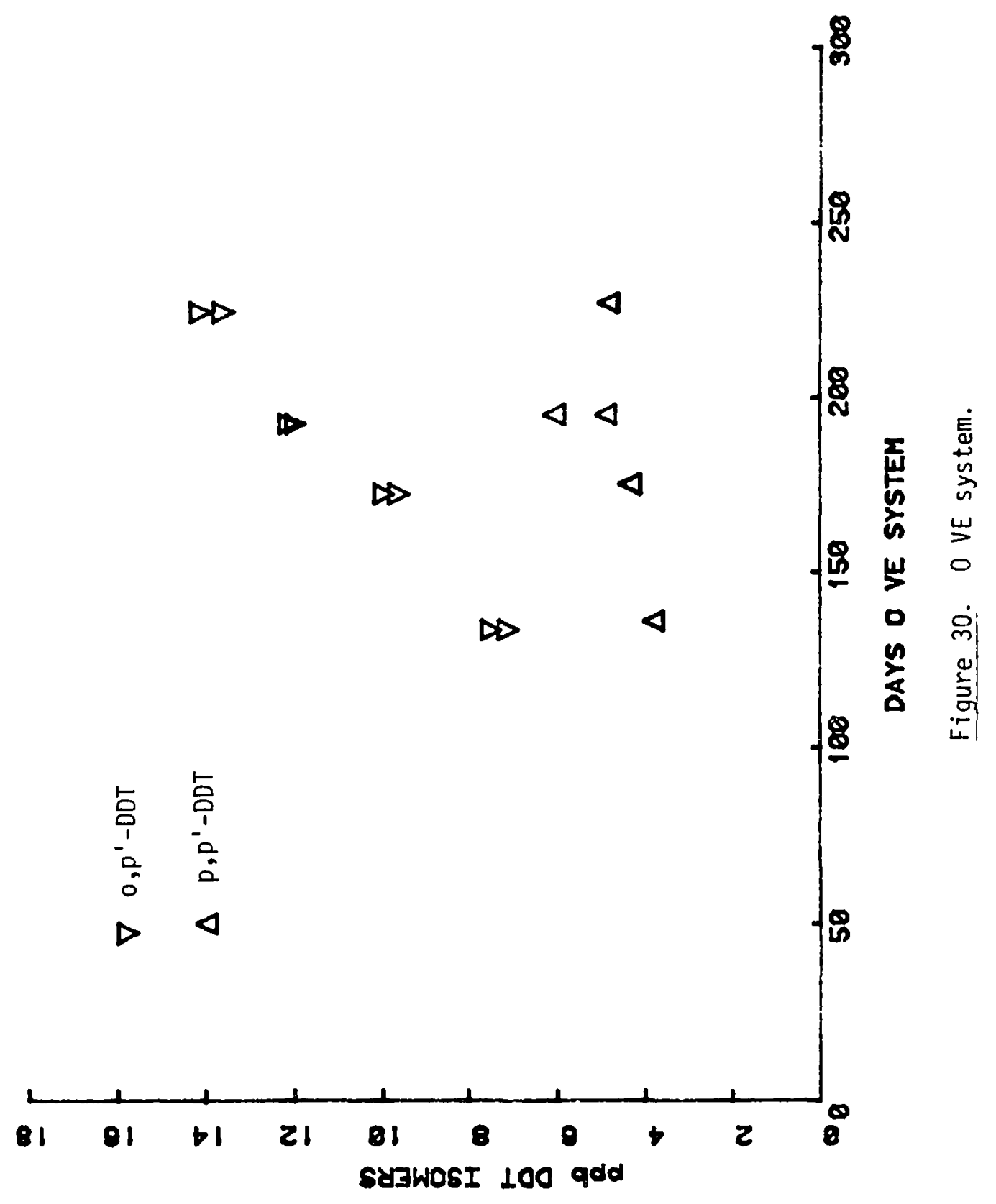




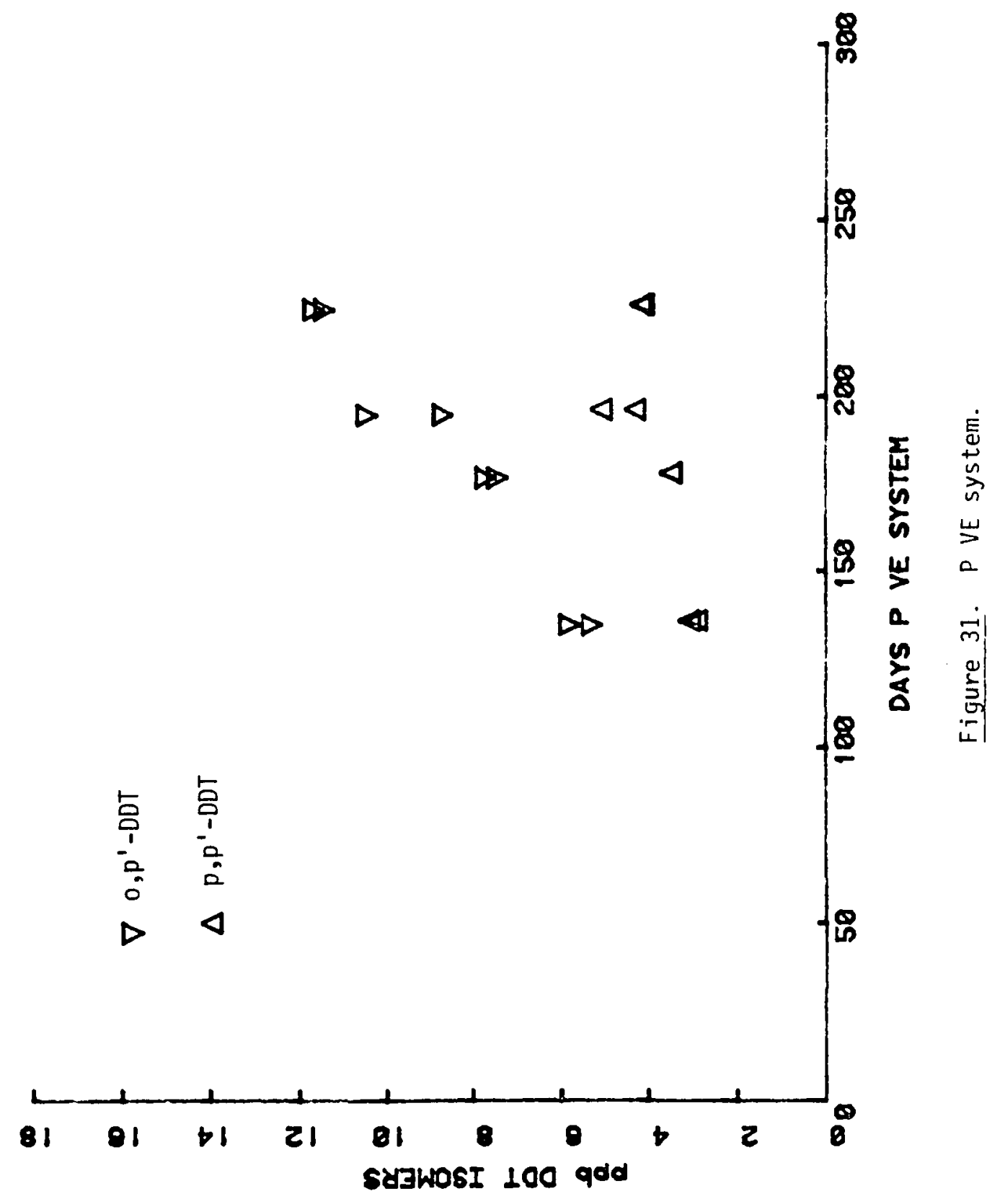




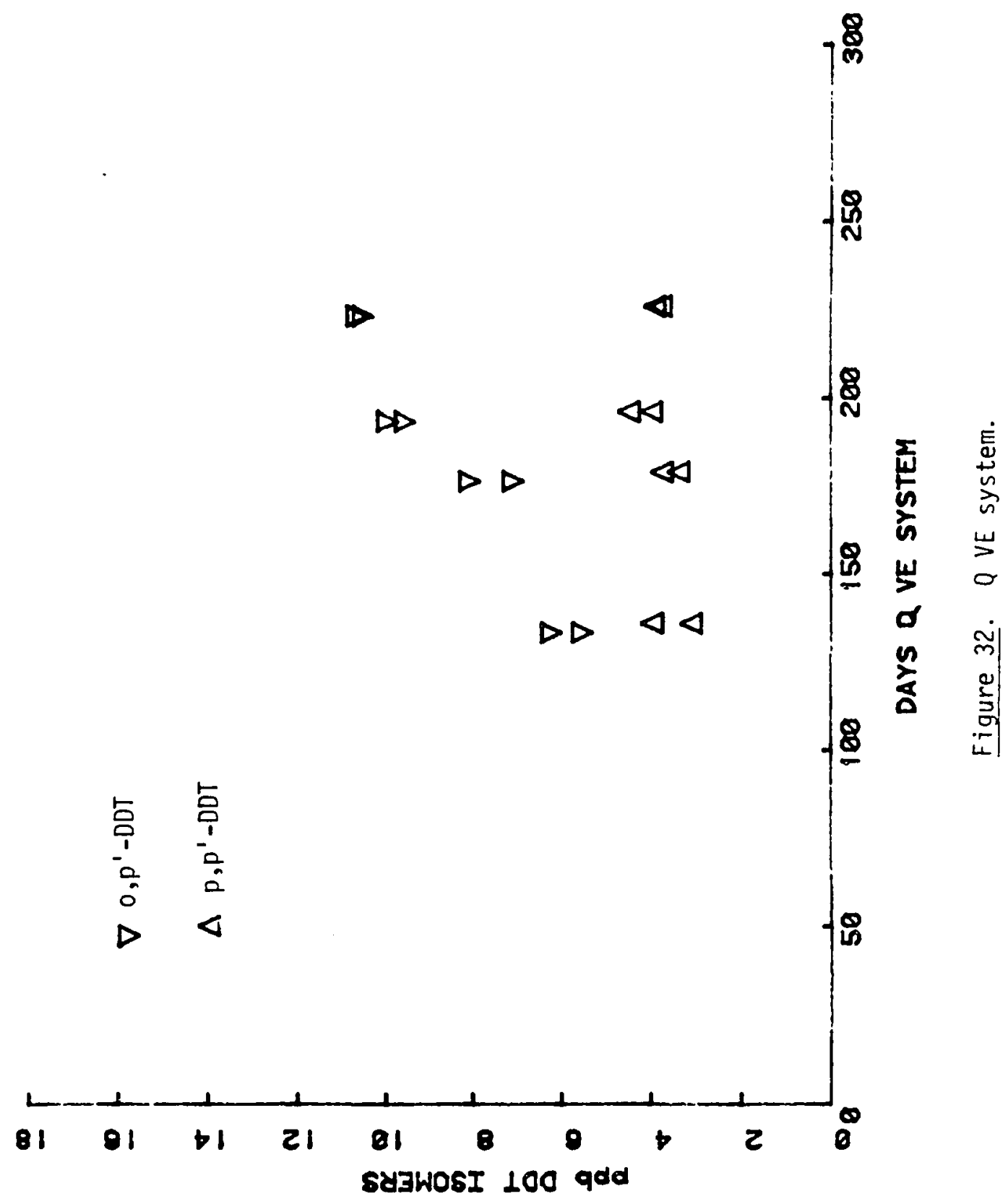




\section{VE SYSTEM DOM CONCENTRATION}

The concentration of the dissolved organic matter in each VE solution was measured within the first ten days and again after 140 to 160 days. The average change between the two determinations was $+0.9 \mathrm{mg} / \mathrm{L}$ DOM. See Table V. 
TABLE V

VE SYSTEM [DOM]

VE SYSTEM

CONCENTRATION DOM (MG/L)

G

I

$\mathrm{J}$

K

L

M

$N$

0

P

Q

B

D

F

W

$x$

Y

Z

\begin{tabular}{|c|c|c|}
\hline $0-10$ days & $140-160$ days & average \\
\hline 65 & 63 & $64 \mathrm{mg} / \mathrm{L}$ \\
\hline 81 & 78 & $80 \mathrm{mg} / \mathrm{L}$ \\
\hline 78 & 80 & $79 \mathrm{mg} / \mathrm{L}$ \\
\hline 74 & 79 & $76 \mathrm{mg} / \mathrm{L}$ \\
\hline 72 & 76 & $74 \mathrm{mg} / \mathrm{L}$ \\
\hline 48 & 47 & $48 \mathrm{mg} / \mathrm{L}$ \\
\hline 51 & 48 & $50 \mathrm{mg} / \mathrm{L}$ \\
\hline 23 & 26 & $24 \mathrm{mg} / \mathrm{L}$ \\
\hline 54 & 56 & $55 \mathrm{mg} / \mathrm{L}$ \\
\hline 26 & 28 & $27 \mathrm{mg} / \mathrm{L}$ \\
\hline 0 & & \\
\hline 0 & & \\
\hline 0 & & \\
\hline 0 & & \\
\hline 0 & & \\
\hline 0 & & \\
\hline 0 & & \\
\hline
\end{tabular}




\section{VE SYSTEM PH}

Each VE solution was initially adjusted to a pH of 5,7 , or 9. Within ten days, in most cases, the solution $\mathrm{pH}$ had shifted from the adjusted value. Measurements taken at 140 to 160 days and again at 230 to 250 days indicated that the $\mathrm{pH}^{\prime} \mathrm{s}$ of the VE solutions were not constant with time. These last two sets of values ranged between $\mathrm{pH}$ 7-9 and imply that this may be a steady-state range for the VE solution $\mathrm{pH}^{\prime} \mathrm{s}$.

VE SYSTEM PH

VE System

$\mathrm{pH}$

\begin{tabular}{|c|c|c|c|c|}
\hline & initial adj. & 5-10 days & $140-160$ days & $230-250$ days \\
\hline G & 7.0 & 7.0 & 7.5 & 7.3 \\
\hline I & 9.0 & 9.4 & 8.9 & 8.7 \\
\hline $\mathrm{J}$ & 7.0 & 8.0 & 8.8 & 8.5 \\
\hline K & 5.0 & 5.7 & 8.0 & 8.2 \\
\hline$L$ & 5.0 & 5.8 & 7.8 & 7.3 \\
\hline$M$ & 5.0 & 7.3 & 7.8 & 7.9 \\
\hline$N$ & 9.0 & 7.7 & 8.8 & 8.4 \\
\hline 0 & 5.0 & 6.0 & 7.9 & 7.6 \\
\hline$P$ & 7.0 & 7.3 & 8.4 & 7.8 \\
\hline$Q$ & 7.0 & 7.5 & 8.3 & 7.6 \\
\hline
\end{tabular}




\section{MICROORGANISMS}

Due to the extended periods of time that the VE systems were in operation, it was necessary to monitor the microorganism populations of the systems. At about 600 days for the distilled $\mathrm{H}_{2} \mathrm{O}$ systems (200 days for the DOM systems) analyses for total and for viable microorganisms (those organisms capable of reproduction when cultured) were performed. As microorganisms were an unanticipated consideration, populations of initial solutions were not checked.

Total populations were estimated from microscopic examination ( $2000 \times$ magnification) of solution aliquots. Results indicated populations of $210^{6}$ organisms per $\mathrm{mL}$ for both the distilled $\mathrm{H}_{2} \mathrm{O}$ and the DOM solutions. The organisms were characterized as being four to five types of bacteria (one of which was Bacillus) and a relatively small number of fungi.

The populations of viable organisms in the systems were determined by culturing aliquots of the solutions. Samples were plated on a threenutrient agar plus yeast extract medium and incubated at $20^{\circ} \mathrm{C}$. The resulting plate counts showed a marked difference between the distilled $\mathrm{H}_{2} \mathrm{O}$ and DOM solutions. While the distilled $\mathrm{H}_{2} \mathrm{O}$ solutions ranged from 300 to 500 viable organisms per $\mathrm{mL}$, the DOM solutions showed populations of $10^{5}$ to $10^{6}$ viable organisms per $\mathrm{mL}$.

\section{DDT SORPTION TO GLASS}

A distilled water VE system that had been running for 405 days was analyzed to determine how much DDT was sorbed to the vessel walls. The 
remaining DDT-saturated solution in the system was poured out, and the two-liter flask (and the remaining drops of solution) were rinsed three times with dichloromethane. The combined rinses were worked up and analyzed in the usual manner. The emptied flask was found to contain $173.2 \pm .5 \mathrm{ng}$ of $\mathrm{p}, \mathrm{p}^{\prime}-\mathrm{DDT}$, or the amount of this isomer that would be found in $286 \mathrm{~mL}$ of DDT-saturated distilied water.

\section{BIOLOGICAL DEGRADATION OF AQUEOUS DDT}

The presence of the major degradation products of $p, p^{\prime}-D D T$, namely $p, p^{\prime}-D D E$ or $p, p^{\prime}-D D D$, in a VE sample would suggest that biological degradation had occurred in that system. VE systems were sampled over periods of 200 to 600 days. A small amount of $p, p^{\prime}-D D E \quad(<0.3 \mathrm{ppb}$ in distilled $\mathrm{H}_{2} \mathrm{O},<\mathrm{ppb}$ in DOM) was found in the VE systems, which may be attributed to the DDE contaminant on the glass beads. Larger amounts of $p, p^{\prime}-D D E$ were not found in the VE solutions nor was the presence of $p, p^{\prime}-D D D$ detected in any of the samples.

CHEMICAL DEGRADATION OF AQUEOUS DDT

A check was made to determine if DDT in distilled water would degrade over time. A DDT-coated glass bead was placed in $225 \mathrm{~mL}$ of distilled water and sonicated for 5 minutes in a $250 \mathrm{~mL}$ Erlenmeyer flask. The flask was sealed with a glass stopper and allowed to stand, exposed to fluorescent light. Immediate analysis of the solution indicated a small amount $(<1 \%)$ of $p, p^{\prime}-D D E$, which was present as a contaminant on the DDT bead. After 26 months, the solution showed the same contaminant, $\mathrm{p}, \mathrm{P}^{\prime}-\mathrm{DDE}(<1 \%)$, and no detectable amounts of DDD. 


\section{CHAPTER IV}

\section{DISCUSSION}

\section{CONTROLLED PARAMETERS}

DOM concentration, ionic strength and $\mathrm{pH}$ were varied as each of the different VE systems was initiated. Of the three adjusted parameters, DOM concentration and ionic strength were "controlled" successfully, while $\mathrm{pH}$ was not. The concentration of dissolved organic matter in various systems ranged from zero to $80 \mathrm{mg} / \mathrm{L}$ and did not vary significantly with time (see Data). The ionic strength was initially adjusted to 0.001 or $0.01 \mathrm{M}$, and, while it was not monitored, the ionic strength of these solutions would not be expected to change with time.

Initially the $\mathrm{pH}$ was adjusted to 5,7 or 9 . However, the $\mathrm{pH}$ of the VE solutions did not remain constant with time. Instead, all of the solutions appeared to be shifting to a $\mathrm{pH}$ between 7 and 9 (see Data). This $\mathrm{pH}$ shift from an initially adjusted value could be attributed to the presence and growth of microorganisms within a system. In the absence of microorganisms, DOM solutions have maintained an initially adjusted pH (199).

\section{IONIC STRENGTH}

At the adjusted levels ( $I=0.001$ and $0.01 \mathrm{M})$, there was no observable relationship between ionic strength and DDT concentration, for either distilled water or dissolved organic matter solutions. This observation 
is in agreement with other work $(69,79,143)$. While equilibrium values were not obtained for DOM systems, the kinetic data for these systems showed no ionic strength correlation.

\section{MICROORGANISMS}

The VE systems were monitored over a considerable length of time (250 - 650) days, longer than originally anticipated. It was discovered that microorganisms in the systems reached populations of significant size during this time. Populations in all systems reached about $10^{6}$ organisms per $\mathrm{mL}$. Microorganisms in the DOM solutions were capable of reproduction when cultured while the populations of the distilled water systems were not (see Data).

Microorganisms could affect the concentration of DDT in the VE systems in two ways. The DDT could be biologically degraded by the organisms, and/or the pesticide could partition into the organisms, much like it would into an organic solvent. This partitioning to the organic organisms appears to be the same as for partitioning to any organic carbon, with the same equilibrium constant, $K_{\text {oc }}(165,171)$. On this basis, one can calculate how much DDT could be associated with the organic carbon of the microorganisms. Assuming a $K_{O C}$ of $3.5 \times 10^{5}$, and that one microorganism yields $1 \times 10^{-12} \mathrm{~g}$ dry weight (50\% of which is organic carbon), then a VE solution containing $10^{6}$ organisms/mL would have $0.35 \mathrm{ppb}$ DDT associated with the organisms. It is unclear how successfully DDT is extracted from microorganisms by methylene chloride. If the solvent extraction did not remove the microorganism/DDT from the aqueous layer, the organisms would not affect the analytical results. If, on the other hand, some, or all, of the associated DDT was extrac- 
ted, the maximum effect would be an error of $0.35 \mathrm{ppb}$ in excess of the actual VE solution concentration. As $0.35 \mathrm{ppb}$ is small relative to solution concentrations, the partitioning of DDT to microorganisms in the VE solutions does not significantly affect the analytical solution concentrations.

For reasons discussed in the next section (DDT Loss), microbial degradation of DDT is believed to occur in the VE solutions. During normal system operations, the constant input of DDT vapor from the beads occurs at a rate that is greater than the biological degradation rate. For this reason, the DDT solution concentration increases with time until equilibrium is reached. The effect of the microbial degradation is observed only when the VE system is shut down; that is, when the DDT-coated beads are removed and the system no longer receives a constant input of the pesticide.

\section{DDT LOSS}

The concentration of DDT isomers in a VE solution was observed to decrease over time if the constant source of DDT vapor (the DDT-coated glass beads) was removed. Decline of measured DDT solution concentrations could be caused by a number of factors which shall be discussed. Among these, the most probable cause is microbiological degradation. 
Consider a DOM VE system:

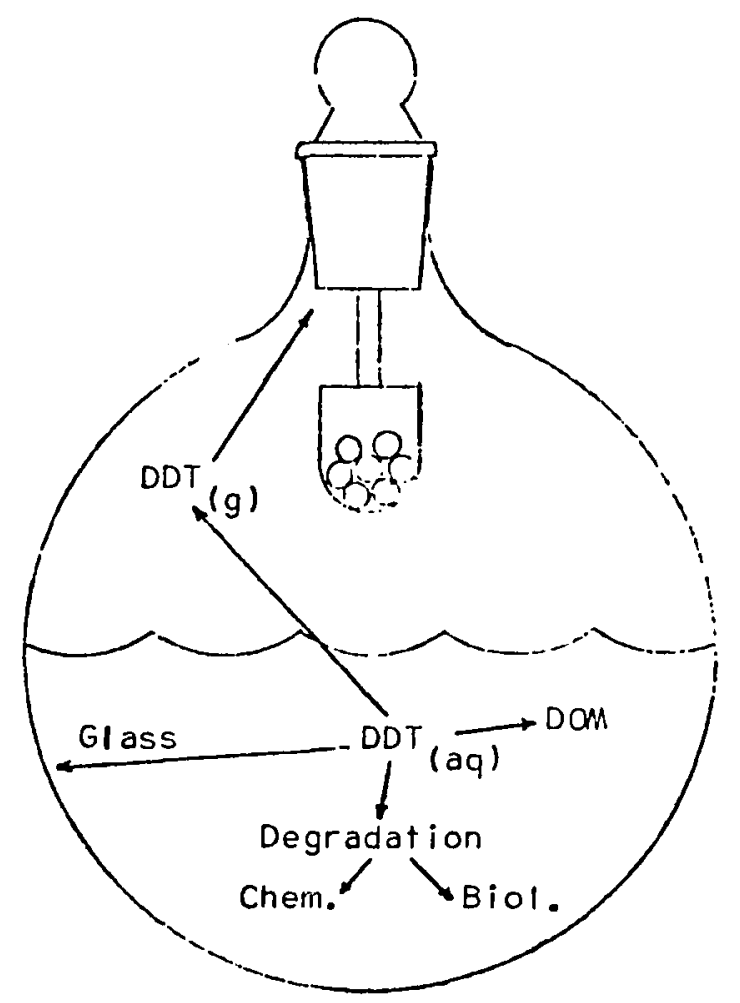

The DDT in solution (as measured) could be diminished in the following ways:

A. Escape - via the gas phase when the system is opened to withdraw a sample

B. Adsorption - irreversible relative to extraction

(1) $\mathrm{DOM}$

(2) Glass

(3) Microorganisms

C. Degradation

(1) Chemical

(2) Biological

Escape of the DDT from the vapor phase when the system is periodically opened does not constitute a significant loss. One can calculate 
the amount of DDT occupying the volume of the VE system above the solution ( $\sim 1$ liter) at $20^{\circ} \mathrm{C}$. If opening the flask to remove a sample resulted in a complete exchange of the vapor within the flask, only $2 \times$ $10^{-9} \mathrm{~g}$ of $\mathrm{P}, \mathrm{P}^{\prime}-\mathrm{DDT}$ would escape the system, which would translate to a loss of only $0.002 \mathrm{ppb}$ in a one-liter solution.

Adsorption of DDT from solution does not constitute a significant loss. Irreversible adsorption (relative to extraction) to DOM is not a problem, as is shown by the extraction recoveries of DDT from spiked DOM solutions over a long period of time (see Data). Glass has been shown not to adsorb appreciable amounts of DDT from aqueous solution. This is evident in the long-term extraction recovery data and in the small amount of DDT found associated with the walls of a VE system after the solution had been removed (see Data). Irreversible adsorption (relative to extraction) to microorganisms would involve a maximum of $0.35 \mathrm{ppb}$ (see Microorganisms section) which is not significantly greater than experimental error.

Degradation of DDT must, by default, be responsible for the observed drop in solution concentration over time. Chemical degradation of DDT in aqueous solution is known to occur very slowly, with a half-life on the order of 12 years (155). Chemical degradation is not an important factor in this work. This conclusion is supported by the absence of any detectable accumulations of DDT degradation products in either the lorig-term extraction recovery data or in a hydrolysis experiment that was run for over two years (see Data).

It is DDT degradation by microorganisms that is thought to account for the VE systems' Tass of solution DDT over time. While no microorganism has been found to utilize DDT as the only source of carbon, DDT is 
cometabolized by some species (169). The presence of the major degradation products, DDD or DDE (a degradation product that is sometimes formed in an aerobic environment) was not detected. However, DDD can subsequently be degraded to $\operatorname{DDCO}\left(4,4^{\prime}\right.$-dichlorobenzophenone $)$ or to DDM (bis(p-chlorophenyl)methane). These subsequent degradation products, if present, would not be identified in the GLC analysis. It is therefore possible that microbial degradation could accumulate products that would not be identified during analysis while maintaining a concentration of the intermediate DDD at an insignificant level.

Assuming that microbial degradation was occurring, an upper limit may be placed on the degradation rate. While data are not available to reliably assess the rate of DDT biotransformation in an aquatic system (155), a comparison with the degradation rate for a similar compound may be made. Under VE system operating conditions, methoxychlor (a compound similar to DDT, but with methoxy groups substituted for the two chlorine atoms on the benzene rings) would be degraded at the rate of $5 \times 10^{-3} \mu \mathrm{g}$ $L^{-1}$ day $^{-1}$ (200). As methoxychlor is generally recognized to biodegrade at a faster rate than DDT (200), this rate would constitute an upper limit for the rate of DDT degradation. Thus, for a VE system, the amount of DDT degraded during a 50-day period could be no more than 0.25 ppb. As Figure 16 shows, the rate of DDT input to the solution is considerably greater than this upper limit for the biodegradation rate.

It is important to note that while microbiological degradation causes a significant decrease in solution DDT levels in a static VE system with no constant input of DDT, there is no significant effect on the data and equilibrium concentration of a dynamic VE system in a normal mode of operation. An operating VE system would normally include 
a constant input of DDT vapor from the coated glass beads at a rate greater than the decomposition rate.

\section{VE SYSTEM - RATE-LIMITING PROCESS}

As the VE systems take an extremely long time to reach equilibration ( 100 days for a distilled water system and more than 240 days for a DOM system), it is of interest to identify the rate limiting step or process of the system. The process operating in a VE system would be:

(1) Vaporization of solid DDT;

(2) Diffusion of DDT in the gas and solution phases;

(3) Transport of DDT across the gas/solution boundary;

(4) Association or complexation of aqueous DDT with DOM.

(1) It is believed that among these, the vaporization of solid DDT is the process which limits the time necessary for a VE system to attain equilibrium. In support of this conclusion, it was observed that when the DDT-coated beads in the flask became wet from condensed water vapor, the concentration of DDT in solution did not rise as rapidly. When the beads in the flask were exchanged for dry beads on a regular basis (every 3 days), the solution concentration of DDT increased at a greater rate.

(2) Diffusion of DDT through either the gas or the solution phases could not be rate-limiting. The system is agitated by an orbital shaker, which thoroughly mixes both phases.

(3) The half-life for the transfer of DDT across a gas/solution boundary can be calculated $(56,58,201)$. For a VE system with DDT-saturated vapor, it would require 25 hours to increase the aqueous DDT concentration in distilled water from zero to $90 \%$ of saturation. As the 
kinetics of equilibrium attairment for the VE system are much slower, bondary transfer must not be rate-limiting.

(4) In systems containing DOM, the association of DDT and the organic matter is another kinetic process. This interaction has been shown, however, to be rapid with respect to the total VE process (143, 202). 


\section{CHAPTER V}

CONCLUSIONS

The solubility of $p, p^{\prime}-D D T$ in distilled water was determined to be $1.87 \pm .01 \mathrm{ppb}$. The solubility of the $0, \mathrm{p}^{\prime}$-DOT isomer in distilled water was determined to be $4.88 \pm .03 \mathrm{ppb}$.

The concentrations of $p, p^{\prime}-D D T$ and $0, p^{\prime}-D D T$ in distilled water solutions containing dissolved organic matter (DOM) were definitely greater than the aqueous solubilities of these compounds. The VE systems containing these DOM solutions did not reach equilibrium. That is, the concentrations of the DDT isomers continued to increase with time. For this reason, an absolute DDT "solubility" for each DOM solution was not determined. However, the highest DDT concentration measured for each system would represent a minimum value for the equilibrium concentration, had equilibrium been achieved. Thus, the DOM VE systems establish a lower limit for the "solubility" or equilibrium concentrations of $p, p^{\prime}-D D T$ and $o, p^{\prime}-D D T$ in aqueous DOM solutions. These lower limits are presented in Table VI. 
TABLE VI

DOM VE SYSTEMS

LOWER LIMIT FOR EQUILIBRIUM CONCENTRATION

DOM Conc. Lower Limit for Equilibrium Concentration

System $\mathrm{mg} / 1$ $p, p^{\prime}-D D T(p p b)$ $0, p^{\prime}-$ DDT $(p p b)$

$\begin{array}{llll}G & 64 & 4.5 & 11.9 \\ I & 80 & 3.4 & 8.6 \\ J & 79 & 4.3 & 12.0 \\ K & 76 & 5.4 & 15.5 \\ \text { L } & 74 & 5.8 & 15.9 \\ M & 48 & 4.1 & 11.5 \\ N & 50 & 4.7 & 11.2 \\ 0 & 24 & 4.9 & 14.1 \\ P & 55 & 4.2 & 11.8 \\ Q & 27 & 3.9 & 10.8\end{array}$

From these minimum vaives for equilibrium concentrations, a minimum value for the partition coefficient $\left(K_{o c}\right)$ may be calculated.

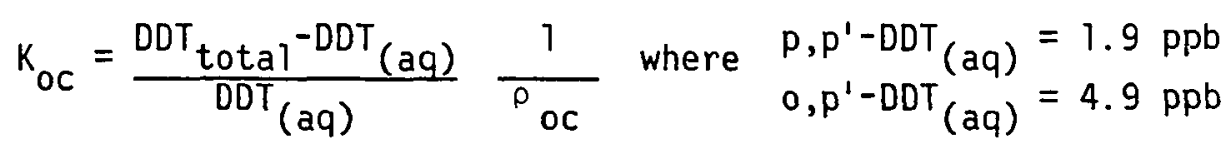


Lower Limit for $K_{\text {oc }}$

\begin{tabular}{ccc} 
System & $p, p^{\prime}-D D T$ & $0, p^{\prime}-D D T$ \\
\hline$G$ & $4.3 \times 10^{4}$ & $4.5 \times 10^{4}$ \\
I & $2.0 \times 10^{4}$ & $1.9 \times 10^{4}$ \\
J & $3.2 \times 10^{4}$ & $3.7 \times 10^{4}$ \\
K & $4.8 \times 10^{4}$ & $5.7 \times 10^{4}$ \\
L & $5.5 \times 10^{4}$ & $6.1 \times 10^{4}$ \\
M & $4.8 \times 10^{4}$ & $5.6 \times 10^{4}$ \\
N & $5.9 \times 10^{4}$ & $5.1 \times 10^{4}$ \\
O & $1.3 \times 10^{5 *}$ & $1.6 \times 10^{5}$ \\
$P$ & $4.4 \times 10^{4}$ & $5.1 \times 10^{4}$ \\
$Q$ & $7.8 \times 10^{4}$ & $8.9 \times 10^{4}$
\end{tabular}

mean

$4.7 \pm 1.6 \times 10^{4}$

$5.2 \pm 7.9 \times 10^{4}$

${ }^{*}$ rejected by $Q$ test at $90 \%$ confidence

These data indicate that a minimum $\log K_{o c}$ for both $p, p^{\prime}-D D T$ and $0, p^{\prime}-$ DDT would be $4.7 \pm .2$ log units. This minimum compares favorably with the literature $\log K_{\text {oc }}$ for $P, P^{\prime}-D D T$ of 5.1 to $5.7 \log$ units for particulate organic matter.

The data definitely establish that DOM does allow for the presence of a greater concentration of DDT in aqueous solution, and that a minimum value for the partition coefficient for the association between DOM and DDT can be calculated. Efforts to extrapolate the results to DDT/ DOM equilibrium values (and hence determine the $k_{o c}$ ) have been made. It appears that, while it may be useful to examine several extrapolation methods, there is not good agreement between different methods as to a projected $K_{o c}$ value. A discussion follows of a model used to describe the concentration of DDT in solution for a VE system over time. 


\section{KINETIC MODEL}

Consider a DOM VE system:

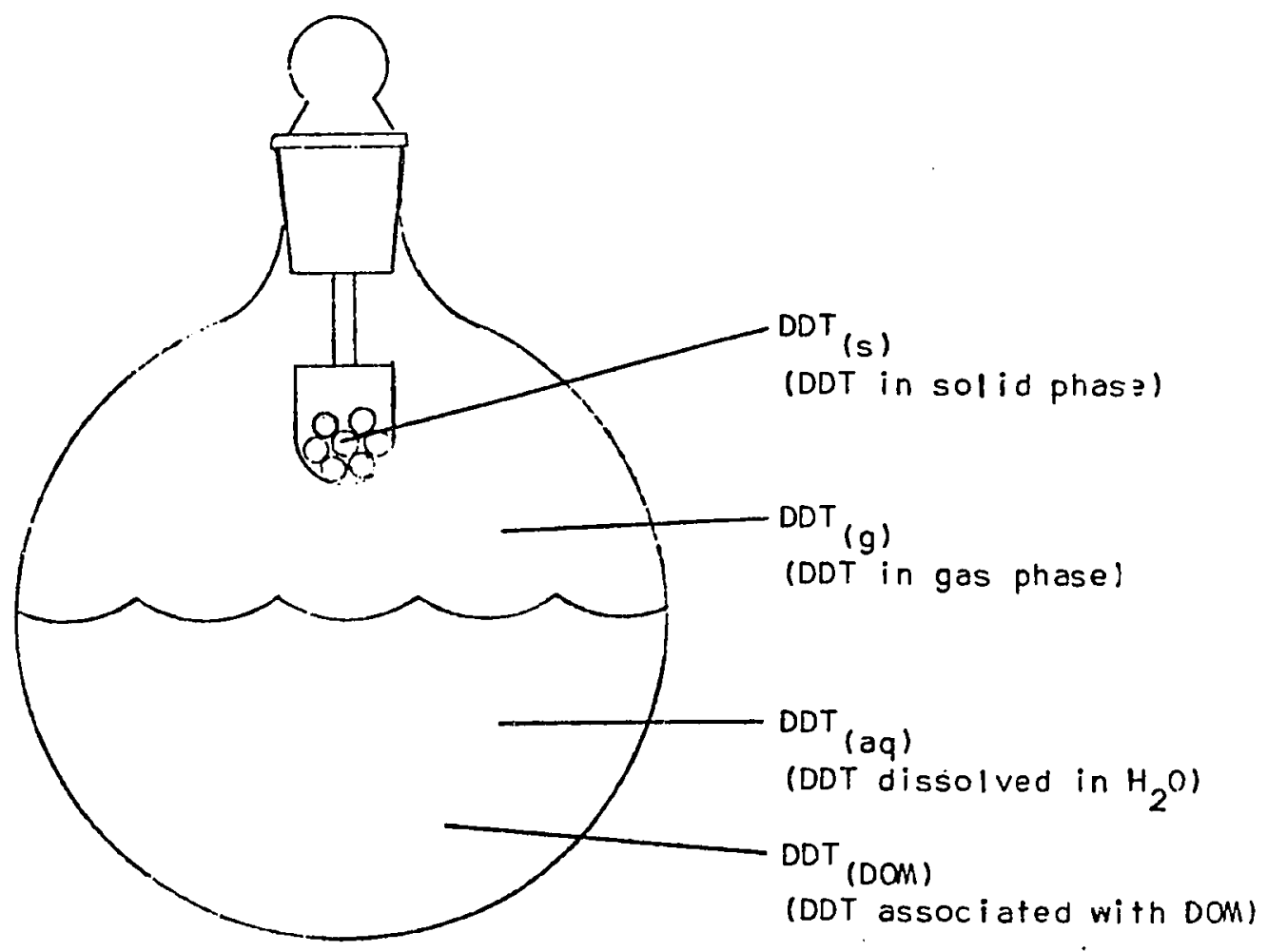

$\mathrm{DDT}_{(\mathrm{s})} \underset{k_{-1}}{\stackrel{k_{1}}{\rightleftharpoons}} \mathrm{DDT}_{(\mathrm{g})} \stackrel{\mathrm{k}_{2}}{\frac{k_{-2}}{\rightleftharpoons}} \mathrm{DDT}_{(\mathrm{aq})} \frac{\mathrm{k}_{3}}{\mathrm{k}_{-3}} \mathrm{DDT}_{(\mathrm{DOM})}$

Assume $k_{3}, k_{-3}>k_{2}, k_{-2}>k_{1}, k_{-1}$, or that DDT(DOM) is aiways in equilibrium with DDT $(g)^{\text {. }}$. The slow step of the sequence is the transition between the solid and vapor phases. The kinetics of such a system would be of the type described by a first-order reversible reaction, such as

$$
z \rightleftharpoons y
$$


Iritial boundary conditions can be chosen to mimic a VE system; $y$, the measured quantity, is not present at time $t=0$. The kinetics of such a system may be recognized to be exponential and of the form

$$
y=a\left(1-e^{-b t}\right)
$$

where $a$ and $b$ are constants.

While the general form of a kinetic model can thus be quickly deduced, a thorough kinetic analysis requires the constants $a$ and $b$ to be expressed in terms of the original equilibria. Such an expression will now be derived.

Rewriting the VE equilibria in terms of the Henry's law constant $(H)$ and the DOM/DDT partitioning coefficient $\left(K_{O C}\right)$,

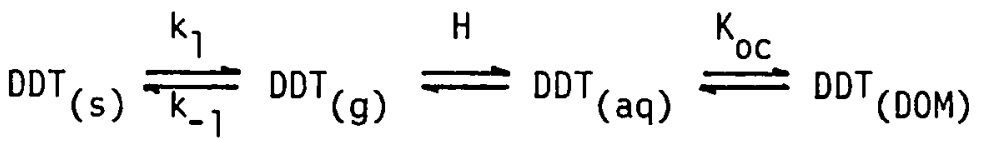

$$
\begin{aligned}
& \text { where } H=\frac{\left[D D T_{(g)}\right]}{\left[D_{(a q)}\right]}, \quad K_{o c}=\frac{\left[D D T_{(D O M)}\right]}{\left[D D T_{(a q)}\right]} \frac{1}{\rho_{o c}} \\
& \text { and } \rho_{o C}=\frac{\text { weight of organic carbon }}{\text { weight of water }} \text {. }
\end{aligned}
$$

Assume that DDT $(g)$ does not directly interact with the solution DOM and that DDT (DOM) does not affect $H\left(k_{-2}\right)$

Assume that DDT(s) is in large excess.

Then a mass balance may be written for the total amount of DDT in a VE system $\left(\mathrm{DDT}_{\mathrm{T}}\right)$ :

$$
\mathrm{DDT}_{T}=\mathrm{DDT}_{(\mathrm{s})}+\mathrm{DDT}_{(\mathrm{g})}+\mathrm{DDT}_{(\mathrm{aq})}+\mathrm{DDT}_{(\mathrm{DOM})}
$$

and

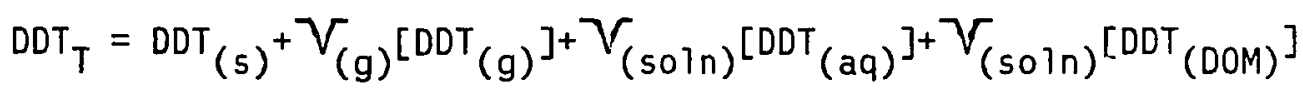




$$
\text { where } V_{(x)}=\text { volume of phase } x
$$

Let $\quad\left[D D T_{(a q)}\right]+\left[D D T_{(D O M)}\right]=\left[D D T_{M}\right]$

where $\left[D D T_{M}\right]$ is the measured concentration of DDT in the solution.

Then $\frac{d D D T_{T}}{d t}=0=\frac{d D D T_{(s)}}{d t}+V_{(g)} \frac{d\left[D D T_{(g)}\right]}{d t}+V_{(\text {soln })} \frac{d\left[_{\left.M D T_{M}\right]}\right.}{d t}$

Examining the three parts of this mass balance sum one at a time,

$$
\left.\frac{d D D T}{d t}(s)=-k_{1} D D T(s)+k_{-1} V_{(g)}{ }^{[D D T}(g)\right]
$$

Since $D D T_{(s)}$ is in excess, let

$$
k_{1} D D T(s)=s_{1} \text {, where } s_{1}=\text { a constant. }
$$

Then

$$
\begin{aligned}
& \left.\frac{d D D T}{d t}=-s_{1}+k_{-1} V_{(g)}^{[D D T}(g)\right] \\
& \text { Since }\left[D D T_{(a q)}\right]=\frac{1}{1+\rho_{O C} K_{O C}}\left[D D D T_{M}\right] \\
& \text { and }\left[D D T_{(g)}\right]=H\left[D D T_{(a q)}\right]=\frac{H}{1+\rho_{O C} K_{O C}}\left[{ }^{2 D T_{M}}\right] \text {, } \\
& \frac{d D D T}{d t}=-s_{1}+k_{-1} V(g) \frac{H}{1+\rho_{o c} K_{o c}} \quad\left[{ }^{[D D T}\right]_{M} \\
& \frac{d D D T}{d t}=V_{(g)} \frac{d[D D T(g)]}{d t} \\
& =V_{(g)} H \frac{d[D D T(a q)]}{d t}
\end{aligned}
$$


96

$$
\begin{aligned}
& \frac{d D D T}{d t}=V_{(g)} \frac{H}{1+\rho_{o c} K_{o c}} \frac{d\left[D_{M}\right]}{d t} \\
& \frac{d D D T_{M}}{d t}=V_{(\text {sol })} \frac{d\left[D D T_{M}\right]}{d t}
\end{aligned}
$$

Let $\left[D D T_{M}\right]=X$ and $\left(1+\rho_{o c} K_{o c}\right)=A$

where $V_{(g)}=V_{(\operatorname{soln})}=1$ liter

$$
\begin{array}{r}
\frac{d D D T}{d t}=-S_{1}+k_{-1} \frac{H}{A} X+\left(\frac{H}{A}+1\right) \frac{d X}{d t} \\
-S_{1}+\frac{k_{-1} H}{A} x+\left(\frac{H}{A}+1\right) \frac{d X}{d t}=0
\end{array}
$$

$$
\int_{0}^{x} \frac{d X}{s_{1}-\frac{k_{-1} H}{A} X}=0_{0}^{t} \frac{d t}{\frac{H}{A}+1}
$$

and

$$
x=\frac{s_{1} A}{k_{-1} H}\left(1-e^{-\frac{k_{-1} H}{H+A} t}\right)
$$

resubstituting,

(1) $\left[D D T_{M}\right]=\frac{S_{1}\left(1+\rho o K_{o c}\right)}{k_{-1} H}\left(1-e^{-\frac{k_{-1} H}{H+1+\rho o K_{o c}} t}\right)$ 
where

$\left[\mathrm{DDT}_{M}\right]$ is $\mu \mathrm{g} / \mathrm{L}$

$S_{1}$ is $\mu \mathrm{g} / \mathrm{hr}$

$k_{-1}$ is $\mathrm{hr}^{-1}$

$\rho_{\text {oc }}$ is dimensionless (wt. organic carbon/wt. solution)

$K_{\text {oc }}$ is dimensionless

$H$ is $1.62 \times 10^{-3} \underset{(\text { gas })}{\mu \mathrm{g} / \mathrm{L}} \underset{(\mathrm{soln})}{\mathrm{L} / \mu \mathrm{g}}$ (DDT at $\left.20^{\circ} \mathrm{C}\right)$

In the case of a distilled $\mathrm{H}_{2} \mathrm{O}$ VE system, $\rho_{\mathrm{OC}}=0$, and the equation reduces to

(2) $\left[\mathrm{DDT}_{M}\right]=\frac{S_{1}}{k_{-1} H}\left(1-e^{-\frac{k_{-1} H}{H+1} t}\right)$

which is the same equation that would result from a derivation similar to that used above for the DOM VE system.

Thus, the equation describing the measured concentration of DDT in a VE solution over time is of the form

$$
y=a\left(1-e^{-b x}\right)
$$

This equation describes a curve of the form

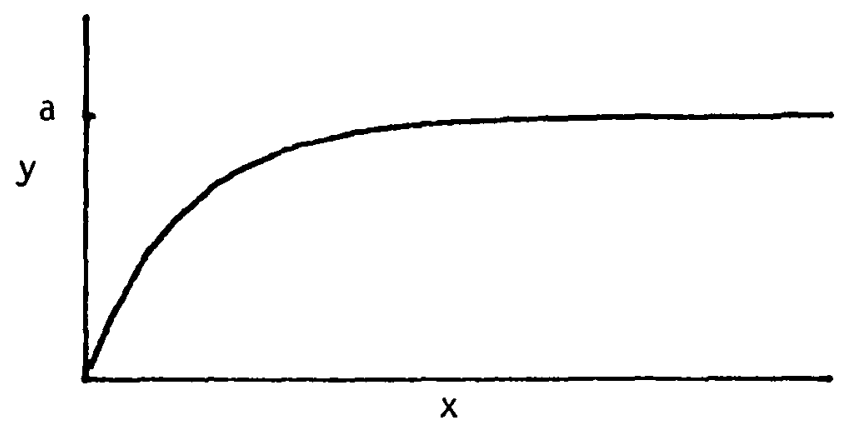


where as $x$ increases, $y$ approaches a value of "a." The constant " $b$ " determines the curvature, or how fast the line levels off. With respect to the model for the VE system, $x$ would be time (in days), $y$ would be DDT concentration (in ppb) and "a" would be the equilibrium DDT concentration or "solubility."

A discussion of various attempts to utilize this kinetic model to calculate equilibrium values will be limited to consideration of the p, p'-DDT data oniy.

The line of best fit of the form

$$
y=a\left(1-e^{-b x}\right)
$$

was calculated for the data from each of the continuous VE systems (those systems that did not undergo an interruption or change in mode of operation). The curve fits were accomplished by use of a modified computer program (see Appendix) for the sequential simplex method of optimization $(203,204)$.

The line of best fit for a distilled water system ( $W$ VE system) is shown in Figure 33. The " $a$ " and " $b$ " constants of this line are

$$
a=1.82, \quad b=0.051
$$

From equation (2), the constants $S_{1}$ and $k_{-1}$ are calculated:

$$
\text { Distilled } \mathrm{H}_{2} \mathrm{O} \text { System }\left(20^{\circ} \mathrm{C}\right)
$$

$$
\begin{aligned}
& S_{1}=9.28 \times 10^{-2} \mu \mathrm{g} / \mathrm{hr} \\
& k_{-1}=31.4 \mathrm{hr}^{-1}
\end{aligned}
$$




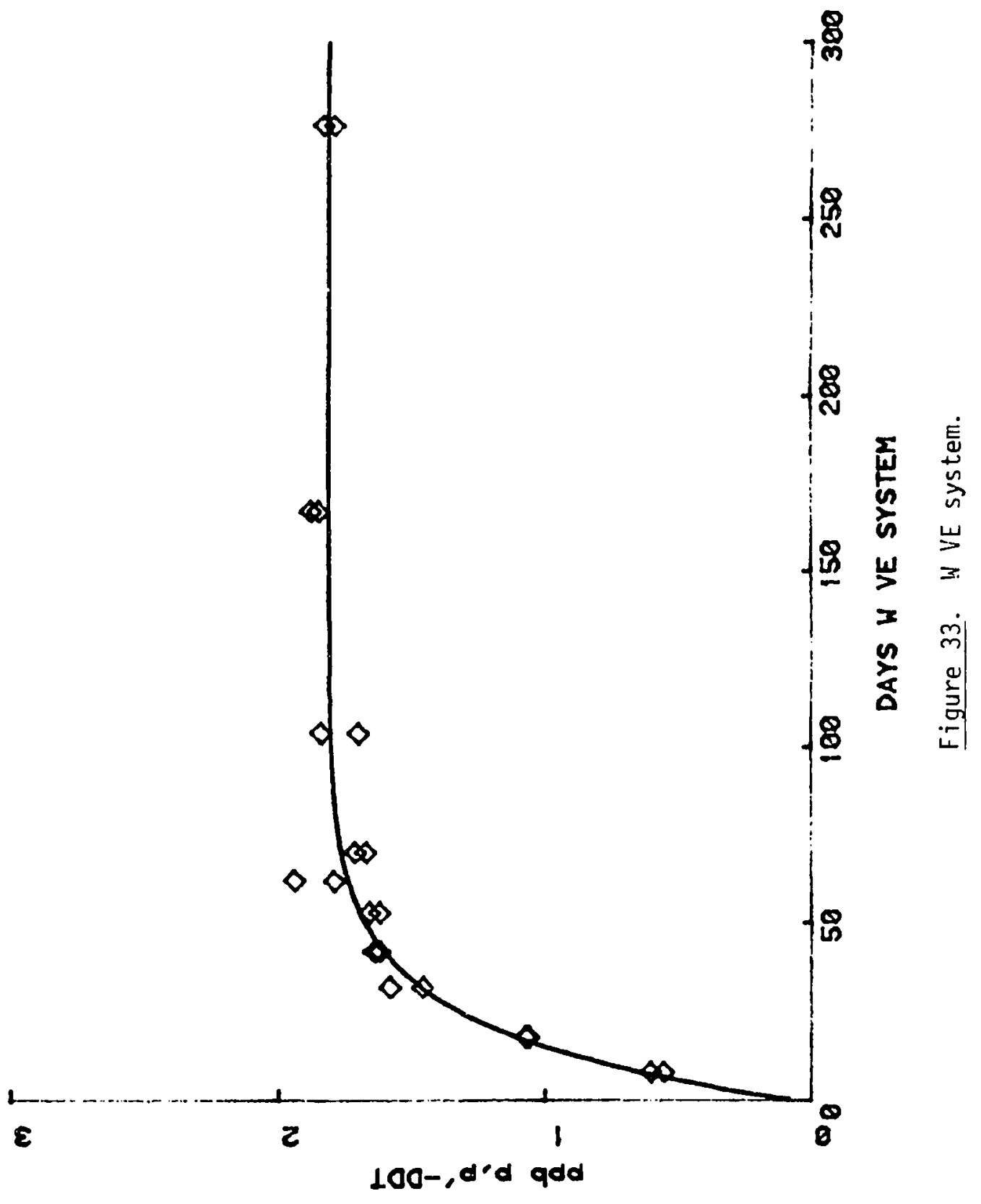


$S_{1}$ is the constant rate of input of DDT into the gas phase from the large excess of solid DDT. $k_{-1}$ is the rate constant for the return reaction, that is, for DDT returning to the solid phase from the gas phase.

Intuition, as well as the kinetic model, indicate that these constants $\left(S_{1}\right.$ and $\left.k_{-1}\right)$ describing the kinetics of transition between the solid and vapor phases should be constant for all VE systems. Thus, the $\mathrm{S}_{1}$ and $\mathrm{k}_{-1}$ calculated from the distilled $\mathrm{H}_{2} \mathrm{O}$ system should be the same $S_{1}$ and $k_{-1}$ operating in the DOM VE systems. On this basis, the distilled $\mathrm{H}_{2} \mathrm{O}$ constants were used to calculate curves for the DOM systems by assuming a series of values for $K_{o c}$.

$K_{\text {oc }}$ values of $3 \times 10^{5}, 8 \times 10^{4}$ and $3.7 \times 10^{4}$ were selected as a wide range of reasonable numbers. The DOM system curves calculated for these $K_{O C}{ }^{\prime} s$ (using $S_{1}$ and $k_{-1}$ from distilled $\mathrm{H}_{2} \mathrm{O}$ ) are shown in Figures 34 and 35 . While the curves do not fit the data particularly we11, it can be seen that the "lower limit" $K_{\text {oc }}$ calculated from the data $(4.7 \times$ $10^{4}$ ) is in the vicinity of $K_{o c}$ 's for the lines most closely approximating the data. It is apparent that, in addition to varying $K_{o c}$, the constants $S_{1}$ and $k_{-1}$ must also be changed if a better fit is to be obtained. Thus, the kinetics of transfer between the solid and liquid phases do not appear to be the same for distilled $\mathrm{H}_{2} \mathrm{O}$ and DOM VE systems. That is, $\mathrm{S}_{1}$ and $\mathrm{k}_{-1}$ calculated from the distilled $\mathrm{H}_{2} \mathrm{O}$ system does not allow for a reasonable curve fit of the DOM data. This disparity would indicate that perhaps it was incorrectly assumed that DOM did not affect the kinetics of the DDT trarisfer between the gas and solution phases. 


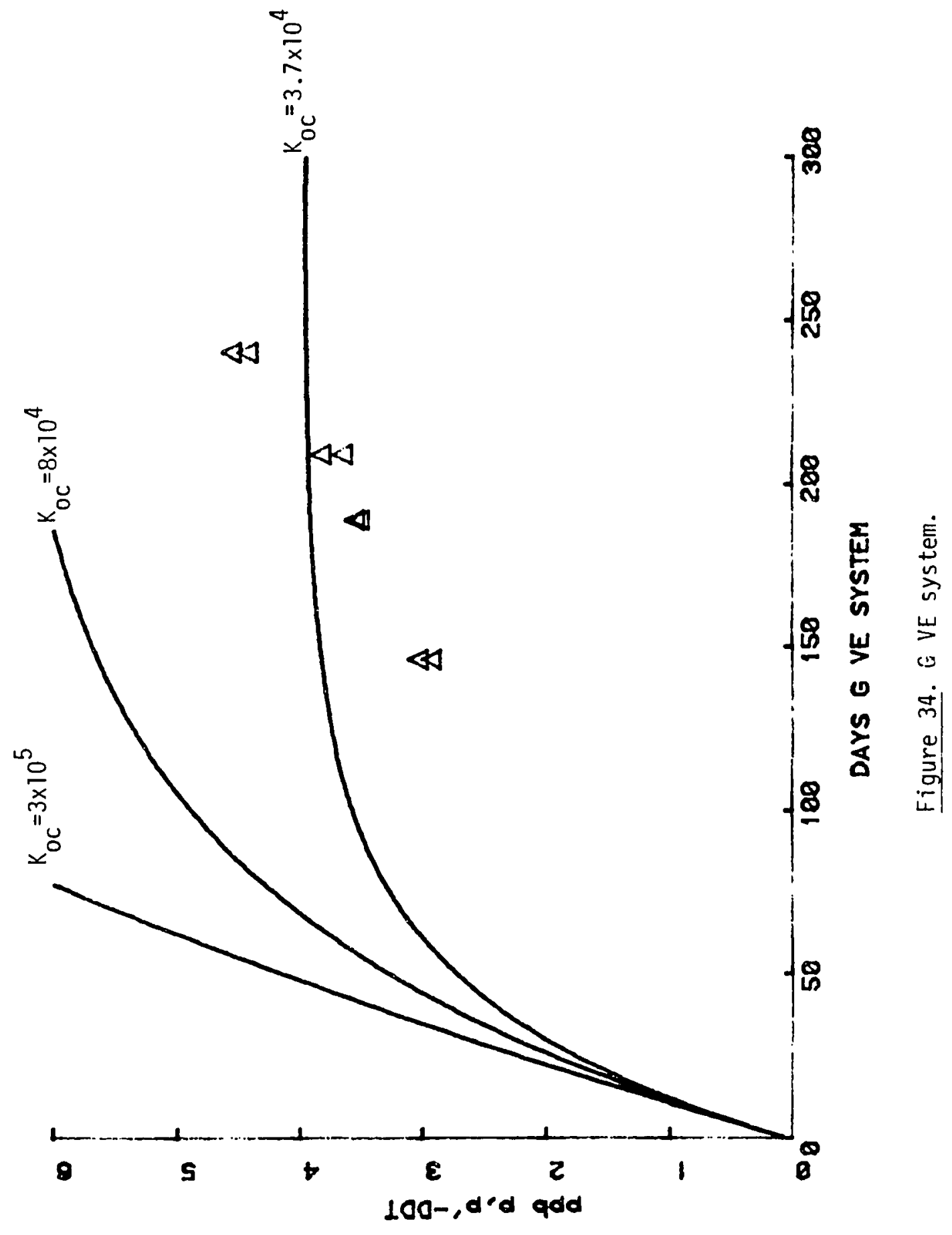




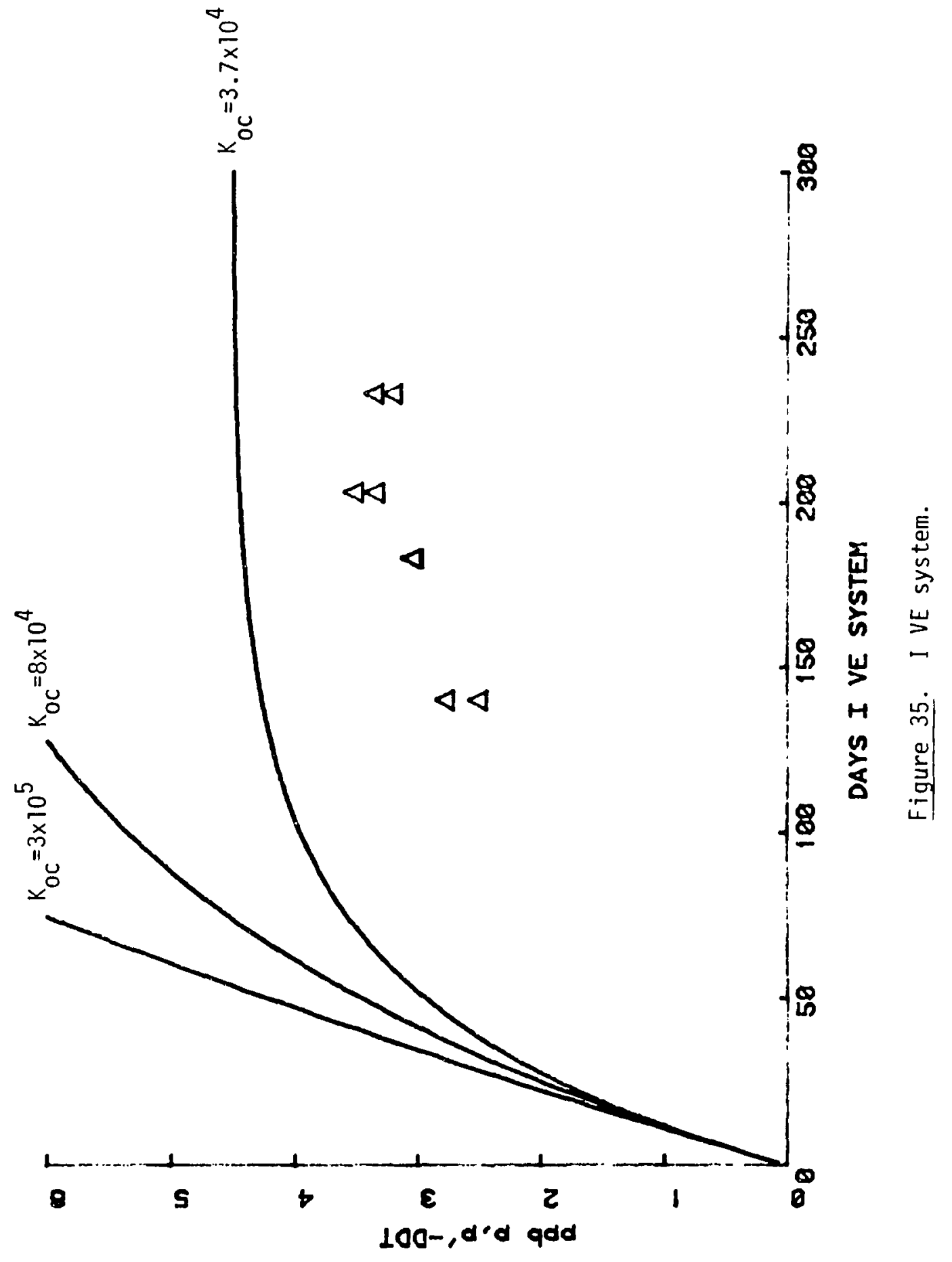


In another attempt to examine the kinetic model, the data for each DOM VE system were curve fitted by the simplex program for the optimal "a" and "b" of

$$
y=a\left(1-e^{-b x}\right)
$$

The resulting values of "a" and " $b$ " are listed below, and the corresponding curves in Figures 36-44.

\begin{tabular}{ccc} 
System & $a$ & $b$ \\
\hline G & 12.82 & 0.0017 \\
I & 4.10 & 0.0076 \\
J & 19.73 & 0.0011 \\
K & & \\
L & 20.75 & 0.0014 \\
M & 10.22 & 0.0023 \\
N & 11.60 & 0.0023 \\
O & 6.73 & 0.0065 \\
P & 7.82 & 0.0037 \\
Q & 4.17 & 0.0140
\end{tabular}




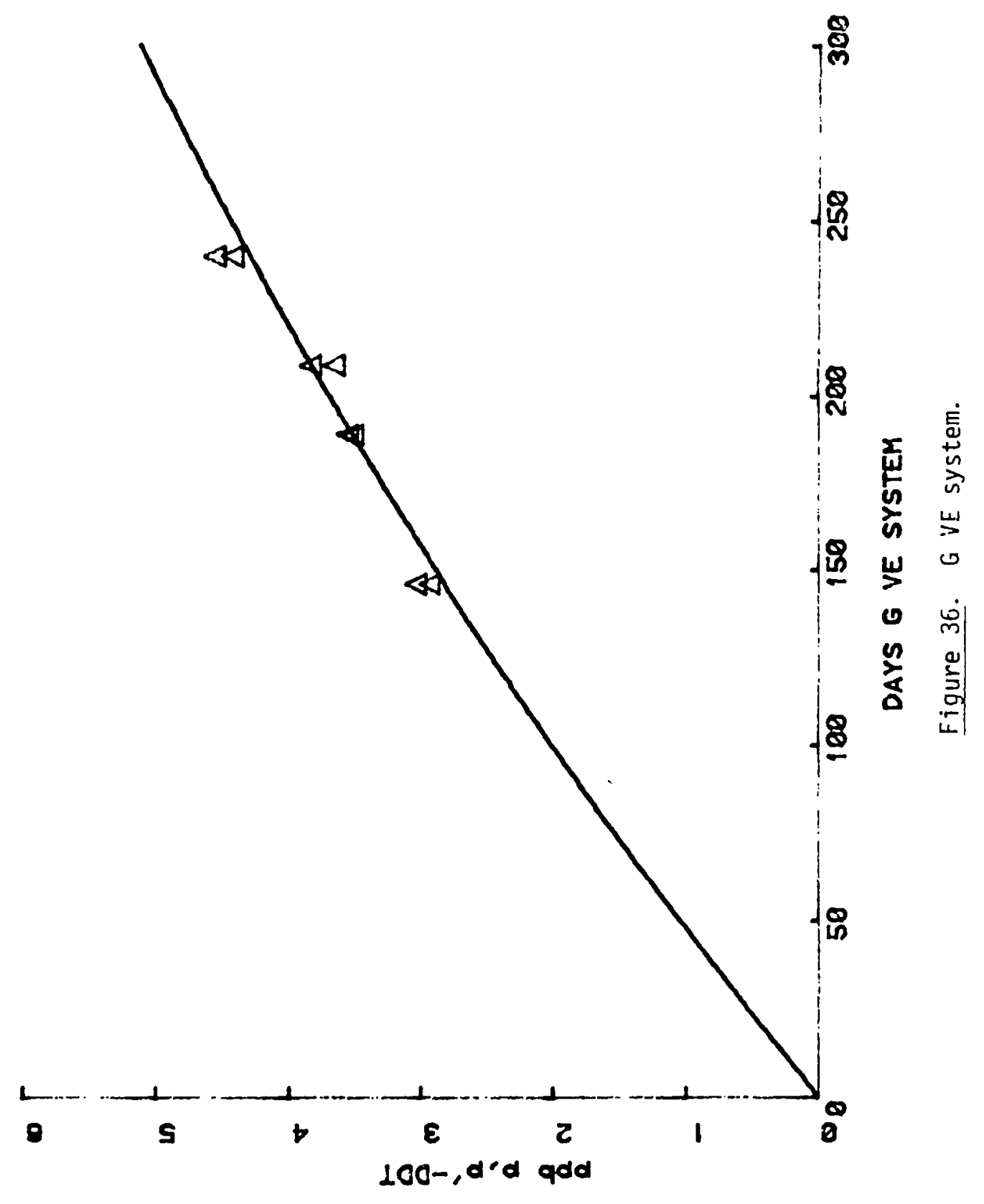




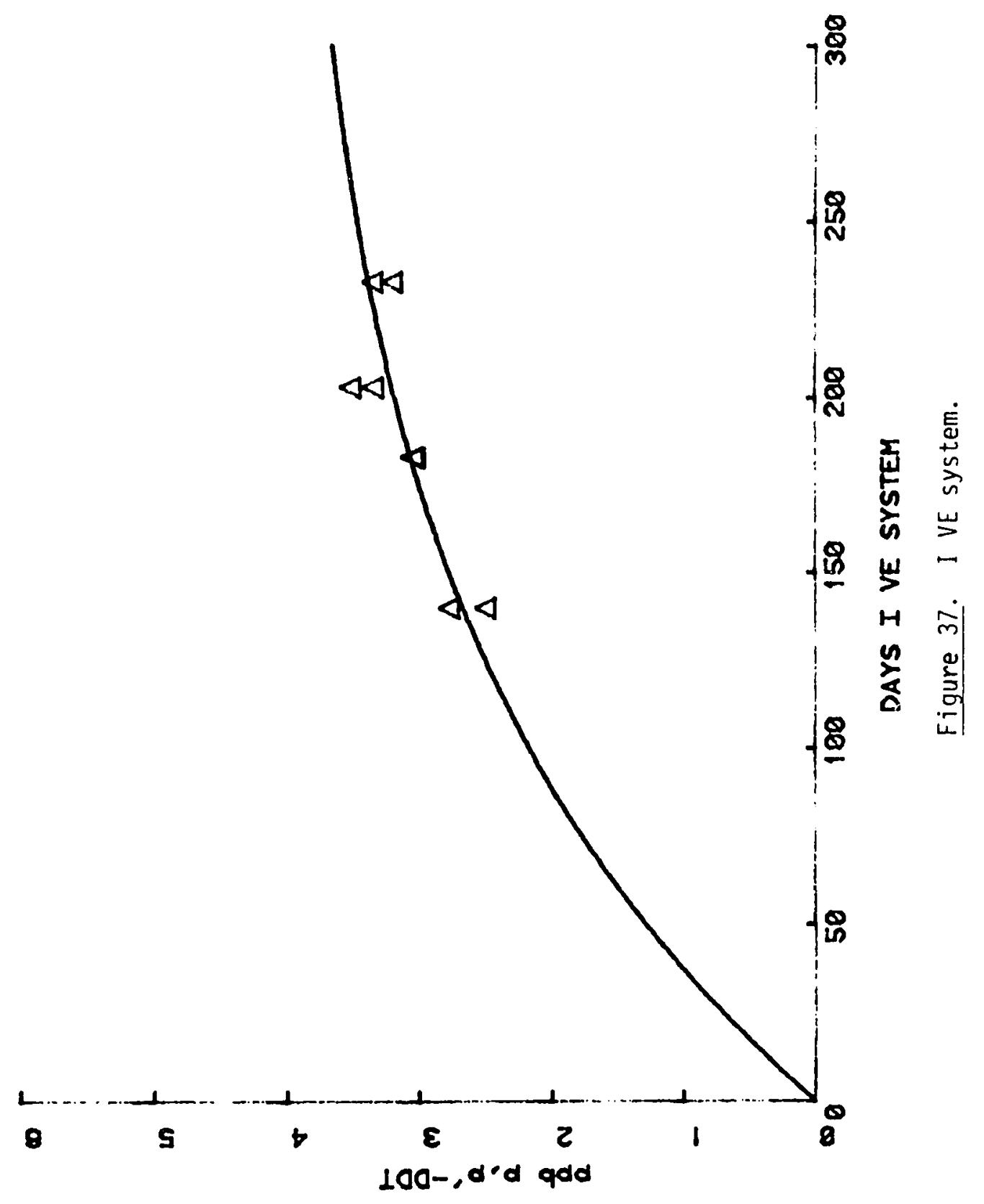




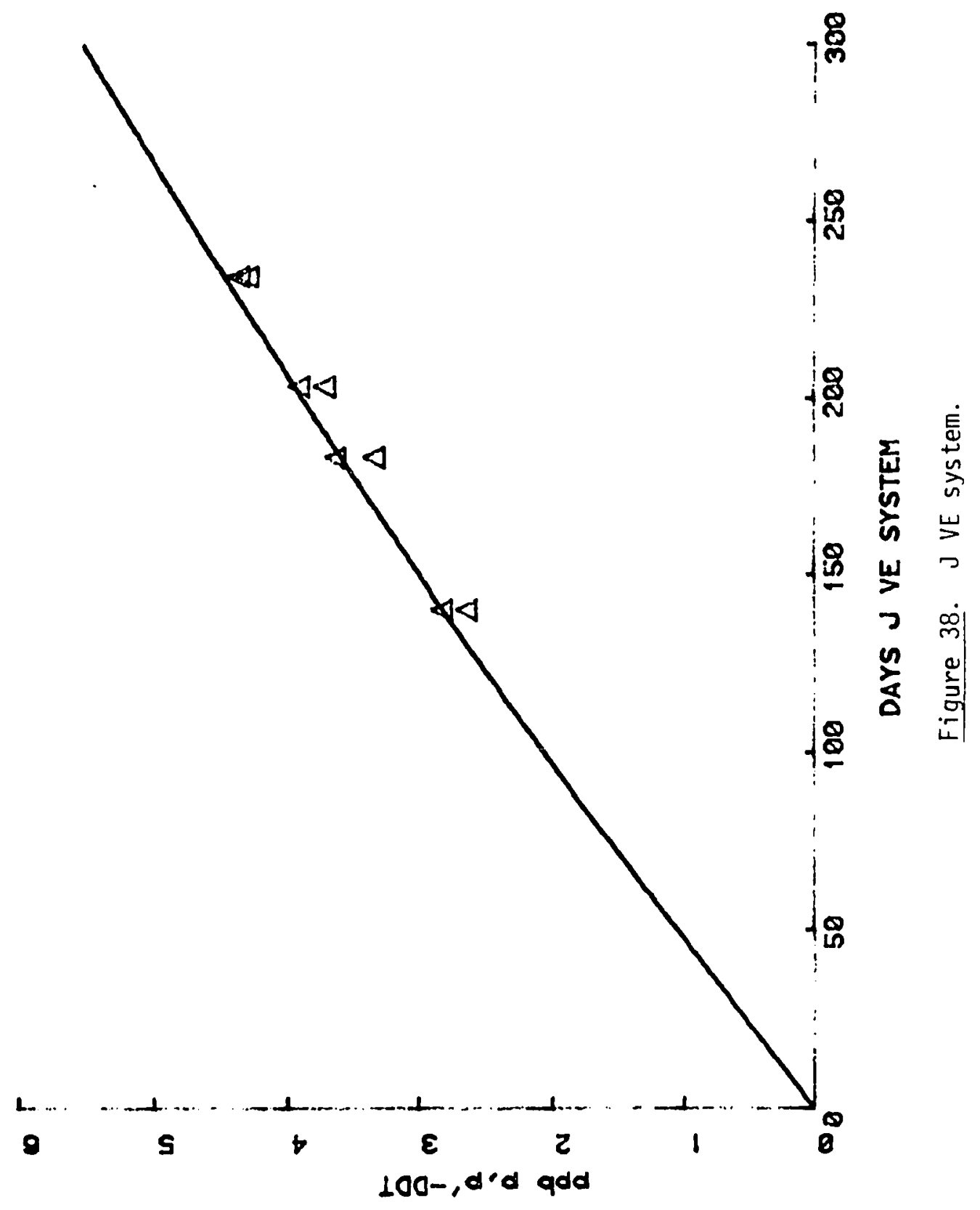




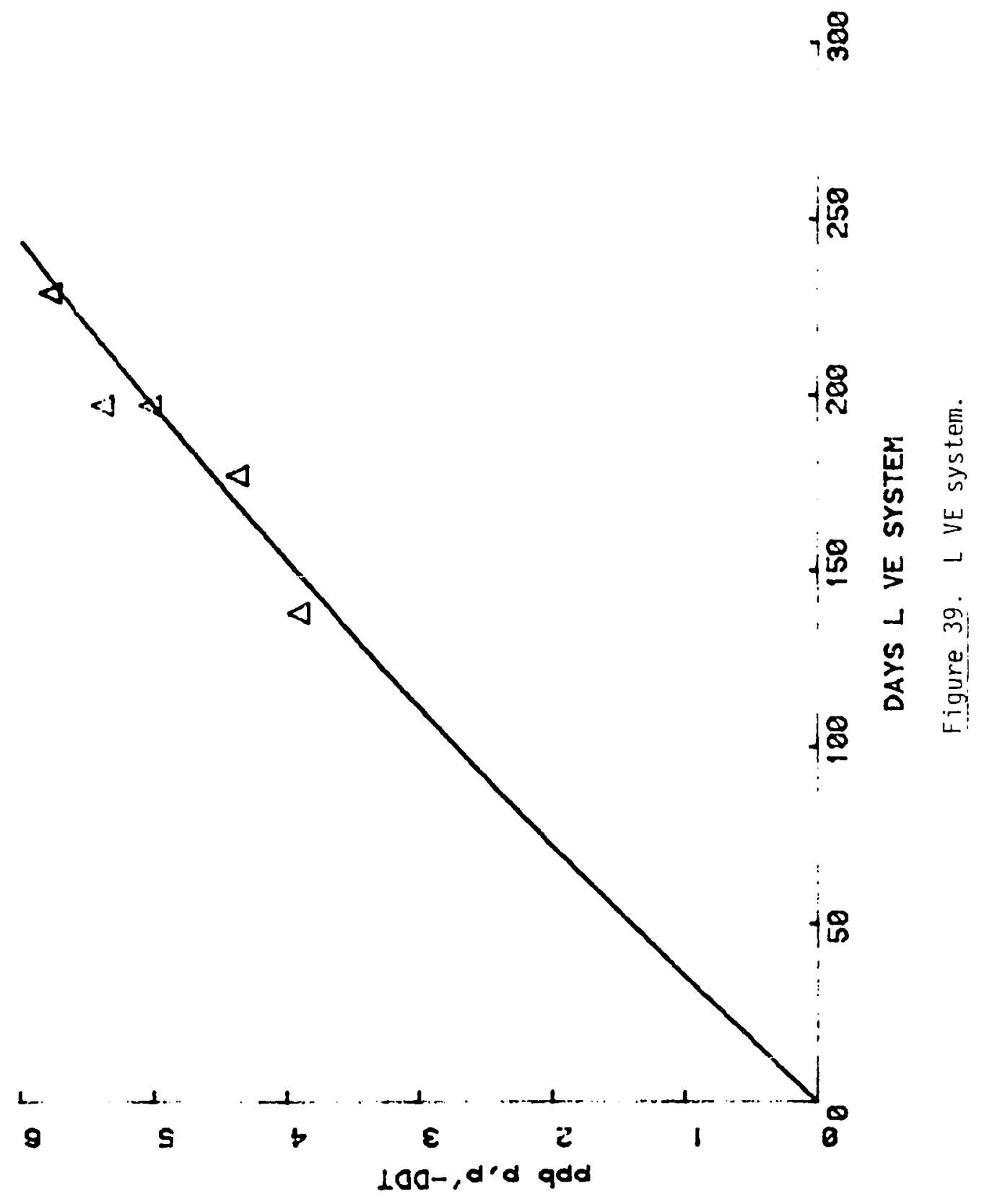




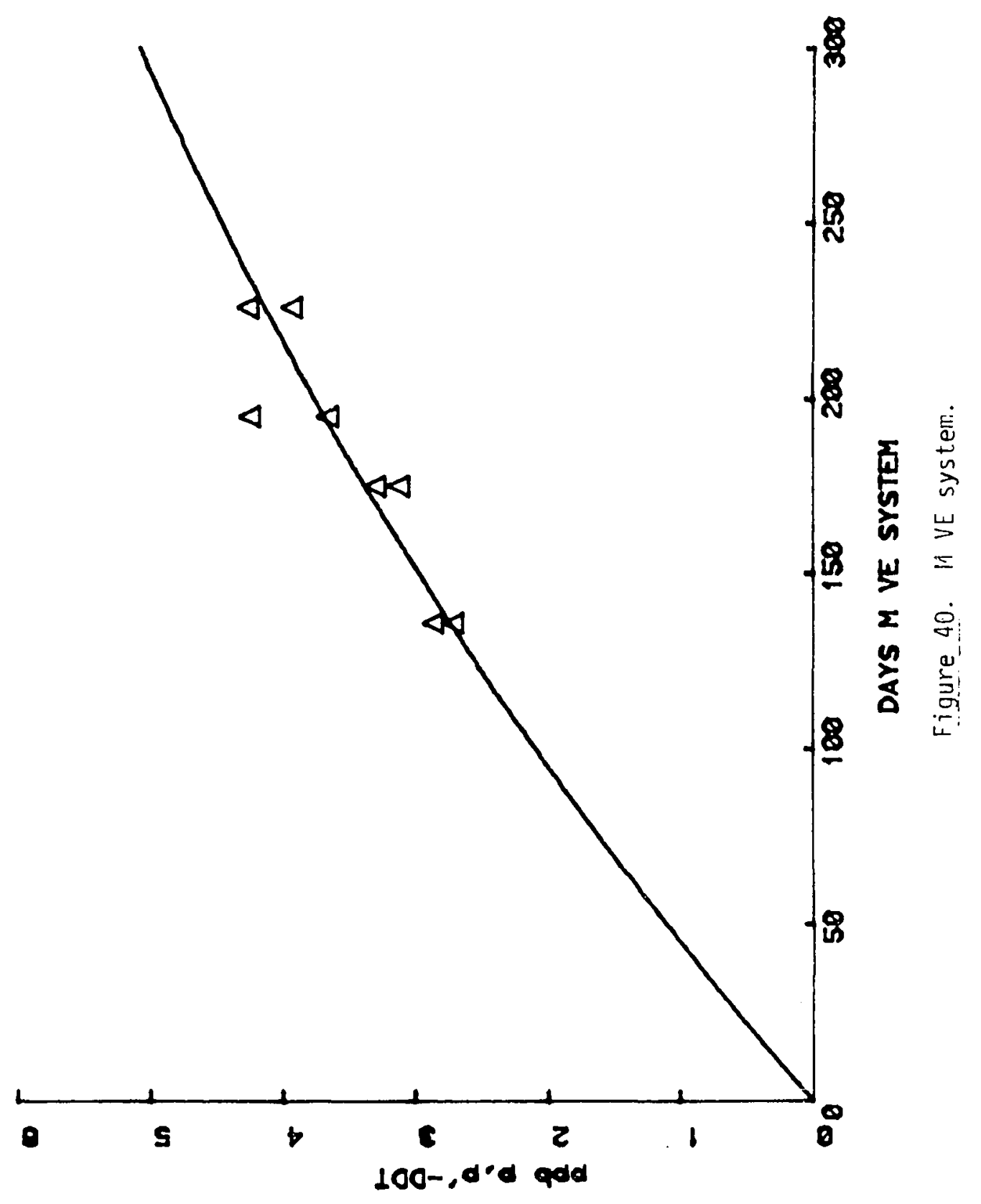




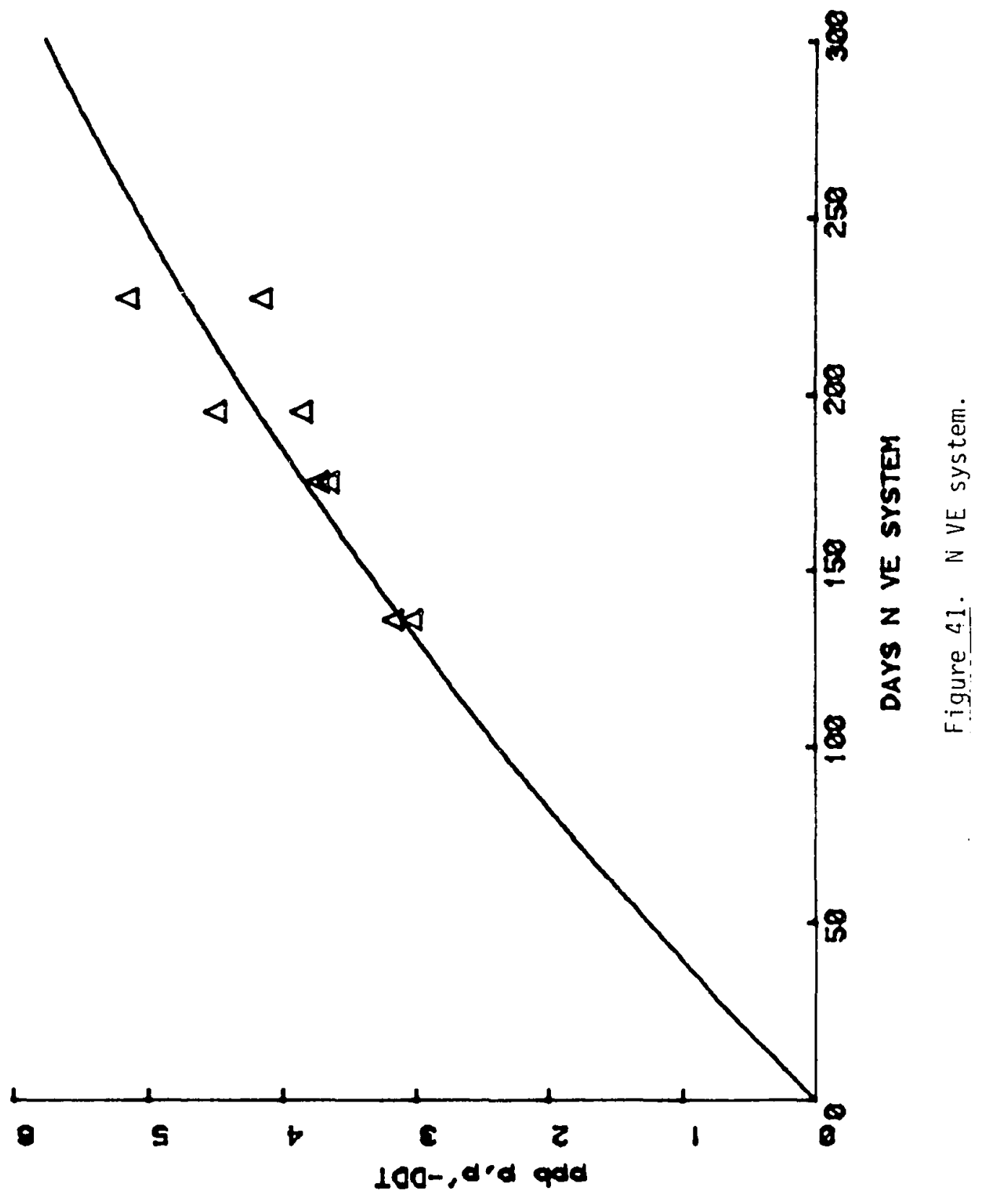




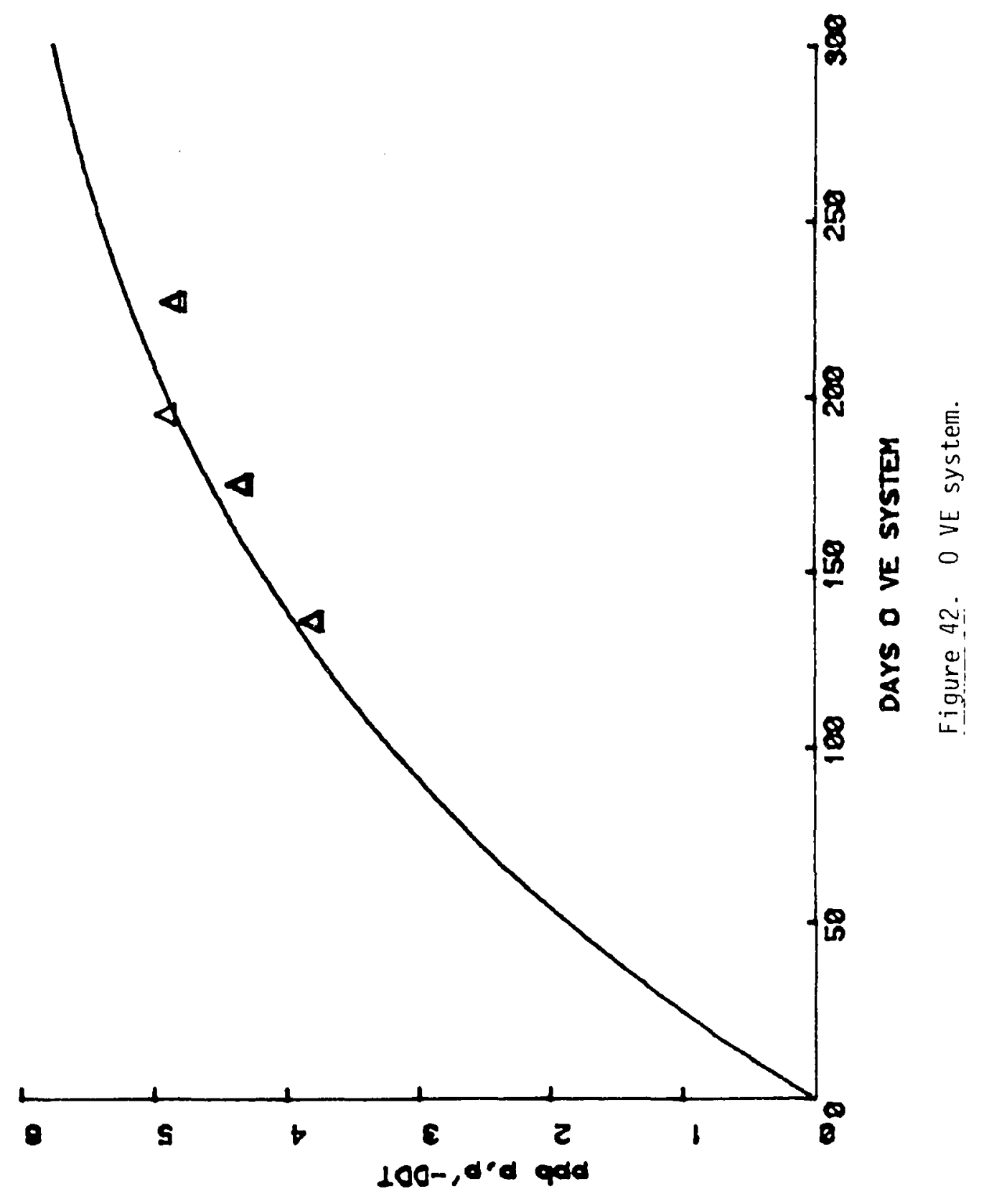




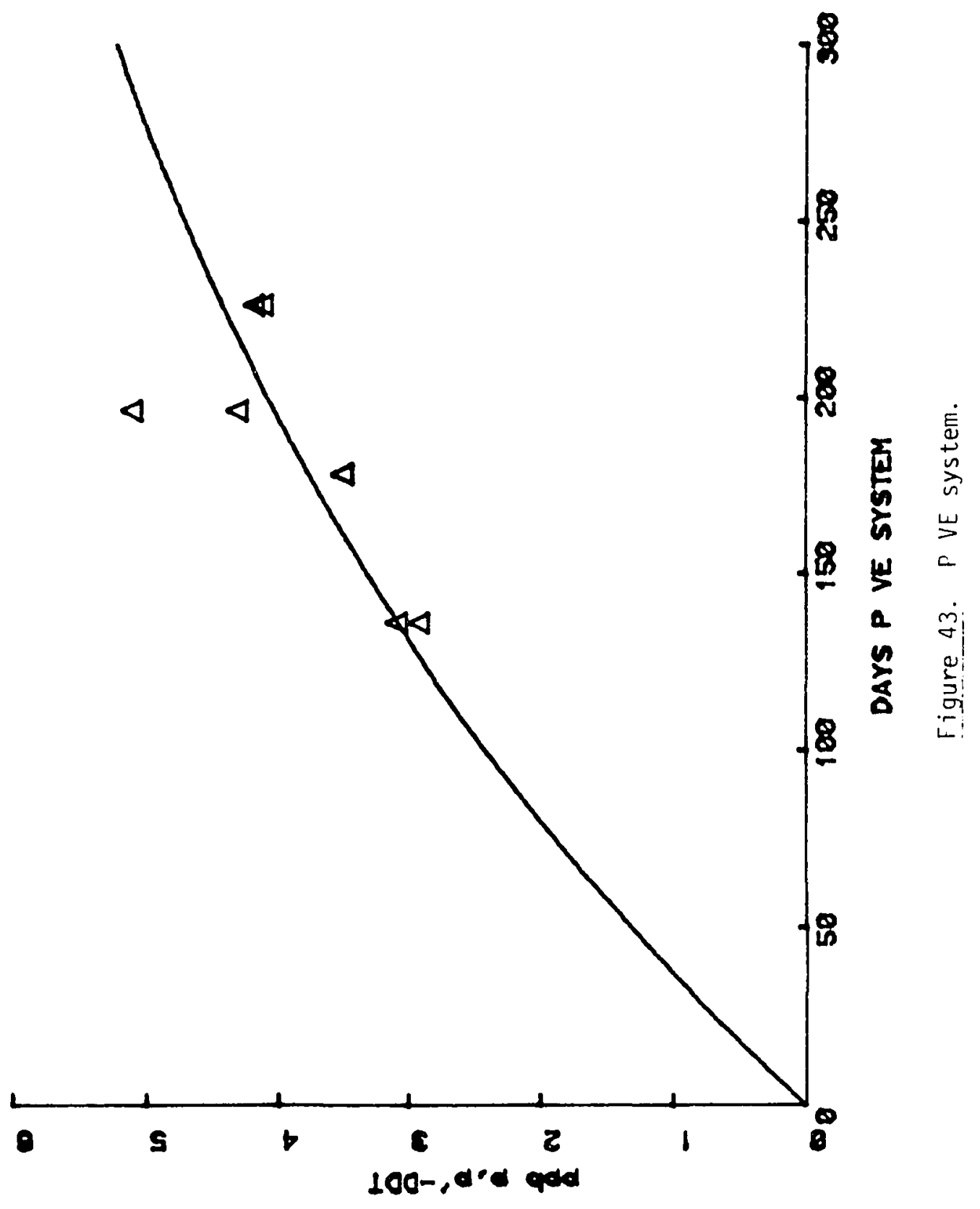




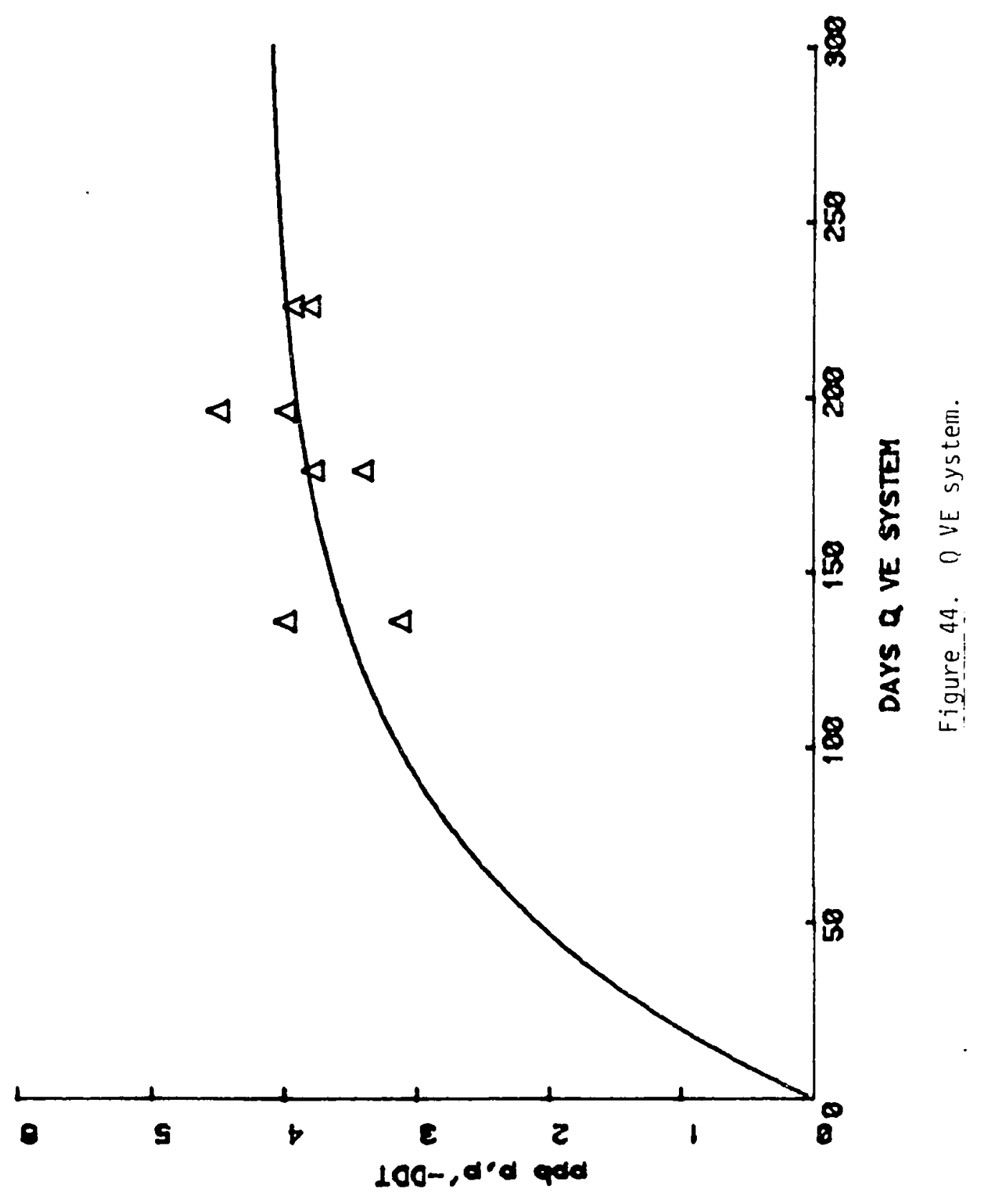


Using the "a" and "b" values from the DOM curve fits, one can calculate the $S_{1}$ and $k_{-1}$ values from equation (1) for various assumed values of $K_{0 c}$. Listed below are the average $S_{1}$ and $k_{-1}$ values calculated for all the DOM systems for several values of $K_{o c}$. Included is the previously discussed $S_{1}$ and $k_{-1}$ calculated from the curve fit of the distilled $\mathrm{H}_{2} \mathrm{O}$ data.

$$
\begin{aligned}
& \operatorname{DOM}\left(K_{o C}=3 \times 10^{5}\right) \\
& \operatorname{DOM}\left(K_{o C}=1 \times 10^{5}\right) \\
& \operatorname{DOM}\left(K_{o C}=8 \times 10^{4}\right)
\end{aligned}
$$

Distilled $\mathrm{H}_{2} \mathrm{O}$

\begin{tabular}{cc}
$\mathrm{S}_{1}$ & $k_{-1}$ \\
\hline 0.023 & 10.8 \\
0.028 & 5.6 \\
0.029 & 4.7
\end{tabular}

0.093

31.4

The above comparison indicates that a good curve fit requires that $S_{1}$ and $k_{-1}$ for DOM systems be markedly different from the distilled $\mathrm{H}_{2} \mathrm{O}$ values. As previously stated, this disparity would indicate that it was incorrectly assumed that DOM did not affect the kinetics of the DDT transfer between the gas and solution phases.

In addition, the data for each DOM VE system can be analyzed by a somewhat different method. This involves calculating the best fitting curve of equation (1) for each system. $\rho_{\text {oc }}$ is known for each solution, and the simplex program can be used to simultaneously solve for the values of $S_{1}, k_{-1}$ and $K_{o c}$ that yield the curve of best fit. Unfortunately, there is no unique set of these three constants for the line of best fit. While $S_{1}$ may be calculated as a unique value for each DOM system, $k_{-1}$ and $k_{o c}$ cannot be similarly evaluated. Close inspection of 
the fitted equation (1) reveals that since $H$ is $\ll 1, k_{-}$and $K_{o c}$ appear as a ratio,

$$
\frac{1+\rho_{O C} K_{O C}}{k_{-1} H} \text { and } \frac{K_{-1} H}{1+\rho_{O C} K_{O C}}
$$

which precludes the determination of these constants as unique values by curve fitting.

Modeling Analysis Summary

A mathematical model describing the kinetics of DDT transfer within a VE system can be derived. The model describes a curve of the type that can be successfully fitted to the data. Inconsistencies in fitted constants between the distilled $\mathrm{H}_{2} \mathrm{O}$ and DOM systems indicate that simplifying assumptions made in the model derivation are not correct. As a result, the complexity of the DOM system kinetics prohibits an accurate extrapolation of the DOM data and therefore a precise determination of DDT K oc values.

\section{SUMMARY}

The Vapor Equilibrium technique shows many advantages over other methods for determining true solubilities of low solubility compounds. An unambiguous equilibrium value is obtained, rather than an operationally defined one. As a saturated solution is approached from the low concentration side, the problems associated with removal of undissolved solute are of no concern. In this work, the length of time required for a VE system to reach equilibrium was a problem. For use with compounds 
of very low vapor pressure, the method should be modified to increase the rate of equilibration attainment. As the slow step involved the volatilization of the compound from glass beads (see Discussion), this process could be accelerated by using smaller glass beads or Ballotini (very small glass beads available from Englass - Cities Service Chemicals, Limited, Columbian Division, Quebec, Canada). This would increase the surface area of the solid phase. Surface area could be increased in a number of other ways, such as coating a film of DDT on a porous solid support.

In addition, the VE technique is well suited for solubility enhancement work. An independent system can be initiated for each parameter tc be investigated. With improved rapidity of equilibrium attainment, microorganisms in solution would not be a problem. Sodium azide could be added to control biological growth in solution if the azide was compatible with the experimental design. With these modifications, the Vapor Equilibrium technique can be a valuable tool in solubility work.

The solubility of $p, p^{\prime}-D D T$ in distilled water was determined to be $1.87 \pm .01 \mathrm{ppb}$. The solubility of the $0, \mathrm{p}^{\prime}-\mathrm{DDT}$ isomer in distilled water was determined to be $4.88 \pm .03 \mathrm{ppb}$. The concentrations of $p, p^{\prime}-$ DDT and $O, P^{\prime}-D D T$ in distilled water solutions containing dissolved organic matter (DOM) were definitely higher than the aqueous solubilities of these compounds. A minimum $\log k_{\text {oc }}$ for both $p, p^{\prime-D D T}$ and $0, p^{\prime}-D D T$ was determined to be $4.7 \pm .2 \log$ units. This value is in agreement with DDT $K_{o c}$ 's determined for particulate organic matter (143, 171, 172). A partitioning coefficient of this magnitude indicates that under environmental conditions, the majority of DDT that is present in aqueous systems will be associated with dissolved organic matter, rather 
than in true aqueous solution. This association may significantly affect the kinetics of such transformation processes as volatilization or chemical and biological degradation of DDT.

As DDT represents a class of organic compounds of low vapor pressure and low solubility, the observed association of DDT and naturally occurring dissolved organic matter may be extrapolated to other compounds in this same class. Thus, the natural DOM in rivers can play a significant role in the transport and transformation of insoluble, hydrophobic pollutants within the environment. 


\section{REFERENCES}

1. D. MacKay. Environ. Sci. Technol., 13 (10), 1218-23, 1979.

2. D. Mackay and S. Paterson. Environ. Sci. Technol., 15 (9), 1006$14,1981$.

3. R. Frank and H.E. Braun. Sci. Total Environ., 20 (3), 255-76, 1981.

4. M.M. Rhead. Environ. Chem., 1, 137-59, 1975.

5. R.L. Metcalf. J. Agric. Food Chem., 21, 511-19, 1973.

6. R.L. Metcalf. The Future For Insecticides. Edited by R. L. Metcalf and J.J. McKelvey. New York: John Wiley and Sons, Inc., 1976, pp 223-85.

7. M.A. Haegele and R.K. Tucker. Bull. Environ. Contam. Toxicol., 11 (1), 98-102, 1974 .

8. W. Klein. The Future For Insecticides. Edited by R.L. Metcalf and J.J. Mckelvey. New York: John Wiley and Sons, Inc., 1976, pp 65-95.

9. T.F. Bidleman and C.E. 01 ney. Science, 183, 516-8, 1974.

10. H. Maier-Bode. Residue Rev., 63, 45-76, 1976.

11. M. Wassermann, L. Tomatis. Pure Appl. Chem., $42(1-2), 189-208$, 1975.

12. R. Reinert. Pestic. Monit. J., 3 (4), 233-40, 1970.

13. R. Reinert and H. Bergman. J. Fish. Res. Board Can., 31, 191-9, 1974.

14. C.S. Helling, A.R. Isensee, E.A. Woolson, P.D.J. Ensor, G.E. Jones, J.R. Plimmer, and P.C. Kearney. J. Environ. Qual., 2 (2), $171-8,1973$.

15. G.W. Gribble. Chemistry, 47 (2), 15-8, 1974.

16. V. Zitko and D. Saward. Ecological Toxicology Research. Edited by A.D. McIntyre and C.F. Mills. New York: Plenum Press, 1975, pp $82-90$.

17. G.R. Harvey and W.G. Steinhauer. Environmental Biogeochemistry, Vol. 1. Edited by J.0. Nriagu. Ann Arbor: Ann Arbor Science Publishers, Inc., 1976, pp 203-221. 
18. C.A. Edwards. Pure App1. Chem., 42 (1-2), 39-56, 1975.

19. R.J. Kuhr, A.C. Davis and J.B. Bourke. Pestic. Monit. J., I (3-4), 200-4, 1974.

20. R.F. Tarrant. Pesticides, Pest Control and Safety on Forest Range Lands, 1971 Proceedings Short Course for Pesticide Applicators, OSU, pp 137-41.

21. P.C. Kearney, J.R. Plimmer and C.S. Helling. Kirk-Othmer Encyclopedia Chemistry Technology, 2nd Edition, 18, 515-40, 1969.

22. C.A. Edwards. Organic Chemicals in the Soil Environment, Vol. 2. Edited by C.A.I. Goring and J.W. Hamaker. New York: Marcel Dekker, Inc., 1972, pp 513-68.

23. F. Korte. Environmental Quality and Safety, Vol. 5. Edited by F. Coulston and F. Korte. New York: Academic Press, 1976, pp 183-96.

24. H.E. Johnson and R.C. Ball. Advances in Chemistry Series, 111. Fate of Organic Pesticides in the Aquatic Environment. Edited by R.F. Gould. Washington, D.C.: American Chemical Society, 1972, pp $1-10$.

25. C.A. Edwards. Persistent Pesticides in the Environment, 2nd ed., Cleveland: CRC Press, 1973.

26. A. Bevenue. Residue Rev., 61, 37-112, 1976.

27. W.H. Sticke7. Ecological Toxicology Research. Edited by A.D. McIntyre and C.F. Mills. New York: Plenum Press, 1975, pp 25-74.

28. C.H. Van Middelem. Advances in Chemistry Series, 60. Organic Pesticides in the Environment. Edited by R.F. Gould. Washington, D.C.: American ChemicaT Society, 1966, pp 228-49.

29. E.E. Kenaga. Environmental Toxicology of Pesticides. Edited by F. Matsumura, G.M. Boush, and T. Misato. New York: Academic Press, Inc., 1972, pp 193-228.

30. F. Matsumura. Pesticides in Aquatic Environments. Edited by M.A.Q. Khan. New York: Plenum Press, 1977, pp 77-125.

31. C.A. Edwards. Pesticides in Aquatic Environments. Edited by M.A.Q. Khan. New York: PTenum Press, 1977, Pp 11-38.

32. E.P. Lichtenstein. Pure App 1. Chem., 42 (1-2), 113-9, 1975.

33. J.P. Hassett and G.F. Lee. Environmental Dynamics of Pesticides. Edited by R. Haque and V.H. Freed. New York: Plenum Press, 1975, pp 173-83. 
34. A. Aitsam. Pure App1. Chem., 42 (1-2), 105-11, 1975.

35. R. Hartung. Environmental Dynamics of Pesticides. Edited by R. Haque and V.H. Freed. New York: Plenum Press, 1975, pp 185-97.

36. E.D. Goldberg, Chairman, Working Group Report. Ecological Toxicology Research. Edited by A.D. McIntyre and C.F. Mills. New York: Plenum Press, 1975, pp 233-56.

37. H.B. Poinke and G. Chesters. J. Environ. Qua1. , 2, 29, 1973.

38. R.P. Schwarzenbach and J. Westal1. Environ. Sci. Technol., 15 (11), 1360-7, 1981.

39. G.W. Bailey and J.L. White. Residue Rev., 32, 29-92, 1970.

40. B.T. Hargrave and K. Kranck. Symp. Nonbiological Transport and Transformation of Pollutants on Land and Water, Abstracts, May 11-13, 1976, NBS, Gaithersburg, Maryland.

41. J. Letey and J.K. Oddson. Organic Chemicals in the Soil Environment, Vol. 1. Edited by C.A.I. Goring and J.W. Hamaker. New York: Marcel Dekker, Inc., 1972, pp 399-440.

42. M.M. Rhead. Specialist Periodical Report. Environmental Chemistry, Vol. 1. Senior Reporter: G. Eglinton. London: The Chemical Society, 1975, pp 137-59.

43. S.D. Faust. Fate of Pollutants in the Air and Water Environments, Pt. 2. Edited by I.H. Suffet. New York: John Wiley and Sons, 1977, pp 317-65.

44. R. Haque, P.C. Kearney, V.H. Freed. Pesticides in Aquatic Environments. Edited by M.A.Q. Khan. New York: Plenum Press, 1977, pp 39-52.

45. B.L. Grau and T.J. Peterle. Bull. Environ. Contam. Toxicol., 22 (6), 846-53, 1979.

46. D. Hanse1, A.J. Wilson, D.R. Nimmo, S.C. Schimmei, and L.H. Bahner. Science, 193, 528, 1976.

47. W.N. Yule and A.D. Tomlin. Bull. Environ. Contam. Toxicol., $\underline{5}$ (6), 479-88, 1970.

48. H. Riekerk and S.P. Gessel. Soil Sci. Soc. Am. Proc., 32 (4), 595-6, 1968.

49. L. Salonen and H.A. Vaajakorpi. Environmental Quality and Safety, Vol. 5. Edited by F. Coulston and F. Korte. New York: Academic Press, 1976, pp 130-40. 
50. Morbidity and Mortality Weekly Report, 28 (11), 123-9, 1979.

51. C.E. Junge. Pure App 1. Chem., 42 (1-2), 95-104, 1975.

52. L. I. Medved. Pure App 1. Chem., 42 (1-2), 119-29, 1975.

53. E. Atlas and C.S. Giam. Science, 211, 163-5, 1981.

54. P.M. Williams and K.J. Robertson. Fish. Bull., 73 (2), 445-7, 1975.

55. J.A. Singmaster. Environmental Behavior of Hydrophobic Pollutants in Aqueous Solutions. Ph.D. Thesis. Univ. California, Davis, Calif., University Microfilms, Ann Arbor, Mich., Order No. 76-14, 237.

56. D. Mackay and A.W. Wolkoff. Environ. Sci. Technol., 7, 611-14, 1973.

57. C.E. Junge. Fate of Pollutants in the Air and Water Environments, Pt. 1. Edited by I.H. Suffet. New York: John Wiley and Sons, 1977, pp 7-25.

58. D. Mackay and P.J. Leinonen. Environ. Sci. Technol., 9, 1178-80, 1975).

59. D. Mackay, W.Y. Shiu and R.P. Sutherland. Environ. Sci. Technol., 13 (3), 333-7, 1979.

60. J.W. Hamaker. Organic Chemicals in the Soil Environment, Vol. 1. Edited by C.A.I. Goring and J.W. Hamaker. New York; Marcel Dekker, Inc., 1972, pp 341-93.

61. R.H. Pierce, C.E. Olney and G.T. Felbeck. Environ. Lett. 1, $157-72,1971$.

62. F.J. Stevenson. Bound and Conjugated Pesticide Residues. ACS Symp. Ser., 29, 1976. D. Kaufman, Ed., pp 180-207.

63. R.W. Meikle, A.J. Regoli and N.H. Kurihara. Bound and Conjugated Pesticide Residues. ACS Symp. Ser., 29, 1976. D. Kaufman, Ed., pp 272-84.

64. R. Haque and D.J. Schmedding. Environ. Sci. Health, B 11 (2), 129-37, 1976.

65. T.M. Ballard. Soil Sci. Soc. Am. Proc., 35 (1), 145-6, 1971.

66. E.T. Degens and K. Mopper. Soil Sci., 119 (1), 65-72, 1975.

67. R.A. Griffin and E.S.K. Chian. Environ. Geol. Notes, 86, 1979. 
68. S.U. Kahn. Soil Organic Matter. Edited by M. Schnitzer and S.U. Khan. Amsterdam: ETsevier Scientific Publishing Co., 1978, pp 137-72.

69. J.W. Hamaker and J.M. Thompson. Organic Chemicals in the Soil Environment, Vol. 1. Edited by C.A.I. Goring and J.W. Hamaker. New York: Marcel Dekker, Inc., 1972, pp 49-143.

70. J.B. Weber. Advances in Chemistry Series. 111. Fate of Organic Pesticides in the Aquatic Environment. Edited by R.F. Gould. Washington, D.C.: American Chemical Society, 1972, pp 55-120.

71. M.G. Browman and G. Chesters. Fate of Pollutants in the Air and Water Environments, Pt. 1. Edited by I.H. Suffet. New York: John Wiley and Sons, 1977, pp 49-105.

72. D.F. Goerlitz \& L.M. Law. J. Res. U.S. Geol. Sur., 2, 541-3, 1974.

73. M.J. Zabik, B.E. Pape, and J.W. Bedford. Pestic. Monit. J., $\underline{5}$, 301-8, 1971.

74. A.J. Wilson. Bull. Environ. Contam. Toxicol., 15 (5), 515-21, 1976.

75. F.J.H. Fredeen, J.G. Saha, and M.H. Balba. Pestic. Monit. J., $\underline{8}$, 241-6, 1975.

76. R.H. Pierce, C.E. Olney, and G.T. Felbeck. Geochim. Cosmochim. Acta, 38 (7), 1061-73, 1974.

77. M.A. Poirrier, B.R. Bordelon, and J.L. Laseter. Environ. Sci. Technol., 6 (12), 1033-5, 1972.

78. R.M. Pfister, P.R. Dugan, and J.I. Frea. Science, 166, 878-9, 1969.

79. S.W. Karickhoff, D.S. Brown, and T.A. Scott. Water Res., 13, 241-8, 1979.

80. C.T. Chiou, L.J. Peters, and V.H. Freed. Science, 206, 831-2, 1979.

81 C.T. Chiou. Science, 213, 684, 1981.

82. S.W. Karickhoff. Chemosphere, 10 (8), 833-46, 1981.

83. J.W. Hamaker. Environmental Dynamics of Pesticides. Edited by R. Haque and V.H. Freed. New York: Plenum Press, 1975, pp 115-33.

84. J.C. Means, S.G. Wood, J.J. Hassett, and W. L. Banwart. Environ. Sci. Technol., 16 (2), 93-8, 1982. 
85. G. Wetzel. Limnology. Philadelphia: W.B. Saunders Company, 1975, pp 538-621.

86. J.E. Richey, J.T. Brock, R.J. Naiman, R.C. Wissmar, and R.F. Stallard. Science, 207, 1348-51 1980.

87. W.H. Schlesinger and J.M. Melack. Tellus, 33, 172-87, 1981.

88. E.M. Perdue, C.R. Lytle, M.S. Sweet, and J.M. Sweet. The Chemical and Biological Impact of Klamath Marsh on the Williamson River, Oregon. March 1981, Water Resources Research Institute, Oregon State University.

89. C. Steelink. J. Chem. Educ., 54 (10), 599-603, 1977.

90. J.A. Leenheer. Acta Amazonica, 10 (3), 513-26, 1980.

91. K.C. Beck, J.H. Reuter, and E.M. Perdue. Geochim. Cosmochim. Acta, 38, 341-64, 1974.

92. T. Jackson. Soil Sci., 119 (1), 56-64, 1975.

93. E.T. Gjessing. Physical and Chemical Characteristics of Aquatic Humus. Ann Arbor: Ann Arbor Science Publishers, Inc., 1976.

94. J.H. Reuter and E.M. Perdue. Geochim. Cosmochim. Acta, 41, 325$34,1977$.

95. P.A. Cranwel1. Specialist Periodical Report. Environmental Chemistry, Vol. 1. Senior Reporter: G. Eglinton. London: The Chemical Society, 1975, pp 22-54.

96. S.A. Visser. Nature (London), 204, 581, 1964.

97. R.L. Wershaw and P.J. Burcar. Proc. Annu. Am. Water Resour. Conf., 3rd, 351-64, 1967.

98. S.U. Kahn. Soil Sci., 112, 401-9, 1971.

99. G.T. Felbeck. Soil Biochem., 2, 36-59, 1971.

100. S.U. Khan and M. Schnitzer. Can. J. Chem., 49 (3), 2302-9, 1971.

101. W. Flaig. Adv. Org. Geochem. Proc. Int. Meet., 5th, 1971 (Pub. 1972), pp 49-67.

102. R. Riffaldi and M. Schnitzer. Soil Sci., 115 (5), 349-66, 1973.

103. M. Schnitzer. Soil Sci., 117 (2), 94-102, 1974.

104. A. Nissenbaum. Adv. Org. Geochem. Proc. Int. Meet., 6th, 1973 (Pub. 1974), pp 39-52. 
105. M. Schnitzer and E. Vendette. Can. J. Soil Sci., 55 (2), 93-103, 1975.

106. M. Schnitzer. Environmental Biogeochemistry, Vol. 1. Edited by J.0. Nriagu. Ann Arbor: Ann Arbor Science Publishers, Inc., 1976, pp 89-107.

107. D.H. Stuermer and G.R. Harvey. Mar. Chem., 6 (I), 55-70, 1978.

108. D. Grant. Nature (London), 270, 709-10, 1977.

109. R.L. Wershaw, D. Pinckney, and S.E. Booker. J. Res. U.S. Geol. Surv., $\underline{5}(5), 565-9,1977$.

110. R.L. Wershaw and D.J. Pinckney. Science, 199, 906-7, 1978.

111. P.G. Hatcher, I.A. Breger and M.A. Mattingly. Nature (London), $285,560-2,1980$.

112. E.M. Perdue, J.H. Reuter, and M. Ghosal. Geochim. Cosmochim. Acta, 44, 1841-51, 1980.

113. J.H. Rueter and E.M. Perdue. Geochim Cosmochim. Acta, 45, 2017$22,1981$.

114. O.K. Borrggaard. Acta Chem. Scand., 28 (1), 121-2, 1974.

115. H. Kerndorff and M. Schnitzer. Water, Air, Soil Pollut., 12 (3), 319-29, 1979.

116. M. Schnitzer and H. Kerndorff. J. Environ. Sci. Health B, B15, $431-56,1980$.

117. M. Schnitzer and S.U. Khan. Humic Substances in the Environment. New York: Marcel Dekker, Inc., 1972.

118. M. Schnitzer. Soil Organic Matter. Edited by M. Schnitzer and S.U. Khan. Amsterdam: Elsevier Scientific Publishing Co., 1978, pp. 1-64.

119. R.L. Wershaw and P.J. Burcar. Science, 157, 1429-31, 1967.

120. H. Kodama and M. Schnitzer. Fuel (London), 46 (2), 87-94, 1967.

121. R.L. Wershaw and D.J. Pinckney. U.S. Geol. Surv., Prof. Pap., 750-D, D206-D218, 1971.

122. W. Flaig, H. Beutelspacher, and E. Rietz. Soil Components. Vol. 1. Organic Components. Edited by J.E. Gieseking. New York: Springer-Verlag New York, Inc., 1975, pp 1-211. 
123. H. Van Dijk. Soil Biochem., 2, 16-35, 1971.

124. R. L. Wershaw and D.J. Pinckney. J. Res. U.S. Geol. Surv., I (6), 701-7, 1973.

125. M. Schnitzer and H. Kodama. Geoderma, 13 (4), 279-87, 1975.

126. Y. Chen and M. Schnitzer. Soil Sci. Soc. Am. J., 40 (6), 866-72, 1976.

127. R. L. Wershaw and D.J. Pinckney. J. Res. U.S. Geol. Surv., 5 (5), $571-7,1977$.

128. D.S. Orlov, Ya. M. Ammosova, and G.I. Glebova. Geoderma, 13 (3), 211-29, 1975.

129. F.J. Mangravite, T.D. Buzzell, E.A. Cassell, E. Matijevic, and G. B. Saxton. J. Am. Water Works Assoc., 67 (2), 88-94, 1975.

130. A.I. Chebaevskii, N.A. Tuev, and N.P Stepanova. Pochvouedenie, I, $31-7,1971$.

131. P. Mukerjee. Adv. Colloid Interface Sci., 1, 241-75, 1967.

132. C. Horvath \& W. Melander. Am. Lab., October, 17-36, 1978.

133. G. Ogner and M. Schnitzer. Science, 170, 317-8, 1970.

134. R.L. Wershaw and M.C. Goldberg. Advances in Chemistry Series. 111. Fate of Organic Pesticides in the Aquatic Environment. Edited by R.F. Gould. Washington, D.C.: American Chemical Society, 1972, pp 149-58.

135. S.U. Khan. Environ. Lett., 3 (1), I-12, 1972.

136. R.L. Wershaw, M.A. Mikita, and C. Steelink. Environ. Sci. Technol., 15 (12), 1461-3, 1981.

137. K Ghosh and M. Schnitzer. Soil Sci., 129 (5), 266-76, 1980.

138. J.P. Hassett and M.A. Anderson. Environ. Sci. Technol., 13 (12), 1526-9, 1979.

139. F.R. Boucher and G.F. Lee. Environ. Sci. Technol., 6 (6), 538-43, 1972.

140. J.A. Coburn, I.A. Valdmanis, and A.S.Y. Chau. J. Assoc. Off. Anal. Chem., 60 (I), 224-8, 1977.

141. R.L. Wershaw, P.J Burcar, and M.C. Goldberg. Environ. Sci. Technol., $\underline{3}(3), 271-3,1969$. 
142. P.D. Boehm and J.G. Quinn. Geochim. Cosmochim. Acta, 37 (11), 2459-77, 1973.

143. C.W. Carter and I.H. Suffet. Symp. Terrestrial and Aquatic Humic Materials, Poster Session. Chapel Hi11, N.C., Nov. 4 and 5, 1981.

144. W.F. Spencer and M.M. Cliath. J. Agric. Food Chem., 20 (3), $645-9,1972$.

145. R.L. Metcalf. Crit. Rev. Environ. Control, 3 (1), 25-59, 1972.

146. A.M. Rothman. J. Agric. Food Chem., 28, 1225-8, 1980.

147. J.W. Westcott, C.G. Simon, and T.F. Bidleman. Environ. Sci. Technol., 15 (11), 1375-8, 1981.

148. F.H. Babers. J. Am. Chem. Soc., 77, 4666, 1955.

149. M.C. Bowman, F. Acree, and M.K. Corbett. J. Agric. Food Chem., $\underline{8}$ (5), 406-8, 1960.

150. J.W. Biggar, G.R. Dutt, and R.L. Riggs. Bul1. Environ. Contam. Toxicol., 2 (2), 90-100, 1967.

151. V.L. Wei1, G. Dure' and K.E. Quentin. Z. Wasser Abwasser Forsch., I. $169-75,1974$.

152. H.C. Hollifield. Bul1. Environ. Contam. Toxicol., 23 (4-5), 579-86, 1979.

153. C.T. Chiou, D.W. Schmedding, and M. Manes. Environ. Sci. Techno1., 16 (1), 4-10, 1982 .

154. C.T. Chiou, V.H. Freed, D.W. Schmedding, and R.L. Kohnert. Environ. Sci. Techno1., 11 (5), 475-8, 1977.

155. EPA. Water-Related Environmental Fate of 129 Priority Pollutants, Vol. 1. 1979, EPA-440 4-79-029a, Pp 25-1 to 25-22.

156. J. Roburn. Chem. Ind., Sept., 1555-6, 1963.

157. J.R. Plimmer, U.I. Klingebiel, and B.E. Hummer. Science, 167, $67-9,1970$.

158. A.R. Mosier, W.D. Guenzi, and L.L. Miller. Science, 164, 1083-5, 1969.

159. D.W. Hill and P.L. McCarty. J. Water Pollut. Control Fed., 39 (8), 1259-77, 1967.

160. R.T. Williams, P.C. Hirom, and A.G. Renwick. Ecological Toxicology Research. Edited by A.D. McIntyre and C.F. Mills. New York: Plenum Press, 1975, pp 91-106. 
161. D.A. Stotter. J. Inorg. Nuc]. Chem., 39, 721-7, 1977.

162. C.I. Chacko and J.L. Lockwood. Can. J. Microbiol., 13, 1123-6, 1967.

163. W.D. Burge. J. Agric. Food Chem., 19 (2), 375-8, 1971.

164. W.W. Gregory, J.K. Reed, and L.E. Priester. J. Protozool., 16 (1), 69-71, 1969.

165. W.C. Steen and S.W. Karickhoff. Chemosphere, 10, 27-32 1981.

166. F. Matsumura, K.C. Pati\}, and G.M. Boush. Nature (Loridon), 230, $325-6,1971$.

167. F. Matsumura and G.M. Boush. Science, 156, 959-61, 1967.

168. F. Matsumura and H.J. Benezet. Pesticide Microbiology. Edited by IR. Hill and S.J.L. Wright. London: Academic Press, Inc., 1978, pp 639-42.

169. R.E. Johnsen. Residue Rev., 61, 1-28, 1976.

170. C.H. Walker. Organochlorine Insecticides: Persistent Organic Pollutants. Edited by F. Moriarty. London: Academic Press, Inc., 1975, pp 73-130.

171. Y. Shin, J.J. Chodan and A.R. Walcott. J. Agric. Food Chem., 18, $1129-33,1970$.

172. E.E. Kenaga and C.A.I. Goring. Am. Soc. Test. Mater., Third Aquat. Toxicol. Symp., New Orleans, LA., 1978.

173. EPA. Determination of Octanol/Water Distribution Coefficients, Water Solubilities, and Sediment/Water Partition Coefficients for Hydrophobic Organic Pollutants. 1979, EPA-600 4-79-032.

174. J.W. Biggar and R.L. Riggs. Hilgardia, 42 (10), 383-91, 1974.

175. C.T. Chiou, D.W. Schmedding, and J.H. Block. J. Pharm. Sci., 70 (10), 1176-7, 1981.

176. C.T. Chiou and V.H. Freed. Environ. Sci. Technol., 11 (13), 1220, 1977.

177. M.B. Abou-Donia. Anal. Lett., 7 (5), 313-25, 1974.

178. W. Thornburg. Anal. Chem., 47 (5), 157R-169R, 1975.

179. J. Unnák, M. Sackmauerová, A. Szokolay, and 0. Pal'ušová. J. Chromatogr., 91, 545-7, 1974. 
180. M.B. Abou-Donia. J. Assoc. Off. Anal. Chem., 51 (6), 1247-60, 1968.

181. S.G. Zelenski. J. Chromatogr., 84, 67-73, 1973.

182. W. A. Aue. J. Chromatogr. Sci., 13 (7), 329-33, 1975.

183. J.H. Ford, C.A. McDaniel, F.C. White, R.E. Vest, and R.E. Roberts. J. Chromatogr. Sci., 13 (6), 291-5, 1975.

184. C.A. Burgett. Res./Dev., 25, 28-35, 1974.

185. A. Shatkay and S. Flavian. Anal. Chem., 49 (14), 2222-8, 1977.

186. E.D. Pellizzari. J. Chromatogr., 98, 323-61, 1974.

187. J.E. Lovelock. J. Chromatogr., 99, 3-12, 1974.

188. R.G. Lewis. Nat. Bur. Stand. Spec. Publ. 422, Accuracy in Trace Analysis, Proc. of 7th IMR Symp. 1974 (Pub. 1976), pp. 9-34.

189. S.D. Faust and I.H. Suffet. Am. Soc. Test. Mater., Symp. Microorg. Matt. in Water, pp 24-64.

190. H.V. Morley and K.A. McCully. Method. Chim., 1, Pt. B, 824-77, 1974.

191. J.A. Burke, P.A. Mills and D.C. Bostwick. J. Assoc. Off. Anal. Chem. , 49, 999-1003, 1966.

192. C. Gosselin, G.B. Martin, and A. Boudreau. J. Chromatogr., 90, $113-8,1974$.

193. W.W. Thornburg. Residue Rev., 14, 1-11, 1966.

194. Rohm and Haas, Inc. "Summary Bulletin Amberlite Polymeric Absorbants", 1971.

195. J.R. Ertel and J.I. Hedges. Symp. Terrestrial and Aquatic Humic Materials. Chapel Hill, N.C., Nov. 4 and 5, 1981.

196. R.C. Dougherty, J.D. Roberts and F.J. Biros. Anal. Chem., 47, 54-9, 1975.

197. P.C. Rankin. J. Assoc. Off. Anal. Chem., 54, 1340-8, 1971.

198. R.C. Dougherty, J. Dalton and F.J. Biros. Org. Mass Spectrom., $\underline{6}$, $1171-81,1972$.

199 E.M. Perdue and N. L. Wolfe. Environ. Sci. Technol., in press.

200. R.G. Zepp. Personal Communication. EPA, Athens, GA., 1982. 
201. P.S. Liss and P.G. Slater. Nature (London), 247, 181-4, 1974.

202. J.H Fendler and E.J. Fendler. Catalysis in Micellar and Macromolecular Systems. New York: Academic Press, Inc., 1975, pp 86-103.

203. S. Deming and S. Morgan. Anal. Chem., 45 (3), 278A-83A, 1973.

204. S. Deming and L. Parker. C.R.C. Crit. Rev. Anal. Chem., Sept., 187-202, 1978. 


\section{APPENDIK}

Initial DDT solubility work utilized a procedure different from the vapor equilibrium system described in the main text. This earlier method involved generating a saturated DDT solution via centrifugation of a supersaturated aqueous DDT mixture. This procedure was used by others in the determination of DDT solubility (references - DDT solubility). An investigation of the centrifugation method showed it to be incapable of furnishing unambiguous solubility data in general and to be clearly unsuitable for solubility enhancement work in particular.

The specific procedure tried was as follows:

DDT was deposited in a glass Erlenmeyer flask by evaporation of 1 $\mathrm{mL}$ of a $\mathrm{DDT} /$ hexanes solution at room temperature.

After addition of $200 \mathrm{~mL}$ of distilled water (or the aqueous solution under investigation), the mixture was sonicated to suspend the DDT and sealed with a glass stopper.

The mixture was shaken in the flask prior to placing $33 \mathrm{~mL}$ in each of four stainless steel centrifuge tubes. Filtration through a 4-8 $\mathrm{km}$ glass frit prior to centrifugation was investigated and found not to be beneficial.

The centrifuge tubes were sealed with stainless steel caps fitted with fluorocarbon polymer seals, and the aqueous mixture was centrifuged at $44,100 \mathrm{G}$ and $20^{\circ} \mathrm{C}$ for 18 hours (Beckman L2-65B preparative ultracentrifuge, Ti 60 rotor) . 
After centrifugation, an Allen set screw was removed from the tube caps to allow withdrawal by syringe of a $50 \mathrm{~mL}$ composite aliquot from the supernatent solutions in the four tubes.

The $50 \mathrm{~mL}$ sample of the supernatent solutions was extracted, dried, concentrated and anlyzed by EC-GLC in a manner similar to that oultined in the text.

After considerable effort, the centrifugation method was found to be unsatisfactory as a procedure for obtaining saturated aqueous DDT solutions. One problem with this technique is that a "saturated solution" becomes operationally defined. That is, the supernatent concentration of DDT is dependent on the centrifugation parameters $(150,174)$. The particular centrifugation conditions used in this study $(25,000$ RPM, 18 hours, Ti 60 rotor) theoretically would remove DDT particles with a diameter greater than $69 \AA\left(6.9 \times 10^{-9} \mathrm{~m}\right)$ (149). These conditions were similar to those used in previous $\mathrm{DDT} / \mathrm{H}_{2} \mathrm{O}$ solubility work, and distilled $\mathrm{H}_{2} \mathrm{O} / \mathrm{DDT}$ concentrations in the supernatent liquid were in agreement with other centrifugation solubility determinations $(1.0-2.0 \mathrm{ppb})(149,150)$. The problem lies in the fact that it is difficult to relate a true saturated solution to a supernatent concentration of DDT generated by a specific set of centrifugation parameters. An operationally defined concentration of DDT in the supernate would be reproducible, but may not represent a saturated solution.

An additional problem was discovered when an attempt was made to obtain a DDT mass balance on the centrifugation step. With initial mixture concentrations of $210 \mathrm{ppb}$ (after sonification), only $250 \%$ of the DDT was recovered after centrifugation. Post-centrifugation recovery included: 
(1) DDT in the composite $50 \mathrm{~mL}$ supernatent aliquot;

(2) DDT in the remaining liquid in the tubes plus exhaustive extraction of the tube walls (sometimes analyzed separately from the residual liquid; and

(3) DDT extracted from tube caps and seals.

A typical mass balance data set follows:

Pre-centrifuge

$11.5 \times 10^{-7} \mathrm{~g} \mathrm{DDT}$

\section{Post-centrifuge}

$1.1 \pm .1 \times 10^{-7} \mathrm{~g}$ DDT (supernatent solution)

$2.2 \pm .2 \times 10^{-7} \mathrm{~g}$ DDT (residual liquid and tube walls)

$22.7 \times 10^{-7} \mathrm{~g}$ DDT (tube caps and seals)

Total recovery: $6.0 \pm .3 \times 10^{-7} \mathrm{~g}$ DDT (52\%)

Further mass balance work showed that the centrifugation step involved the loss of a constant amount of DDT, not a constant fraction of the initial mixture. Thus, higher initial concentrations of DDT ( 50 $\mathrm{ppb}$ ) yielded almost $100 \%$ recoveries, although the same amount of DDT was still being lost during centrifugation. Precisely what happened to the unrecovered DDT was not discovered. Perhaps it leaked past the cap seals and escaped to the atmosphere.

In addition, the concentration of DDT in the supernate was found to depend to some degree on the pre-centrifugation DDT loading. It appeared that the centrifuge was effectively removing no more than 283 percent of the total DDT. That is, an initial mixture of 60 to $70 \mathrm{ppb}$ 
DDT would yield a supernatent concentration of 10 to $12 \mathrm{ppb}$. The inability to obtain consistent supernatent concentrations from varying initial loadings made this method particularly unsuitable for solubility entancement work. If one is looking for an increase in DDT supernatent concentrations, it is impractical to be limited to initial DDT loadings of only six times DDT/distilled $\mathrm{H}_{2} \mathrm{O}$ levels.

For these reasons (operationally defined "solubility", unexplained loss of DDT during process and limiation of initial loading), centrifugation was deemed unsatisfactory as a method of obtaining saturated aqueous DDT solutions for this work. 


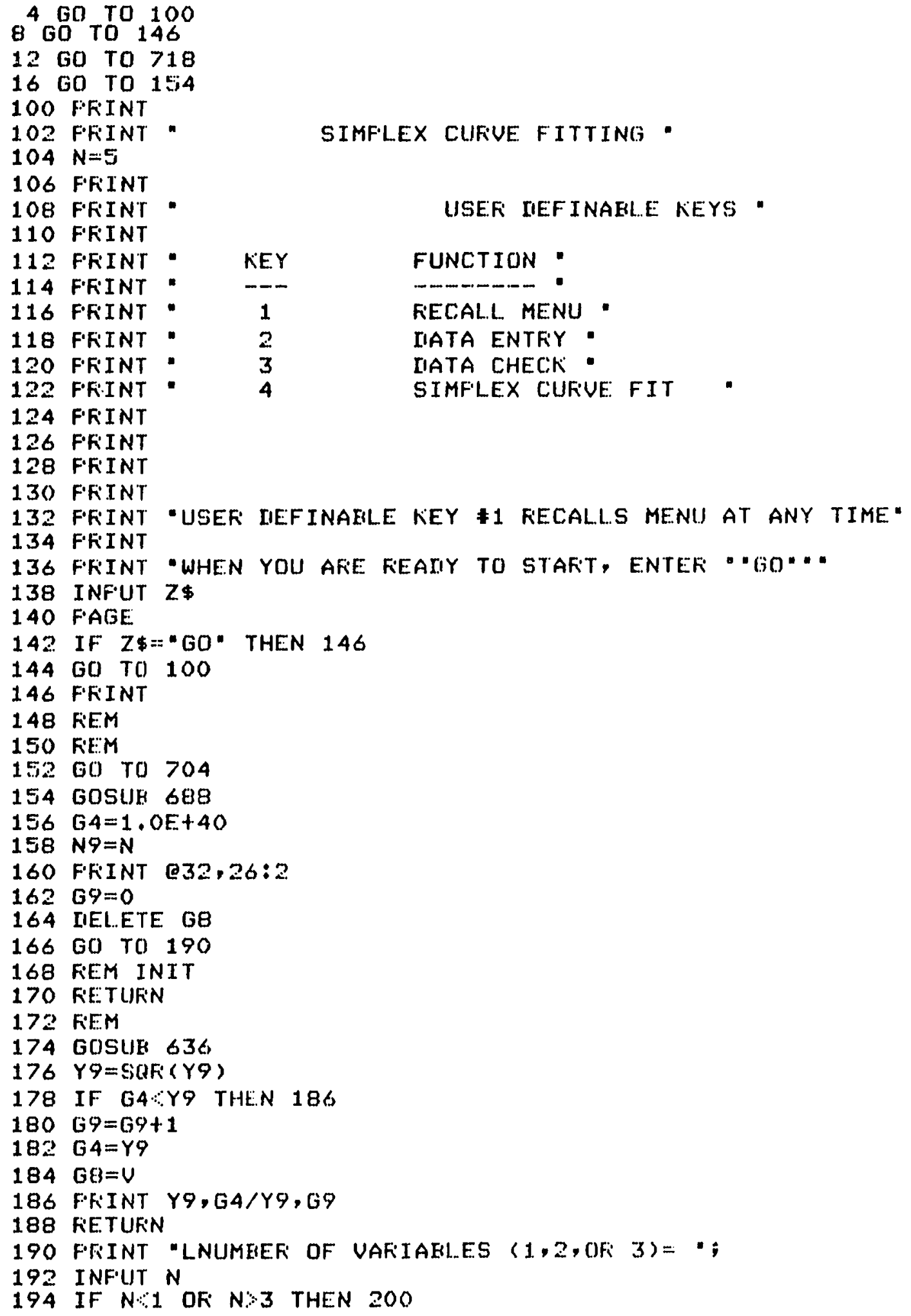




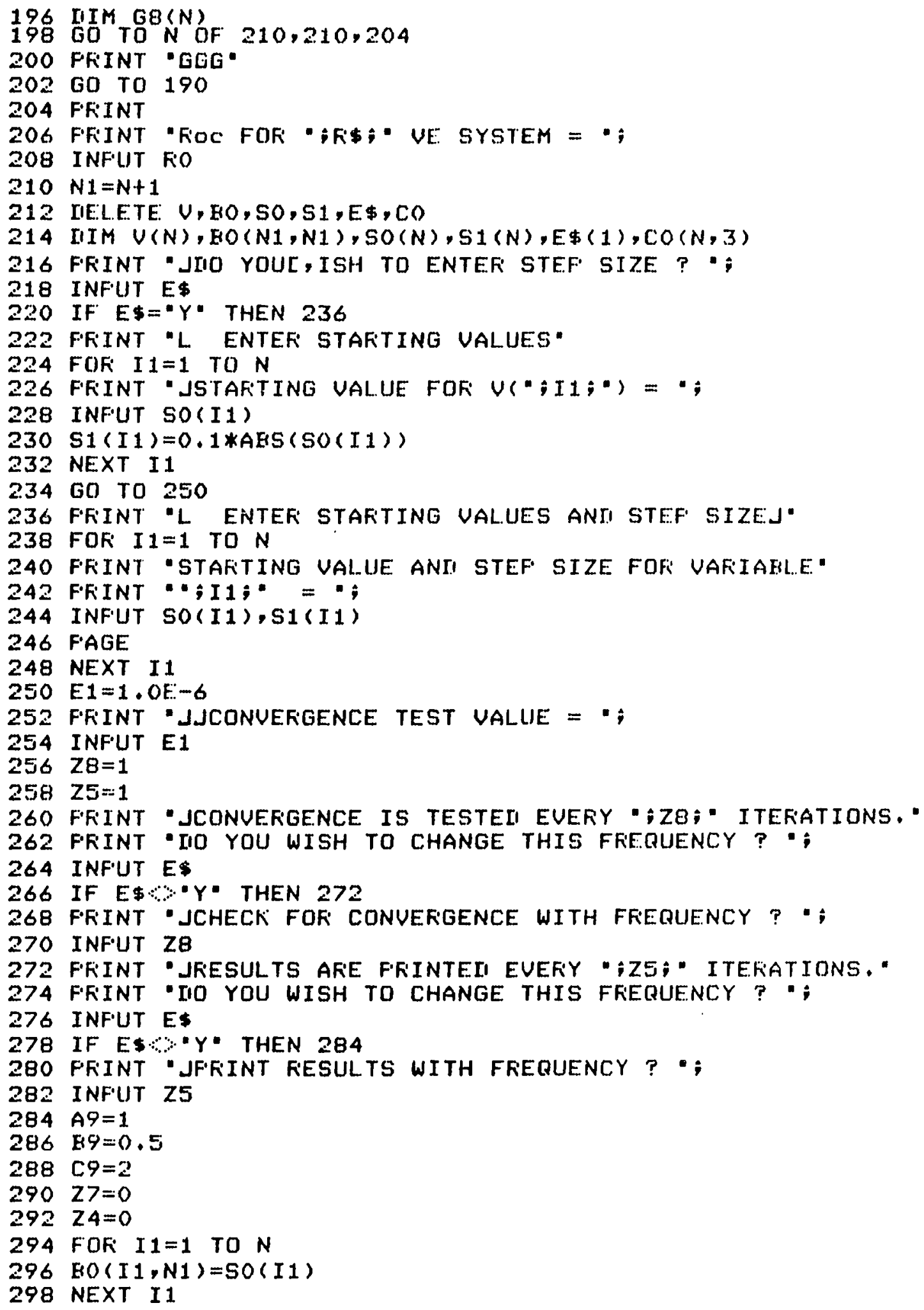




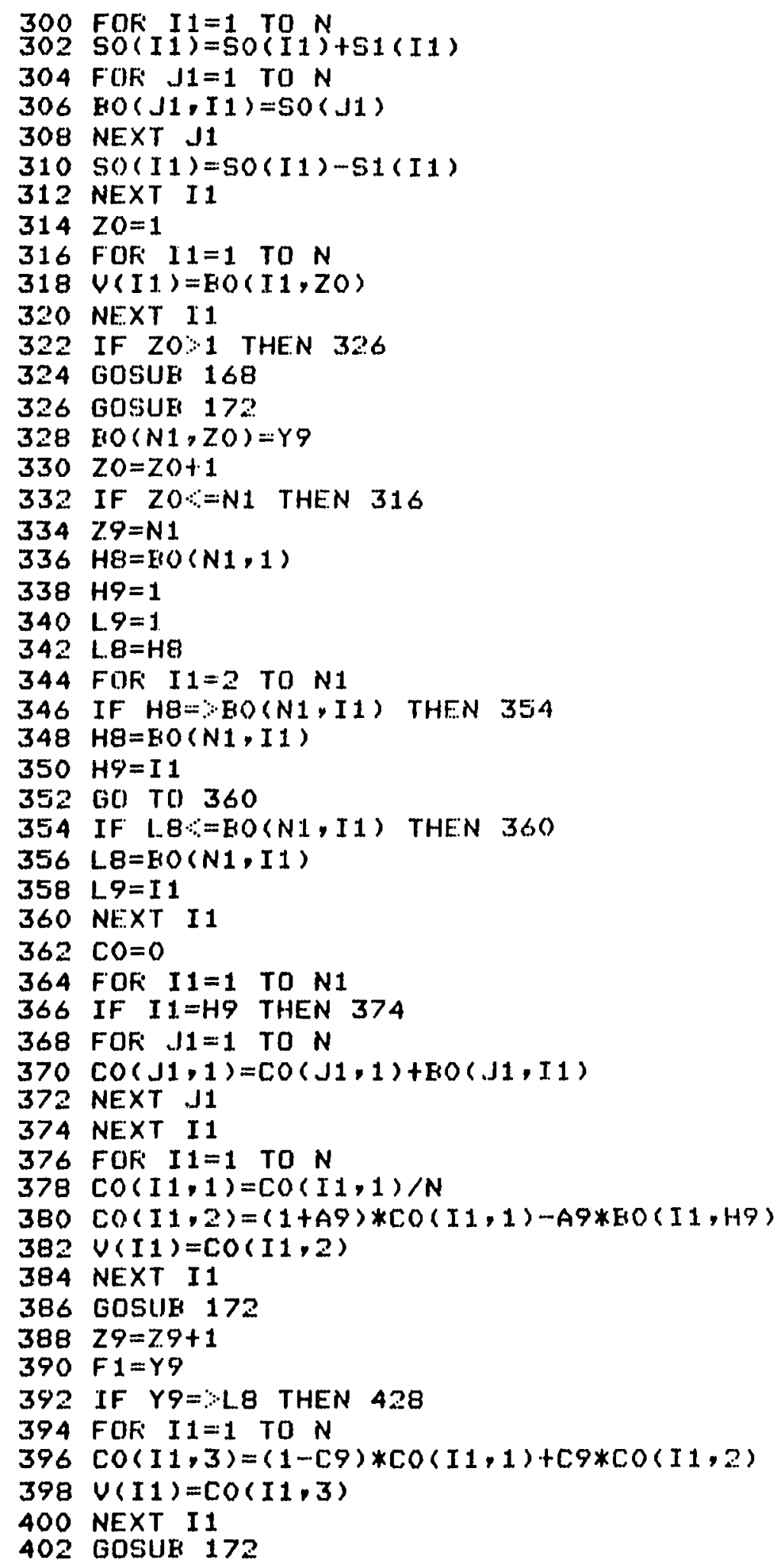




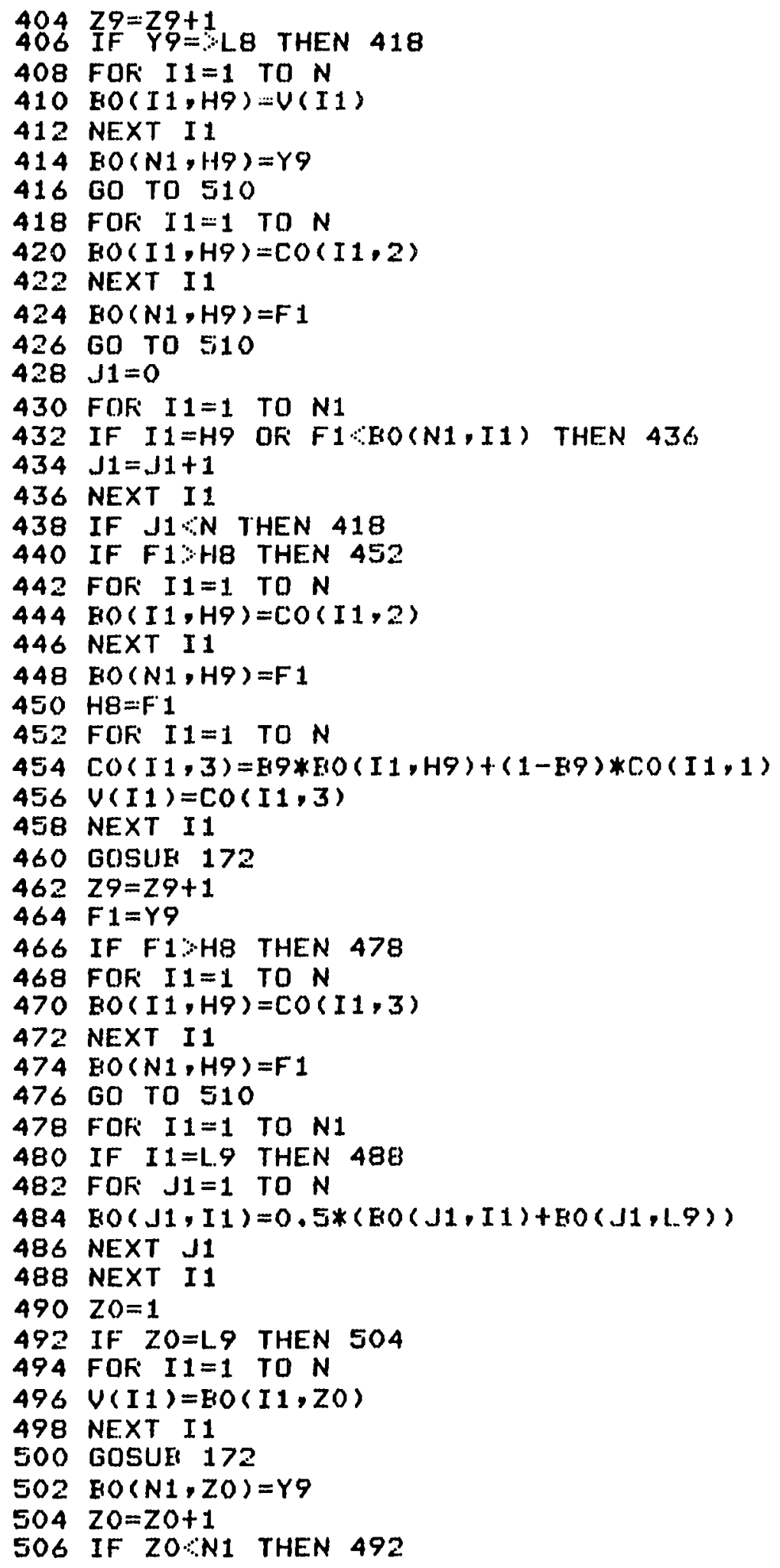




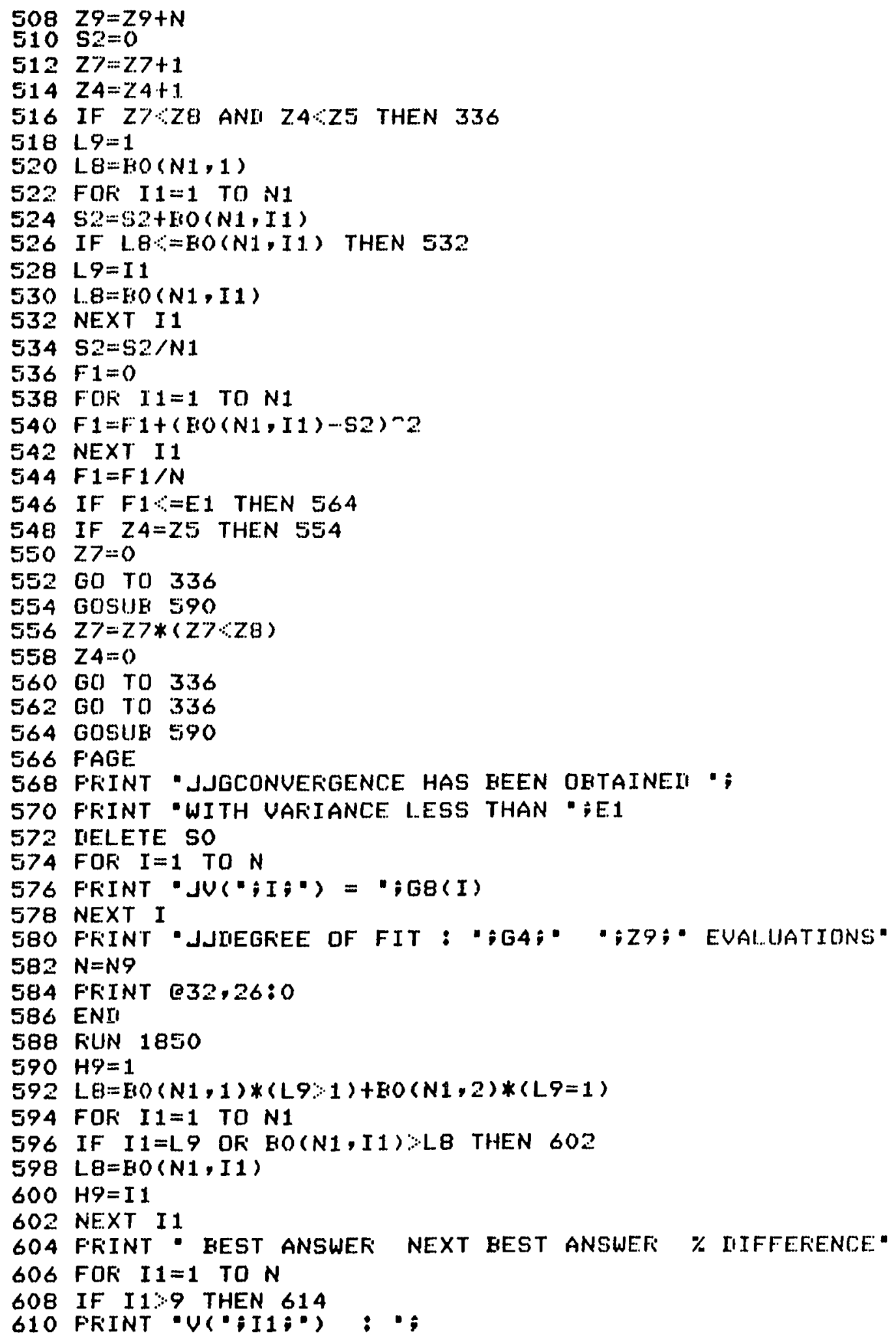




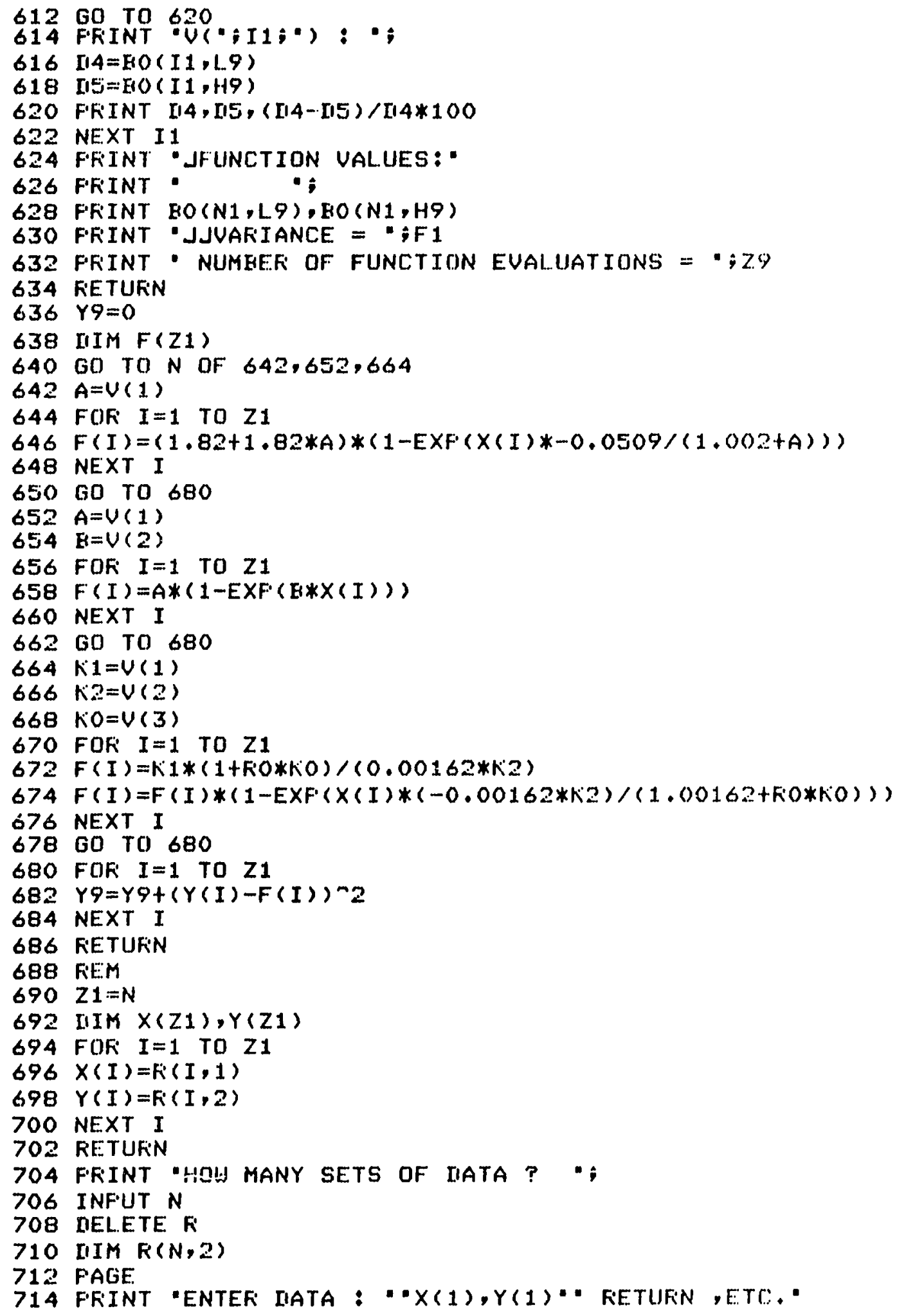




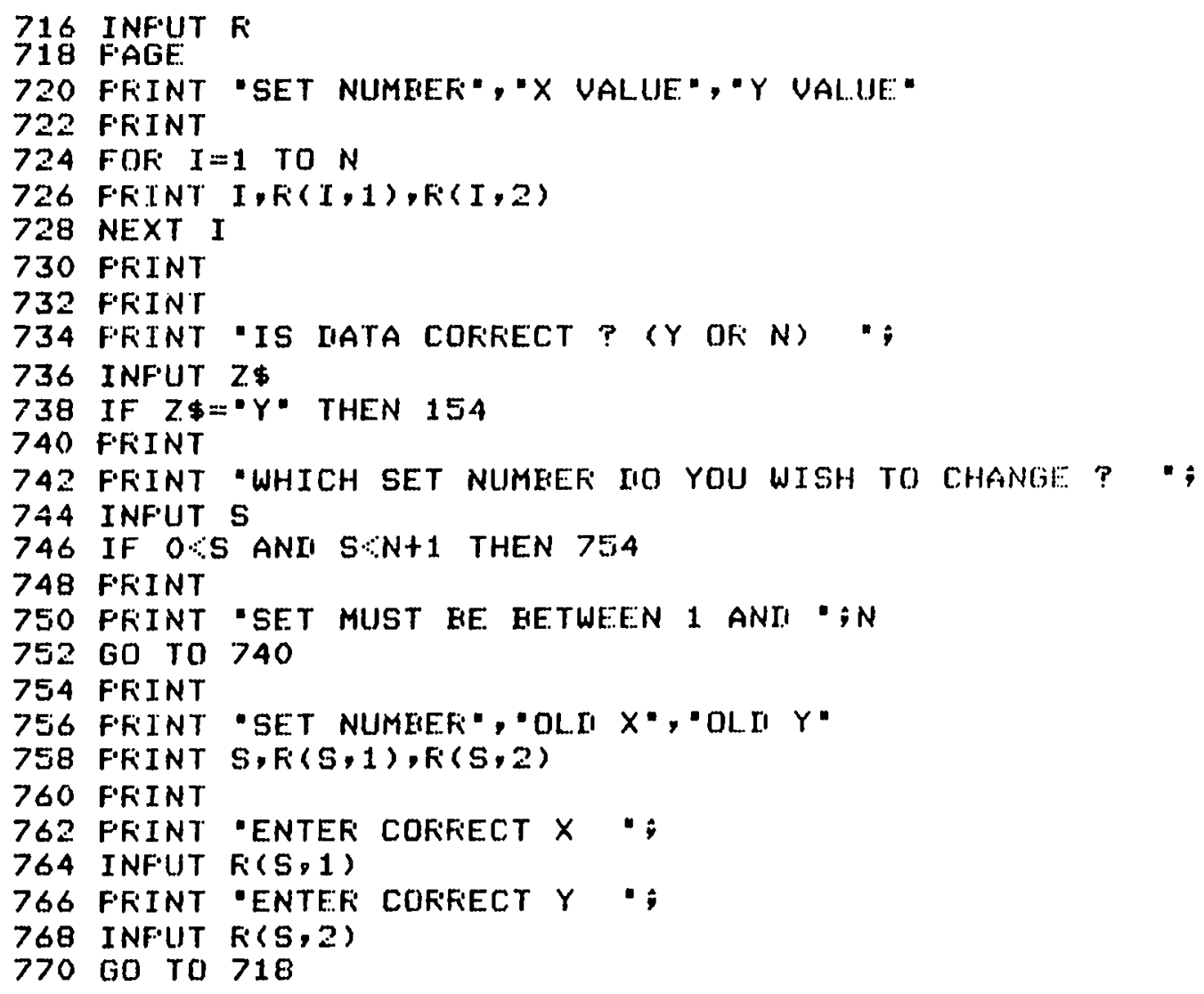

